Aus der Abteilung Psychiatrie und Psychotherapie

(Prof. Dr. med. B. Bandelow)

im Zentrum Psychosoziale Medizin

der Medizinischen Fakultät der Universität Göttingen

\title{
Interindividuelle Unterschiede der Impulsivität und Impulskontrolle
}

Eine fMRT-Studie

\author{
INAUGURAL - DISSERTATION \\ zur Erlangung des Doktorgrades \\ der Medizinischen Fakultät \\ der Georg-August-Universität zu Göttingen \\ vorgelegt von \\ Lesly Nerenberg \\ aus \\ Hamburg
}

Göttingen 2012 
Dekan: Prof. Dr. H. K. Kroemer

I. Berichterstatter: Prof. Dr. med. O. Gruber

II. Berichterstatterin: Prof. Dr. rer. nat. M. Wilke

III. Berichterstatter/in: -

Tag der mündlichen Prüfung: 08. April 2013 


\section{Inhaltsverzeichnis}

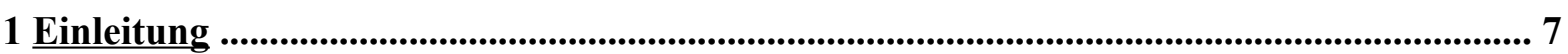

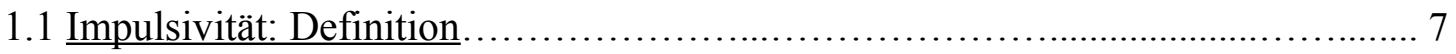

1.2 Impulsivität und Psychopathologie ..................................................... 10

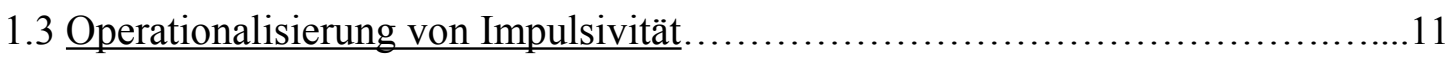

1.3.1 Psychometrisches Verfahren............................................... 11

1.3.1.1 Die Barratt- Impulsivitätsskala, 11. Revision (BIS-11)

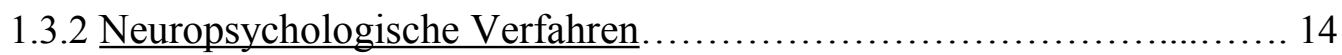

1.3.2.1 Messung der motorischen Impulsivität.............................14

1.3.2.1.1 Das Go-/ No-Go-Paradigma......................................... 14

1.3.2.2 Messung der kognitiven Impulsivität...............................15

1.3.2.2.1 Das Delay-Discounting- Paradigma..............................16

1.4 Vorstudie von Diekhof \& Gruber (2010).............................................................18

1.4.1 Das Studiendesign................................................... 18

1.5 Neuronale Korrelate der Impulsivität und der Selbstkontrolle: Assoziation zu anatomischen Hirnstrukturen ...................................................................... 20

1.5.1 Die Studienergebnisse von Diekhof \& Gruber (2010)......................20

1.5.2 Ergebnisse anderer neurowissenschaftlicher Studien.................... 21

1.5.2.1 Das Belohnungssystem.........................................21

1.5.2.2 Der Nucleus accumbens............................................. 22

1.5.2.3 Der präfrontale Kortex..................................... 22

1.6 Neurochemische Grundlage der Impulsivität und der Selbstkontrolle: Das

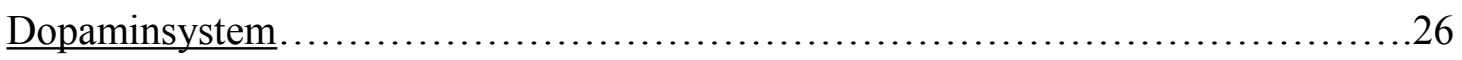

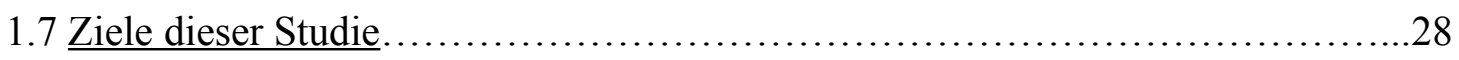

2 Material und Methoden .................................................................................................................29

2.1 Die Funktionelle Magnetresonanztomographie (fMRT) ....................................... 29

2.1.1 Physikalische Grundlagen....................................................................... 29

2.1.2 Grundlagen des BOLD- Effekts (Blood Oxygenation Level Dependency) ............................................................................................. 31

2.2 Stichprobenerhebung und -zusammensetzung.................................................... 34

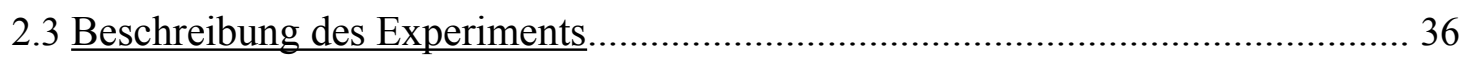

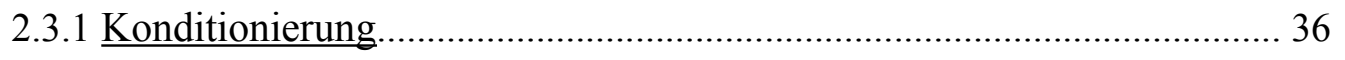




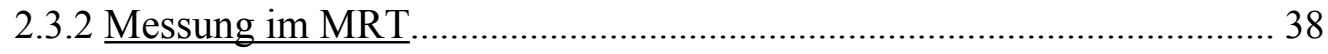

2.4 Barratt- Impulsivitätsskala, 11. Revision (BIS- 11) ............................................. 42

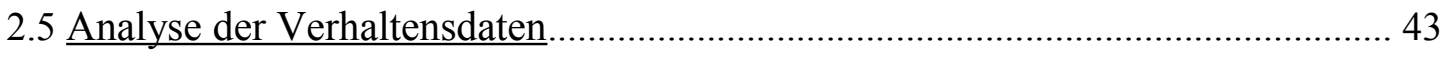

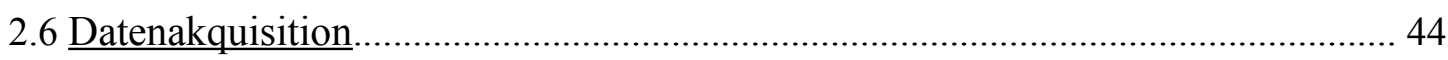

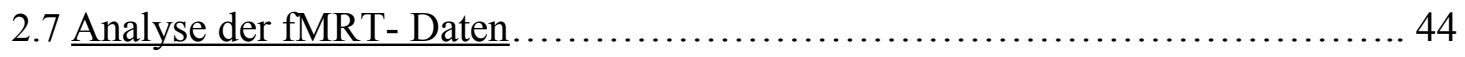

2.7.1 Vorverarbeitung............................................. 45

2.7.2 Statistische Analyse der fMRT- Daten ............................ 45

2.7.3 Psychophysiologische Interaktionsanalyse (PPI) ................... 47

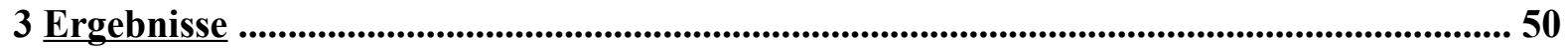

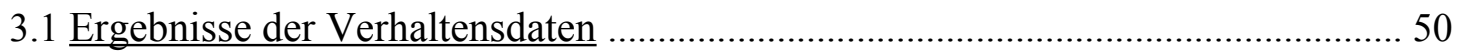

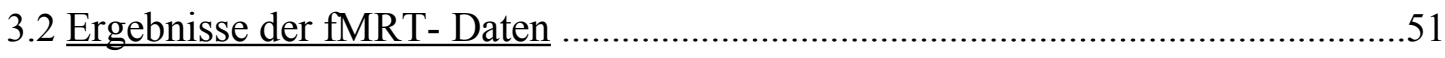

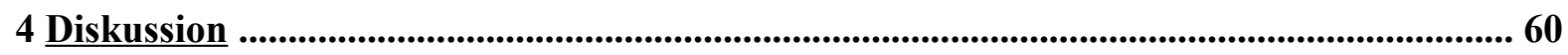

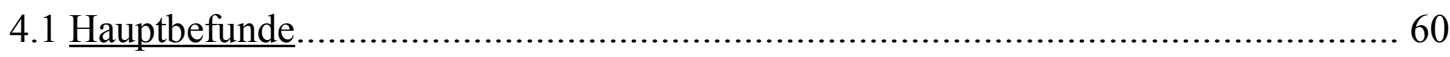

4.2 Ein neuartiges Studiendesign zur Messung der Impulsivität................... 61

4.3 Gesunde, hoch- impulsive Probanden können ihren generellen Wunsch nach einer unmittelbaren Belohnung durch einen persönlichkeitsspezifischen neuronalen

Mechanismus kontrollieren.

4.4 Hoch- impulsive Probanden können ihr Verlangen nach einer Belohnung zunehmender Wertigkeit durch einen persönlichkeitsspezifischen Mechanismus

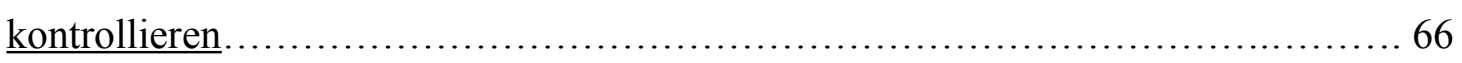

4.5 Extrem- kontrollierte Probanden können durch bestimmte neuronale Mechanismen

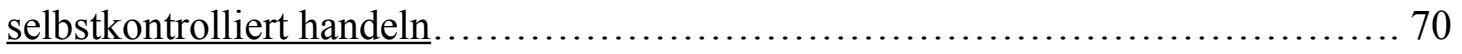

4.6 Hoch- und niedrig- impulsive Probanden nutzen gemeinsame neuronale Mechanismen zur Annahme oder Ablehnung einer Bonusoption.....................71

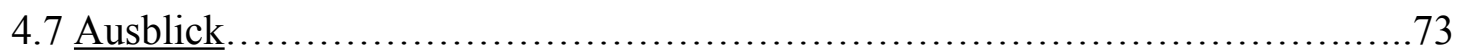

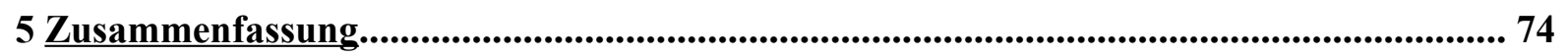

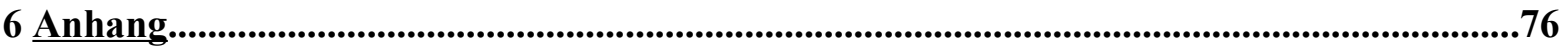

6.1 Barratt- Impulsivitäts-Skala, 11. Revision (BIS-11)...........................................76

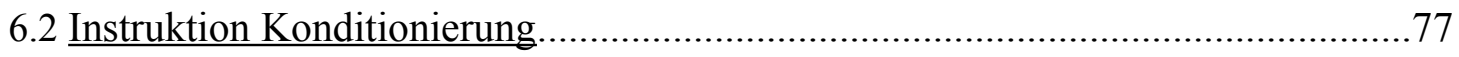

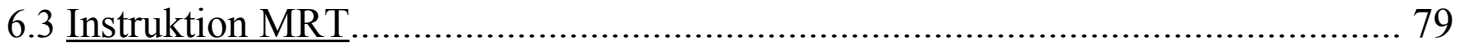

7 Literaturverzeichnis........................................................................................................................... 81 


\section{Abbildungsverzeichnis}

Abbildung 1: Darstellung impulsiven Verhaltens als hyperbolische Belohnungsfunktion... 17

Abbildung 2: Zeitlicher Verlauf des BOLD- Signals

Abbildung 3: Experimentelles Design der modifizierten Forced- ChoiceAufgabe . .40

Abbildung 4: Downregulation der belohnungsabhängigen Aktivierung und Veränderungen in der präfrontostriatalen Konnektivität bei hoch- impulsiven Probanden während des DesireReason-Dilemmas. 53

Abbildung 5: Parametrische Deaktivierung des VMPFC während der Ablehnung einer unmittelbaren Belohnungsoption zunehmender Wertigkeit während des Desire- ReasonDilemmas in der Gruppe der HI- Probanden. 54

Abbildung 6: Wertigkeitsabhängige Zunahme der inversen funktionellen Interaktion zwischen dem VMPFC und dem rechten ventralen Striatum mit zunehmender Wertigkeit der vorangegangenen Belohnungsoption während des Desire- Reason- Dilemmas in der HIGruppe 57 


\section{Tabellenverzeichnis}

Tabelle 1: Persönlichkeits- und demographische Merkmale der

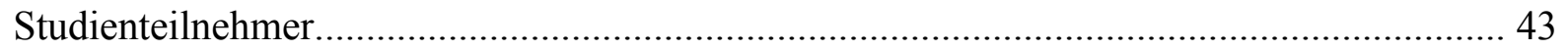

Tabelle 2: Verhaltensdaten...................................................... 51

Tabelle 3: Downregulation der belohnungsabhängigen Aktivierung während des DesireReason-Dilemmas.

Tabelle 4: Abnahme der positiven funktionellen Konnektivität im Vergleich zur impliziten Baseline (inverse funktionelle Konnektivität) zwischen dem rechten Nacc und dem linken avPFC während des Desire-Reason- Dilemmas in der Gruppe der HIProbanden 52

Tabelle 5: Positive funktionelle Konnektivität zwischen dem rechten Nacc und dem linken avPFC während der Verarbeitung konditionierter (Belohnungs-)

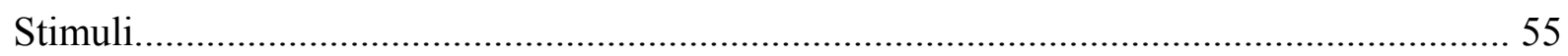

Tabelle 6: Parametrische Downregulation der wertigkeitsabhängigen Aktivierung während des Desire-Reason- Dilemmas 56

Tabelle 7: Parametrischer Anstieg der inversen Konnektivität zwischen dem VMPFC und dem rechten ventralen Striatum in der Gruppe der HI- Probanden während des DesireReason-Dilemmas. 58

Tabelle 8: Hirnregionen, die in der Bonusrunde und/ oder während der Zielverfolgung einen parametrischen Anstieg der Hirnaktivierung mit zunehmender Wertigkeit der Belohnungsoption zeigten. 59 


\section{Abkürzungsverzeichnis}

ADHS

ALM

ANOVA

avPFC

BIS

BOLD

DLPFC

EPI

fMRT

FWE

FWHM

GABA

HI

hrf

i.e.S.

IFS

L

LO

$\mathrm{mm}$

Nacc

Matlab

MFG

MNI

MRT/ MR

n.s.

ms
Aufmerksamkeitsdefizit /Hyperaktivitätsstörung

allgemeines lineares Modell

univariate Varianzanalyse

anteroventraler präfrontaler Kortex

Barratt- Impulsivitätsskala

Blood Oxygenation Level Dependent

dorsolateraler präfrontaler Kortex

echoplanare Bildgebung (echo planar imaging)

funktionelle Magnetresonanztomographie

Family- wise- Fehlerrate

full width at half maximum

$\gamma$-Aminobuttersäure

hoch- impulsiv

hämodynamische Antwortfunktion

im engeren Sinne

inferiorer frontaler Sulkus

links/linker/linke

niedrig- impulsiv (low- impulsive); kontrolliert

Millimeter

Nucleus accumbens

Matrix Laboratory

mittlerer frontaler Gyrus

Montreal Neurologic Institute

Magnetresonanztomographie

nicht signifikant

Millisekunde 
PFC

PPI

r

$\mathrm{R}$

S

SPM 2

SPSS

$\mathrm{T} 1$

$\mathrm{T} 2$

TR

vgl.

VMPFC

VS.

VTA präfrontaler Kortex

psychophysiologische Interaktionsanalyse

Korrelationskoeffizient nach Pearson

rechts/rechter/rechte

Sekunde

Statistical parametric mapping 2

Statistical Package for the Social Sciences

longitudinale Relaxation

transversale Relaxation

Repetitionszeit

vergleiche

ventromedialer präfrontaler Kortex

versus

Area tegmentalis ventralis 


\section{$1 \quad$ Einleitung}

Impulsivität ist ein Merkmal, das sich sowohl günstig als auch ungünstig auf unser tägliches Leben auswirken kann. Die Fähigkeit, auf einen Impuls hin zu agieren, erlaubt es uns, eine günstige Gelegenheit zu ergreifen, aber auch eine Entscheidung zu treffen, die katastrophale Auswirkungen haben kann (Winstanley et al., 2006).

In unserer modernen Welt, in der wir Menschen oft ein langfristiges Ziel verfolgen müssen, um großen Benefit zu erzielen, ist die Fähigkeit, impulsive Wünsche zu unterdrücken, äußerst bedeutend für Erfolg im Leben. Ein Mangel an Selbstkontrolle ist mitverantwortlich für viele der heutigen Probleme, zum Beispiel spielt es eine Rolle bei der Entstehung von Übergewicht oder der Kaufsucht. Diese Tatsachen haben zu einem beachtlichen Interesse an dem mechanistischen Verständnis des impulsiven Phänotyps geführt (Congdon \& Canli, 2005).

\subsection{Impulsivität: Definition}

Im täglichen Sprachgebrauch und klinischen Alltag ist Impulsivität ein üblicher und weit verbreiteter Begriff. Vorwiegend in neurobiologischen und psychologischen Studien ist das Konstrukt der Impulsivität die Forschungsgrundlage. Dennoch existiert keine weitestgehend übereinstimmende Definition. Unter dem Begriff der Impulsivität versteht man kein einheitliches Konstrukt (Evenden, 1999). Die Definitionen und Methoden, Impulsivität zu messen, unterscheiden sich stark von Studie zu Studie und spiegeln so ihre Vielseitigkeit wider. Dies verhindert den Versuch, ein umfassendes Verständnis der Impulsivität zu entwickeln (Congdon \& Canli, 2005).

In der vorliegenden Studie wurde mittels eines neuartigen Studiendesigns eine Art konditionierte Belohnungsimpulsivität mit motorischer Komponente gemessen. Die Studienteilnehmer sollten im Vorfeld mittels eines Selbstbeurteilungsfragebogens, der Barratt- Impulsivitätsskala, ihre Ausprägung der Persönlichkeitseigenschaft der Impulsivität selbst einschätzen. In der Studie hatten die Probanden die Aufgabe, in Abhängigkeit von den Verhaltensregeln des jeweiligen Aufgabentyps, eine Serie von unterschiedlich farbigen Quadraten durch schnellen Druck einer Taste zu bearbeiten. Dabei kam es zum einen auf eine schnelle Handlungsbereitschaft an. Aber auch die kognitive Entscheidung für oder gegen eine unmittelbare Belohnung im Kontext der übergeordneten Zielsetzung war von unmittelbarer Bedeutung. Eine Definition der Impulsivität für diese Studie muss daher einerseits 
Impulsivität als Persönlichkeitseigenschaft erfassen, anderseits die Umsetzung der kognitiven Reaktion auf einen Belohnungsimpuls in eine motorische Handlung beschreiben. Eine geeignete Definition sollte daher sowohl eine behaviorale als auch eine motorische Komponente der Impulsivität erfassen. Zur Beschreibung der behavioralen Komponente der Impulsivität liefern beispielsweise Eysenck \& Eysenck (1977) einen wichtigen Ansatz. Die motorische Komponente wird sehr gut von Plutchik und van Praag (1995) erfasst.

Schlägt man die enzyklopädische Bedeutung des Begriffs der Impulsivität nach, findet man darunter „die besondere Neigung zu unüberlegten, unerwarteten, plötzlichen Handlungen“ (Peters, 2007). Ganz allgemein kann man Impulsivität demnach als Handeln ohne Voraussicht definieren (Winstanley et al., 2006). Plutchik und van Praag (1995) beschreiben die verschiedenen Facetten der Impulsivität als Tendenz des Individuums, schnell und ohne Reflexion auf Stimuli zu reagieren. Impulsivität versteht sich daher als ein Kontinuum zwischen zwei Komponenten, und zwar Fähigkeit versus Unfähigkeit, sich Dranghaftem zu widersetzen, und der unmittelbaren Reaktion auf einen Stimulus versus planvolles Verhalten. Dickman (1990) unterscheidet zwischen zwei Subtypen der Impulsivität, der funktionalen und der dysfunktionalen Impulsivität. „Als funktionale Impulsivität werden die Tendenzen einer Person zu spontanen, nicht durch Nachdenken gekennzeichneten Aktionen verstanden, wenn solch ein Stil in bestimmten Situationen optimal ist und/oder dadurch vorteilhafte Ziele erzielt werden“ (Marneros, 2007, S.52). Jemand handelt also funktional impulsiv, wenn er schnell und zum richtigen Zeitpunkt agiert. Bei der dysfunktionalen Impulsivität findet man auch spontane und nicht durch Nachdenken gekennzeichnete Handlungen. Diese sind jedoch sowohl für die Person als auch für ihre Umwelt destruktiv (Marneros, 2007).

Herpertz und $\mathrm{Sa}$ (2000) unterteilen das gesamte Konstrukt der Impulsivität in zwei Teilkomponenten, in eine Antriebsdimension und eine Kontrolldimension. Daraus entsteht das Verständnis, dass Verhalten ein Resultat aus Antrieb und Hemmung ist, das mehr oder weniger stark bewusst wahrgenommen wird. Der Begriff der Hemmung kann mit der Impulskontrolle gleichgesetzt werden, während unter „Antrieb“ der impulsive Antrieb verstanden werden kann. Sabine Herpertz (2001) beschreibt das impulsive Verhalten als wenig geplant, vorzeitig oder übereilt ausgeführt und der Situation wenig angepasst. Neben der Verhaltensinhibition berücksichtigt Impulsivität aber auch Aspekte der kognitiven Inhibition, der Interferenzkontrolle, sowie Reaktionen auf Bestrafungshinweise und Neuheiten (Nigg, 2000).

Herpertz und auch andere Autoren beschreiben Impulsivität aber nicht als ein krankheitswertiges Phänomen an sich, das zur gesellschaftlichen Devianz führt, auch wenn 
Impulsivität häufig in dysfunktionalen Manifestationen Beachtung findet. Impulsivität kann als eine Dimension der normalen Persönlichkeit betrachtet werden (Eysenck \& Eysenck, 1977). Als Charaktereigenschaft ist sie vielmehr verbunden mit dem Temperament eines Menschen, seinem Antrieb, seinem Gefühl, Willen und Trieb. Impulsivität ist eine Persönlichkeitseigenschaft, die durch eine Unfähigkeit gekennzeichnet ist, Gedanken und Handlungen zu unterdrücken, als auch Belohnungen abzulehnen (Congdon \& Canli, 2005). Impulsivität ist in diesem Zusammenhang ein Maß für die Willenskraft und emotionale Sensibilität des Menschen gegenüber der Stimulierung durch die Umwelt.

Auch nach Evenden (1999) wird unter dem Begriff der Impulsivität ein heterogenes Persönlichkeitsmerkmal verstanden, das sich aus mehreren Dimensionen zusammensetzt. Aus behavioraler Perspektive kann Impulsivität daher definiert werden als ein breites Spektrum von Handlungen, die unausgereift, voreilig, übermäßig riskant oder der jeweiligen Situation unangemessen sind und häufig zu unerwünschten Ergebnissen führen (Evenden, 1999).

Einfacher ist die Beschreibung der Impulsivität als die Unfähigkeit, den Empfang einer Belohnung zu verzögern oder als Gegenteil der Selbstkontrolle (Monterosso \& Ainslie, 1999). Ainslie (1975) hingegen definiert Impulsivität gezielt in Hinblick auf Belohnungen. Ihrer Ansicht nach kann Impulsivität allgemein als eine Charaktereigenschaft aufgefasst werden, die an Probanden dadurch gemessen werden kann, dass diese aus mehreren Möglichkeiten eine unmittelbare niedrige Belohnung eher wählten als eine größere, aber verzögerte. Der Bezug auf eine Belohnungsoption mit Berücksichtigung einer zeitlichen Komponente stellt für diese Arbeit eine wichtige Grundlage für die Definition des Konstrukts der Impulsivität dar. Denn hoch- impulsive Personen weisen Schwierigkeiten auf, einen Gewinn über einen langen Zeitraum hinweg zu maximieren und sich Veränderungen in belohnten Situationen anzupassen (Franken et al., 2008).

Die zentralen Charakteristika der Impulsivität sind also die verstärkte Suche nach einer sofortigen Belohnung, eine herabgesetzte Toleranz für Verzögerungen und die Unfähigkeit vorauszuplanen (Patton et al., 1995; Kalenscher et al., 2006). Ein Versuch der Definition der Impulsivität, der für die vorliegende Arbeit am geeignetsten erscheint, wurde von Winstanley et al. (2006) aufgestellt. Sie beschreiben Impulsivität als eine abnehmende Impulskontrolle, Intoleranz gegenüber einer verzögerten Belohnung und schnelle Entscheidungsfreudigkeit ohne zu überlegen und abzuwägen, die ebenso eine geringe Aufmerksamkeit beinhaltet. 


\subsection{Impulsivität und Psychopathologie}

Einen Krankheitswert bekommt Impulsivität erst dann, wenn sie keinem adäquaten Kontrollund Hemmungsvermögen unterliegt. Hohe Level der Impulsivität sind häufig mit psychiatrischen Erkrankungen und Persönlichkeitsstörungen assoziiert, die Ausdruck einer Fehlsteuerung dieser Eigenschaft sein können (Winstanley et al., 2006).

In der Psychopathologie hat Impulsivität daher zwei Bedeutungen. Sie kann erstens als ein Symptom psychiatrischer Erkrankungen auftreten und sich in impulsivem Handeln äußern. Zweitens kann sie als Persönlichkeitsmerkmal in Erscheinung treten.

In der DSM- IV-Klassifikation der „American Psychiatric Association“ (1994) gibt es eine eigenständige diagnostische Kategorie der sog. „Störungen der Impulskontrolle nicht andernorts klassifiziert". Sie umfasst folgende diagnostische Merkmale für die Impulsivität:

- Versagen, einem Impuls, einem Trieb oder einer Versuchung zu widerstehen, eine Handlung auszuführen, die schädlich für die Person selbst oder für andere ist

- Ansteigendes Gefühl von Spannung oder Erregung vor Durchführung der Handlung

- Erleben von Vergnügen, Befriedigung oder Entspannung während der Durchführung

- Nach der Handlung können Reue, Selbstvorwürfe oder Schuldgefühle auftreten oder nicht.

Das entscheidende diagnostische Kriterium ist das Vorhandensein eines zunehmenden inneren Spannungszustandes vor der Handlung und ein Gefühl der Entlastung und Erleichterung nach der Handlung. Im Einzelnen sind dieser Kategorie die intermittierende explosible Störung, die Kleptomanie, die Pyromanie, das pathologische Spielen und die Trichotillomanie zuzuordnen. Außerdem beschreibt diese Kategorie zeitlich begrenzte, umschriebene Verhaltensstörungen. Von klinischer Bedeutung ist die Impulsivität auch bei den Essstörungen (Bulimia nervosa), Suchterkrankungen (Alkohol- und Drogenmissbrauch), bei verschiedenen Formen selbstschädigenden Verhaltens und auch beim Aufmerksamkeits- und Hyperaktivitätssyndrom vor allem des Kindesalters. Impulshandlungen können schließlich im Verlauf nahezu aller psychiatrischen Erkrankungen vorkommen, u.a. bei verschiedenen Formen geistiger Retardierung und bei schizophrenen sowie affektiven Psychosen (Herpertz und Saß, 1997). Auf dem Gebiet der Persönlichkeitsstörungen wird unter Impulsivität ein überdauerndes, zentrales Persönlichkeitsmerkmal verstanden. Dabei ist unter der Impulsivität als 
Persönlichkeitsmerkmal eine über verschiedene Situationen hinweg auftretende, überdauernde Neigung zu impulsiven Handlungen und impulsivem Verhalten zu verstehen.

Insbesondere bei der antisozialen und Borderline-Persönlichkeitsstörung spielt die Impulsivität eine bedeutende Rolle und kommt in einer eigenen ICD-10-Kategorie der impulsiven Persönlichkeitsstörung zum Ausdruck (Herpertz und Saß, 1997).

\subsection{Operationalisierung von Impulsivität}

Die multidimensionale Natur der Impulsivität erschwert nicht nur die Etablierung einer allgemeinen Definition der Impulsivität, sondern auch ihre Messung. In Human- und Tierexperimenten wird eine Vielzahl von Messmethoden verwendet, um partielle aber auch globale Aspekte der Impulsivität messen zu können (Arce \& Santisteban, 2006).

Um die Validität von Messmethoden zu überprüfen, wird in Experimenten die Differenzierung der Impulsivität in 2 Hauptkomponenten, eine motorische und eine kognitive, von Evenden (1999) und Bechara (2002) genutzt (Arce \& Santisteban, 2006).

$\mathrm{Da}$ in der vorliegenden Arbeit eine konditionierte Belohnungsimpulsivität mit motorischer Komponente gemessen wurde, soll nachfolgend als Beispiel für ein psychometrisches Operationalisierungsverfahren die Barratt- Impulsivitätsskala vorgestellt werden. Aber auch eine neuropsychologische Messmethode, das Delay-Discounting- Paradigma, wird erörtert.

\subsubsection{Psychometrisches Verfahren}

Eine gebräuchliche Methode in der klinischen Psychologie, verschiedene Aspekte des Verhaltens $\mathrm{zu}$ identifizieren und $\mathrm{zu}$ messen, ist die Anwendung von Selbstbeurteilungsfragebögen. Sie finden vor allem in der Persönlichkeitspsychologie zur Messung der Impulsivität breite Anwendung, um diese als Persönlichkeitseigenschaft standardisiert zu erfassen.

Selbstbeurteilungsfragebögen sind jedoch sehr subjektive Verfahren. Durch die persönliche Interpretation der vorgegebenen Fragen durch die Studienteilnehmer können zwar Aussagen über die Selbstbilder und Selbstkonzepte der Probanden erfasst werden. Die Selbstdarstellung der Probanden geht aber auch mit der Gefahr der Verfälschungstendenz einher. Die zuverlässige Interpretation der Ergebnisse kann beispielsweise durch soziale Erwünschtheit, Simulations- und Dissimulationstendenzen eingeschränkt werden. 
Selbstbeurteilungsfragebögen werden dennoch aufgrund ihrer einfachen, schnellen und kostengünstigen Durchführung zur Untersuchung einer großen Stichprobe eingesetzt und eignen sich daher gut als Screeningmethode.

\subsubsection{Die Barratt- Impulsivitätsskala, 11. Revision (BIS-11)}

Einer der am häufigsten verwendeten Fragebögen ist die Barratt- Impulsivitätsskala (BIS-11) (Barratt, 1994). Sie wurde 1959 von Barratt entwickelt und in einer Reihe von Studien validiert und verbessert.

Die BIS- 11 ist ein Selbstbeurteilungsfragebogen, der aus 30 Items in Ich- Form besteht (siehe Anhang). Der Inhalt der Fragen zielt auf die Erfassung impulsiven Verhaltens und impulsiver Denkweisen ab. Die Probanden beantworten die Aussagen in einem vierfach abgestuften Antwortschlüssel und beschreiben damit, wie oft das genannte Verhalten auf sie zutrifft (Barratt, 1994). Die vierstufige Skala besteht aus den folgenden Antwortmöglichkeiten: 1=

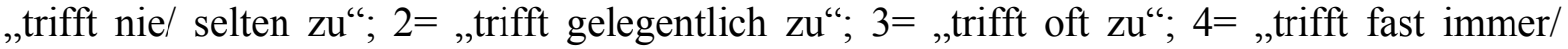
immer zu“. Die Antworten werden entsprechend mit 1,2,3 oder 4 Punkten bewertet. 4 Punkte stellen dabei die maximale Ausprägung der Impulsivität dar. Einige Fragen werden invers bewertet.

Die Auswertung der BIS- 11 kann sowohl auf der Gesamtskala als auch auf den Unterskalen erfolgen. Es werden Mittelwerte für die Gesamtskala und die Unterskalen berechnet. Je höher die Gesamtsumme aller Items, desto höher ist das Level der Impulsivität.

Barratt konzeptionalisiert die Impulsivität in 3 Hauptkomponenten: in eine motorische, eine kognitive und eine nicht- planende Komponente. Die motorische Impulsivität wird mit 11 Items, die kognitive Impulsivität mit 8 Items und die nicht- planende Impulsivität mit 11 Items erfasst. Auf diese Weise ist es möglich, die drei Hauptkomponenten der Impulsivität unabhängig voneinander zu messen.

Unter der motorischen Impulsivität wird die Neigung $\mathrm{zu}$ handeln ohne darüber nachzudenken verstanden. Mögliche Konsequenzen werden im Vorfeld nicht bedacht. Die motorische Impulsivität beschreibt also einen Mangel an Impulskontrolle und zeigt, dass Verhaltensantriebe nur schwer unterdrückt werden können. Die kognitive Impulsivität ist definiert durch eine schnelle kognitive Antwortgeschwindigkeit und Informationsverarbeitung. Sie äußert sich in einer schnellen Entscheidungsbereitschaft und kann zu ungenauem Handeln führen. Die nicht- planende Impulsivität ist charakterisiert durch die Orientierung an der Gegenwart und einen Mangel an Zukunftsdenken. Sie führt zu 
einer Unfähigkeit, zu planen und problemorientierte Lösungen zu finden, da nur kurzfristige Ziele verfolgt werden. Die nicht- planende Impulsivität kann als Ausdruck sozialer Lernprozesse angesehen werden (Barratt, 1985). Sie charakterisiert den Lebensstil einer Person. Die Beschreibung der drei Komponenten der BIS-11 zeigt, dass die Messung einzelner Aspekte der Impulsivität nicht auf die Verhaltensebene beschränkt bleibt. Durch die kognitive Komponente ergänzt Barratt sein Konzept der Impulsivität als ein überdauerndes Persönlichkeitsmerkmal um eine weitere Funktionsebene (Herpertz und Saß, 1997).

Die drei Unterskalen der Barratt- Impulsivitätsskala wurden bei der faktoranalytischen Validierung der elften Version des Fragebogens erkannt und Faktoren zweiter Ordnung genannt. Diese Faktoren zweiter Ordnung korrelieren signifikant miteinander mit 0,46 bis 0,53 ( $\mathrm{p}<$ 0,0001). Dies spricht dafür, dass die Skala zur Messung eines Persönlichkeitsmerkmals verwendet werden kann. Die interne Konsistenz der BIS-11 wird mit dem Koeffizienten Cronbach's alpha angegeben und liegt für Studenten im Bereich von ¿† T́Ğóm(Patton et al., 1995). Individuelle Scores weisen eine hohe Stabilität im Zeitverlauf

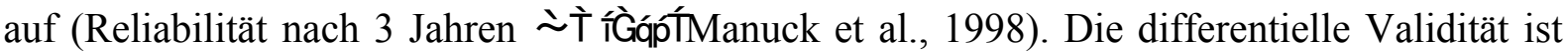
gegeben, da die Skala zuverlässig zwischen verschiedenen Gruppen unterscheidet. Zu diesen Gruppen zählen Studenten, Patienten mit Substanzmissbrauch und Gefängnisinsassen. Es gibt eine Evidenz dafür, dass hohe Level der Impulsivität, die anhand der BIS-11 gemessen wurden, invers mit der serotonergen und dopaminergen Empfindlichkeit korrelieren (Manuck et al., 1998; Buckholtz et al., 2010). Weiterhin wurden erhöhte BIS-11- Scores bei Patienten mit Substanzmissbrauch beobachtet (O'Boyle \& Barratt, 1993; Lee et al., 2009). In der Studie von Diekhof \& Gruber (2010) konnte gezeigt werden, dass die BIS-11- Scores mit der Fähigkeit, einen Verhaltensimpuls während eines Desire- Reason- Dilemmas ${ }^{l}$ zu kontrollieren, korrelierten. Währenddessen konnte eine Abnahme der funktionellen Interaktion zwischen dem anteroventralen präfrontalen Kortex (avPFC) und dem Nucleus accumbens (Nacc) nachgewiesen werden, wenn das Verlangen nach einer kurzfristigen Belohnung mit einem langfristigen Ziel um die Handlungskontrolle konkurrierte.

Für diese Arbeit wurde eine deutsche Übersetzung der BIS-11 verwendet. Der Fragebogen soll in dieser Arbeit ein Maß für die subjektive Impulsivität der Probanden sein.

\footnotetext{
${ }^{1}$ Erklärung Desire- Reason- Dilemma: Gemeint ist ein Konflikt zwischen dem Verlangen, eine unmittelbare Belohnungsoption anzunehmen, und der übergeordneten Zielsetzung, den jeweiligen Block erfolgreich zu beenden. Siehe auch 1.4.1, S.18
} 


\subsubsection{Neuropsychologische Verfahren}

Anders als bei den psychometrischen Methoden wird mit neuropsychologischen Erhebungsmethoden versucht, die Impulsivität unter laborexperimentellen Bedingungen als Eigenschaft direkt zu messen. Für die Messung ist es notwendig, eine Auswahl an Phänomenen zu klassifizieren, die eigenständigen biologischen Mechanismen unterliegen (Evenden, 1999). Durch Fokussierung auf einzelne Aspekte impulsiven Verhaltens ist es möglich, Impulsivität an menschlichen und nicht- menschlichen Versuchsobjekten zu messen. Im Fokus der Untersuchung neuropsychologischer Verfahren steht die behaviorale Impulskontrolle. Innerhalb experimenteller Paradigmen werden interferierende Verhaltensreaktionen erzeugt, die die Versuchsobjekte aktiv inhibieren sollen.

Mithilfe neuropsychologischer Messverfahren kann sowohl der Einfluss der Impulsivität auf das Verhalten (motorische Impulsivität) als auch auf die Entscheidungsfindung (kognitive Impulsivität) gemessen werden.

\subsubsection{Messung der motorischen Impulsivität}

Impulsive Handlungen sind gekennzeichnet durch die Unfähigkeit, bestimmte Verhaltensweisen zu inhibieren. In der Verhaltensforschung und der kognitiven Psychologie wird Impulskontrolle als ein aktiver Inhibitionsmechanismus beschrieben, der einen internen oder externen präpotenten Wunsch nach primären Bedürfnissen wie Essen, Sex oder anderen höherwertigen Belohnungen moduliert. Dieser inhibitorische Kontrollmechanismus könnte dafür verantwortlich sein, dass schnelle konditionierte Antworten und Reflexe vorübergehend supprimiert werden, so dass langsamere kognitive Mechanismen das Verhalten lenken können (Winstanley et al., 2006).

\subsection{Das Go-/ No- Go- Paradigma}

Ein bedeutsamer Aspekt der Verhaltenskontrolle ist die Fähigkeit, unter Zeitdruck eine angemessene Reaktion auszuführen und gleichzeitig einen inadäquaten Verhaltensimpuls zu kontrollieren. Um dies zu überprüfen, wurden experimentelle Tests entwickelt. Einer der am häufigsten angewendeten Tests, um inhibitorische Prozesse an klinischen und nichtklinischen Stichproben zu untersuchen, ist das Go-/ No- Go- Paradigma (Band \& Van Boxtel, 1999; Winstanley et al., 2006). 
Die Go-/ No- Go- Aufgabe ist eine hervorragende Handlungs-/ Inhibitionsaufgabe zur Messung der motorischen Impulsivität. Sie kann sowohl mit verbalen als auch non- verbalen Stimuli durchgeführt werden und liefert adäquate Verhaltensdaten, um die Prozesse zu untersuchen, die in der Inhibition einer präpotenten Go- Antwort involviert sind. Eine der ersten Versionen der Go-/ No-Go- Aufgabe hat Drewe (1975) verwendet, um Lernprozesse und Prozesse der Entscheidungsfindung nach Läsionen des Frontallappens zu untersuchen (Arce \& Santisteban, 2006).

Im Go-/ No- Go - Paradigma kommt es darauf an, eine durch externe Reize getriggerte Reaktion zu Gunsten einer intern kontrollierten Verhaltensweise zu unterdrücken. Bei diesem Paradigma ist der Aufmerksamkeitsfokus auf das vorhersehbare Erscheinen von Reizen gerichtet, die dann eine selektive Reaktion erfordern, d.h. entweder auf diese zu reagieren oder nicht. Go-/ No-Go-Aufgaben sollen die spezifische Fähigkeit zur Unterdrückung einer nicht-adäquaten Reaktion überprüfen, eine Leistung, die insbesondere nach Schädigungen des präfrontalen Kortex defizitär sein soll.

In einem typischen Go-/ No- Go- Paradigma folgen die Probanden einer Versuchsanleitung und lernen immer dann eine Antwort zu geben, wenn sie durch Anzeigen eines Go- Signals dazu aufgefordert werden (d.h. sie sollen dann entweder den gezeigten Stimulus auf dem Bildschirm berühren oder eine bestimmte Taste drücken).Wenn den Probanden im Verlauf des Experiments ein No-Go- Signal präsentiert wird, entweder gleichzeitig mit oder vor der Präsentation eines Go- Signals, sollen die Probanden ihre präpotente Antwort unterdrücken. Bannon et al. (2001) konnten in ihrer Studie zeigen, dass je nach Schwierigkeitsgrad der Go-/ No- Go- Aufgabe sowohl behaviorale als auch kognitive neuronale Prozesse reflektiert werden (Winstanley et al., 2006).

\subsubsection{Messung der kognitiven Impulsivität}

Impulsivität äußert sich nicht nur in menschlichem Verhalten. Es kann auch Einfluss auf die Entscheidungsfindung haben. Die Fähigkeit, nützliche Entscheidungen zu treffen, hängt stark von der Fähigkeit ab, vorauszuplanen und/ oder eine Antwort zu inhibieren (Arce \& Santisteban, 2006). Die kognitive Impulsivität gilt als Unfähigkeit, Konsequenzen aktueller und zukünftiger Ereignisse abzuwägen und eine Belohnung konsequent hinauszuzögern (Arce \& Santisteban, 2006). Lange wurde die Auffassung vertreten, dass sich Impulsivität nur in impulsiven Handlungen sämtlicher Art äußert, so dass vorwiegend die motorische Komponente der Impulsivität Beachtung fand. Mithilfe des Delay-Discounting- Paradigmas 
zum Beispiel können jedoch Rückschlüsse auf die kognitive Impulsivität gezogen werden.

\subsection{Das Delay- Discounting- Paradigma}

In der experimentellen Verhaltensforschung wird Impulsivität allgemein als eine Charaktereigenschaft aufgefasst, die an Probanden dadurch gemessen werden kann, dass diese aus mehreren Möglichkeiten eine unmittelbare niedrige Belohung eher wählen als eine größere, aber verzögerte (Ainslie, 1975).

Unter Delay- Discounting versteht man das Abwerten zukünftiger Belohnungen und Bestrafungen. Es wird sowohl bei Tieren als auch bei Menschen beobachtet. Es ist eine der am erfolgreichsten angewendeten Methoden, impulsive Entscheidungen zu messen.

Die subjektive Entwertung einer verzögerten Belohnung findet in der intertemporalen Entscheidungsfindung Anwendung. Die intertemporale Entscheidungsfindung ist ein wesentlicher Aspekt der menschlichen Entscheidungsfindung, der Auswirkung auf alle Bereiche des menschlichen Lebens hat (Winstanley et al., 2006).

Intertemporale Entscheidung meint, dass eine Wahl zwischen Belohnungsoptionen getroffen werden muss, die $\mathrm{zu}$ unterschiedlichen Zeitpunkten auftreten. Bei dieser Entscheidung müssen Konsequenzen für die Gegenwart und die Zukunft berücksichtigt und abgewogen werden, ob ein kurz- oder langfristiger Nutzen angestrebt werden soll. Für die Zukunftsplanung ist das Aufschieben aktueller und kurzfristiger Bedürfnisse essentiell. Der Aufschub eines Bedürfnisses ist ein Prozess, in dem die subjektive Bewertung einer Belohnungsoption, aber auch die Ausübung von Selbstkontrolle von entscheidender Bedeutung sind. Ein Mangel an Selbstkontrolle führt zu der Unfähigkeit, Bedürfnisse zurückzustellen und geht häufig mit Krankheitsbildern einher, die mit Impulsivität assoziiert werden (Winstanley et al., 2006).

Alle Methoden, Delay- Discounting zu messen, sowohl operante Verhaltensaufgaben als auch auf Fragebögen basierte Methoden, werfen die grundlegende Frage auf, ob eine kleinere, aber unmittelbar zur Verfügung stehende Belohnung mehr oder weniger wert ist als eine größere, aber verzögerte Belohnung (Ainslie, 1975; Logue, 1988). Eine große Anzahl verschiedener Delay-Discounting- Aufgaben wurde für Tierexperimente, vornehmlich für die Untersuchung an Ratten, entwickelt. In allen Delay-Discounting- Aufgaben konnten die Versuchstiere zwischen einem Hebel wählen, dem eine kleine Belohnung folgte und einem anderen, dem eine größere, aber verzögerte Belohnung folgte. Je nach Aufgabentyp konnte entweder der Versuchsleiter die Verzögerung auf unterschiedlich große Verstärker variieren, so dass die 
Anzahl der Entscheidungen für die größere Belohnung mit verschiedenen Verzögerungen gemessen werden konnte. Oder aber die Probanden selbst bestimmten die ausgewählten Verzögerungen durch ihr Verhalten (Winstanley et al., 2006).

Ainslie (1975) hebt verschiedene Theorien unterschiedlicher Disziplinen hervor, in denen impulsives Verhalten dadurch erklärt wird, dass eine unmittelbare Belohnung ihre Attraktivität im Laufe der Zeit verliert. Demzufolge suggeriert er, dass sich die relative Effektivität verzögerter Belohnungen in Abhängigkeit der verstreichenden Zeit verändert. Mehrere Autoren sind sich darüber einig, dass die Wertigkeit eines Verstärkers über die Zeit anhand einer hyperbolischen Funktion erklärt werden kann (Ainslie, 1975; Evenden, 1999; Monterosso und Ainslie, 1999). Das heißt, die Wertigkeit einer Belohnung nimmt als hyperbolische Funktion mit der Größe der Belohnung zu. Mit der zeitlichen Verzögerung und der Chance des Auftretens nimmt sie jedoch als hyperbolische Funktion ab. Diese Funktion kennzeichnet impulsive Entscheidungen dadurch, dass es einen Zeitpunkt gibt, zu dem eine kleinere Belohnung eher präferriert wird als eine größere verzögerte Belohnung (Winstanley et al., 2006). Die Tendenz, eine impulsive Option zu wählen, nimmt daher mit Verkürzung der Verzögerung der größeren Belohnung ab (siehe Abb. 1) (Ainslie, 1975).

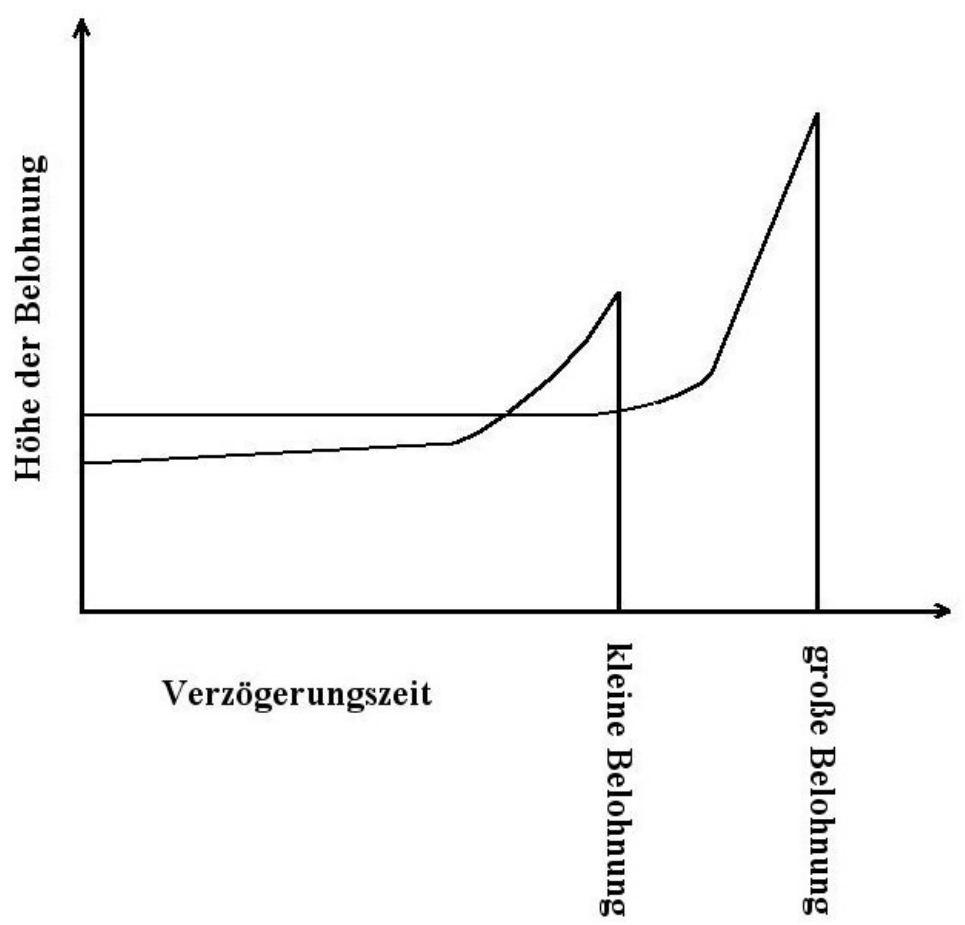

Abbildung 1: Darstellung impulsiven Verhaltens als hyperbolische Belohnungsfunktion:

Die Wertigkeit einer Belohnung nimmt mit der Höhe der Belohnung als hyperbolische Funktion zu, mit der zeitlichen Verzögerung und der Chance des Auftretens jedoch als hyperbolische Funktion ab.

Quelle: Winstanley et al., 2006, S.382; angepasst an Ainslie, 1975 
Logue (1988) betont, dass nicht nur die mit der Belohnung assoziierte Verzögerung selbst von Bedeutung ist, sondern auch die Empfindlichkeit der Testpersonen gegenüber dieser. Dies bedeutet, dass die Vorstellung einer bevorstehenden Belohnung eine starke Rolle bei der Verzögerung einer Belohnung spielt. Die Fähigkeit, eine Belohnung unter Wahrung ihrer Attraktivität hinauszuzögern, ermöglicht es uns, nicht- impulsiv zu handeln.

In Experimenten konnte gezeigt werden, dass die Attraktivität der Wertigkeit einer Belohnung über einen längeren Zeitraum aufrechterhalten werden kann, wenn die Testpersonen während der Wartezeit mit einer Aufgabe beschäftigt waren (Ainslie, 1975; Ho et al. 1998). Die subjektive Bewertung einer Belohnung nimmt in Abhängigkeit von der Zeit ab. Wenn die Testpersonen jedoch, während sie auf ihre Belohnung warteten, zusätzlich mit anderen Mitteln „unterhalten“ wurden, waren sie stärker dazu in der Lage, eine vorzeitige Antwort zu inhibieren (Arce \& Satisteban, 2006).

\subsection{Vorstudie von Diekhof \& Gruber (2010)}

Die Studie von Diekhof \& Gruber (2010) war Ausgangspunkt für die Durchführung der vorliegenden Arbeit. Im Folgenden sollen daher das Design und die Ergebnisse dieser Studie vorgestellt werden.

Diekhof \& Gruber (2010) haben mittels der funktionellen Magnetresonanztomographie die neuronalen Mechanismen des menschlichen Gehirns untersucht, die für die Abwägung zwischen belohnungsorientierten kurzfristigen und langfristigen Handlungen verantwortlich sind. Zielsetzung der Studie war es, in vivo die dynamischen Interaktionen zwischen den Hirnregionen zu beschreiben, in denen wunsch- und zielorientierte Handlungen repräsentiert werden. Die Probanden hatten die Aufgabe, einer übergeordneten Zielsetzung zu folgen, die an einem langfristigen Ziel orientiert war und die Annahme einer unmittelbaren Belohnung untersagte.

\subsubsection{Das Studiendesign}

An der Studie nahmen 18 Studienteilnehmer mit akademischem Hintergrund teil, darunter 10 Probandinnen. Ihre Aufgabe war es, eine neuartige Forced-Choice-Aufgabe zu bearbeiten, in der sie eine Serie von Stimuli nach bestimmten Regeln entweder annehmen oder ablehnen 
sollten, um einer übergeordneten Zielsetzung zu folgen. Bei erfolgreicher Durchführung eines Aufgabenblocks erhielten die Probanden am Ende jeden Blocks eine hohe Belohnung. Vor der Teilnahme am Experiment füllten die Probanden die deutschsprachigen Versionen der Persönlichkeitsfragebögen der Barratt- Impulsivitätsskala (BIS-11) und der NoveltySeeking- Skala (TCI-NS) aus, um später interindividuelle Unterschiede ihrer Impulsivität untersuchen zu können.

Das Experiment bestand aus 2 Teilen. Vor der Messung im MRT erfolgte eine Konditionierungsphase. Den Probanden wurden in zufälliger Reihenfolge Quadrate in 6 unterschiedlichen Farben präsentiert. Die Annahme einiger Stimuli war mit einer kleinen, direkten Belohnung assoziiert. Die Studienteilnehmer wurden aufgefordert, durch freies Ausprobieren herauszufinden, welche der farbigen Quadrate eine Belohnung als Feedback zur Folge hatten. Durch Drücken der linken Taste konnte ein farbiges Quadrat eingesammelt werden. Drücken der rechten Taste bedeutete die Ablehnung eines Quadrates. Unmittelbar nach der Entscheidung für oder gegen ein Quadrat wurde den Probanden angezeigt, ob der entsprechenden Farbe eine unmittelbare Belohnung von +1 Punkt folgte oder nicht. Den meisten Quadraten folgte unanhängig von der gedrückten Taste ein neutraler Stimulus (0 Punkte). Ziel dieser operanten Konditionierungsphase war es, Stimulus- AntwortBelohnungskontingenzen $\mathrm{zu}$ erarbeiten und $\mathrm{zu}$ festigen. Die Probanden sollten diese neu erlernten Verhaltensweisen, also welchen gezeigten Stimuli als Antwort eine unmittelbare Belohnung folgte, im zweiten Teil des Experiments wieder anwenden.

Der zweite Teil des Experiments fand im MRT statt. Den Studienteilnehmern war es nunmehr nicht mehr erlaubt, frei über die Annahme oder Ablehnung der meisten Trials zu entscheiden. Die Probanden hatten eine sequentielle Forced-Choice- Aufgabe zu bearbeiten, in der sie im Verlauf von vier bis sechs Quadraten einer übergeordneten Zielsetzung folgen mussten. Die übergeordnete Zielsetzung eines Blockes besagte, dass jede der drei zielrelevanten Farben nur einmal, und zwar bei ihrem ersten Erscheinen während eines Blocks eingesammelt werden durfte. Für die erfolgreiche Durchführung eines Blocks wurden die Probanden mit einer hohen Belohnung von 4 Punkten belohnt. Nichteinhalten der Zielsetzung führte dagegen zum Abbruch des Blocks. Das Ziel galt dann als verfehlt. Sollte eine der drei zielrelevanten Farben ein weiteres Mal (Repeat) im Verlauf desselben Blocks erscheinen, durften die Probanden diese nicht mehr einsammeln, sondern mussten sie durch Drücken der rechten Taste ablehnen, um der übergeordneten Zielsetzung zu folgen und den Block erfolgreich zu beenden. Wichtig war, dass in einigen dieser Blöcke den Probanden auch die konditionierten Stimuli als zielrelevant präsentiert werden konnten. In diesem Fall waren die Probanden angehalten, der 
übergeordneten Zielsetzung zu folgen, und auch die präsentierten Belohnungsquadrate bei ihrem erneuten Erscheinen abzulehnen (Desire- Reason- Dilemma). Nur in den Fällen, in denen den Probanden eine Farbe gezeigt wurde, die für den jeweiligen Block nicht als zielrelevant galt, konnten sie frei über dessen Annahme oder Ablehnung entscheiden (DesireSituation). In diesen Fällen wäre die Einsammlung der belohnungsassoziierten Farben die beste Strategie gewesen. Konditionierte, belohnte Quadrate sollten die Probanden demnach immer dann annehmen, wenn sie die Möglichkeit dazu hatten. Die eingesammelten Boni wurden den Studienteilnehmern nach erfolgreicher Beendigung eines Blocks gutgeschrieben und zur Gesamtpunktzahl dazu addiert (Diekhof \& Gruber, 2010).

\subsection{Neuronale Korrelate der Impulsivität und der Selbstkontrolle: Assoziation zu anatomischen Hirnstrukturen}

Das nachfolgende Kapitel erörtert die neuronalen Korrelate der Impulsivität und der Selbstkontrolle. Es wird insbesondere die Assoziation $\mathrm{zu}$ anatomischen Hirnstrukturen aufgezeigt. Im Mittelpunkt steht dabei die Interaktion zwischen dem Belohnungssystem und präfrontalen Kortexarealen.

\subsubsection{Die Studienergebnisse von Diekhof \& Gruber (2010)}

In der Studie von Diekhof \& Gruber (2010) konnten neuronale Mechanismen aufgezeigt werden, die für die Fähigkeit, Selbstkontrolle auszuüben, verantwortlich sind und es dem Menschen erlauben, Handlungen auszuführen, die sich an langfristigen Zielsetzungen orientieren und dafür unmittelbare und unvorteilhafte Belohnungen abzulehnen.

Diekhof \& Gruber (2010) fanden heraus, dass Entscheidungen, die den Wunsch nach einer unmittelbaren Belohnung erfüllten, auf neuronaler Ebene mit einer signifikanten bilateralen Aktivierung des Nucleus accumbens (Nacc) und der Area ventralis tegmentalis (VTA) assoziiert waren. Eine Entscheidung für ein langfristiges Ziel mit Verzicht auf eine direkte Belohnung ging mit einer zunehmenden, negativen funktionellen Interaktion zwischen dem Nacc und dem anteroventralen präfrontalen Kortex (avPFC) (i.e.S. dem frontomarginalen Kortex und dem angrenzenden Teil des anterioren lateralen orbitofrontalen Kortex) einher. Der Erfolg einer Handlung, trotz Konfrontation mit einer direkten Belohnung, ein langfristiges Ziel zu verfolgen, konnte durch das Ausmaß dieser funktionellen Interaktion zwischen dem avPFC und dem Nacc vorhergesagt werden. Die beschriebene Interaktion 
stellte weiterhin ein Maß für interindividuelle Unterschiede in der Impulsivität als Persönlichkeitsmerkmal dar und konnte Unterschiede im Erfolg des Verhaltens der Probanden aufzeigen. Probanden mit einer hohen inversen Kopplung dieser Regionen haben unter der Bedingung, die übergeordnete Zielsetzung $\mathrm{zu}$ erreichen, die konditionierten Stimuli erfolgreicher abgelehnt. In der BIS-11 zeigten diese Probanden auch niedrigere Impulsivitätsscores.

Die Ergebnisse der Studie von Diekhof \& Gruber (2010) verdeutlichen, dass für langfristige Entscheidungen der avPFC eine mögliche Rolle in der Handlungskontrolle des menschlichen Gehirns spielt. Sie weisen darauf hin, dass bei Handlungen, die die Hemmung von unmittelbaren wunschorientierten Einflüssen erfordern, möglicherweise inhibitorische Einflüsse des avPFC auf die Aktivität des Nacc erforderlich sind (Diekhof \& Gruber, 2010).

\subsubsection{Ergebnisse anderer neurowissenschaftlicher Studien}

Die Ergebnisse von Diekhof \& Gruber (2010) stehen in Übereinstimmung mit der Auffassung, dass es für die Abwägung zwischen einem unmittelbaren, belohnten Ereignis und der Verfolgung eines langfristigen Ziels eine Interaktion zwischen dem Belohnungssystem und präfrontalen Arealen gibt (Diekhof \& Gruber, 2010). Nachfolgend werden daher einzelne anatomische Strukturen näher beschrieben, die für die vorliegende Arbeit von Bedeutung sind. Anschließend werden Studienergebnisse vorgestellt, die diese Annahme bestätigen.

\subsubsection{Das Belohnungssytem}

Das mesolimbische Belohnungssystem hat seinen Ursprung in der Area tegmentalis ventralis (VTA) des Mesenzephalons und ist Teil des limbischen Systems. Neurotransmitter des Belohnungssystems ist Dopamin (für eine nähere Beschreibung des Dopaminsystems siehe unten). Das mesolimbische System hat in erster Linie eine modulatorische Funktion und bewirkt durch Verschaltung mit anderen Bereichen des limbischen Systems eine positive Verstärkung des Verhaltens (Belohnungslernen), weil seine Aktivierung an der Entstehung von Lustgefühlen beteiligt ist (Thews et al., 2007). 


\subsubsection{Der Nucleus accumbens}

Der Nucleus accumbens liegt als relativ kleiner Abschnitt im ventrorostralen Bereich des Striatums, in dem der Nucleus caudatus und das Putamen miteinander verschmelzen (Trepel, 2004). Der Nucleus accumbens hat insbesondere Verbindungen zum orbitofrontalen und medialen präfrontalen Kortex (Haber \& Knutson, 2010). Es wird aber auch eine intensive Verbindung zu Strukturen des limbischen Systems beschrieben. Aus diesem Grund wird der Nucleus accumbens als eine wichtige Umschaltstation von „Motivation in Aktion“ und „Emotion in Lokomotion“ angesehen. Er fungiert als Bindeglied zwischen Basalganglien und dem limbischen System bzw. dem psychomotorischem System. Im Nucleus accumbens befinden sich Dopaminrezeptoren vom Typ D2, die durch dopaminerge Afferenzen der VTA stimuliert werden und für ein Glücksgefühl sorgen (Trepel, 2004).

Zahlreiche Studien belegen die Bedeutung des Nucleus accumbens in der Regulation belohnungsassoziierten Verhaltes (Winstanley et al., 2006). Der Nucleus accumbens kann als ein Knotenpunkt des limbischen- kortikostriatalen Kreislaufs angesehen werden, da er zielgerichtetes Verhalten fördert und emotionale Stimuli und Ereignisse bewertet (Winstanley et al., 2006). Cardinal et al. (2001) konnten zeigen, dass Beeinträchtigungen des Kerns des Nucleus accumbens impulsive Entscheidungen, die in einer Delay-Discounting- Aufgabe gemessen wurden, verstärkten. Winstanley et al. (2004) haben beobachtet, dass zu einer Übererregung führende Läsionen der basolateralen Amygdala eine Zunahme impulsiver Entscheidungen bewirkten. Da die basolaterale Amygdala in enger Beziehung zum Nucleus accumbens steht, weisen diese Ergebnisse von Winstanley et al. (2004) auf eine Interaktion der basolateralen Amygdala und des Nucleus accumbens in der Regulation der Impulsivität hin.

\subsubsection{Der präfrontale Kortex}

Der präfrontale Kortex ist ein Teil des Frontallappens. Zum präfrontalen Kortex gehören all diejenigen neokortikalen Anteile, die rostral der prämotorischen Rinde bis vorne zum Frontallappen lokalisiert sind. Den präfrontalen Kortex kann man in einen orbitofrontalen, medialen und lateralen Anteil unterteilen. Der laterale präfrontale Kortex wird in dorsolaterale und ventrolaterale Bereiche gegliedert (Trepel, 2004).

Afferenzen erhält der präfrontale Kortex aus fast allen anderen Arealen der Großhirnrinde, insbesondere aus den medialen Kernen des Thalamus und aus dopaminergen 
Hirnstammzentren der Formatio reticularis. Efferenzen ziehen vom präfrontalen Kortex, analog zu den Afferenzen, zu zahlreichen Kortexarealen und dem Thalamus.

Funktionell spielt der präfrontale Kortex eine bedeutende Rolle für das Kurzzeitgedächtnis, sowie für soziale, psychische und geistige Leistungen des Menschen. Dazu zählen beispielsweise die Achtung von Werten und Normen, die Handlungsmotivation, aber auch höhere kognitive Leistungen wie Rechnen und planerisches Denken (Trepel, 2004).

Neuere neuropsychologische Studien bringen den präfrontalen Kortex mit der Vorbereitung einer Handlung (Brass \& von Cramon, 2002), dem Wechseln zwischen Antwortalternativen (Dove et al., 2000) und der Inhibition einer unangemessenen Antwort in Strategieaufgaben (Dove et al., 2000) in Verbindung.

Der orbitofrontale Kortex erhält seine Informationen hauptsächlich aus anderen kortikalen Arealen und dem subkortikalen limbischen System. Seine Aufgaben sind die Emotionskontrolle, Impulskontrolle und soziale Anpassung (Wrase et al., 2007). Er beeinflusst die Beurteilung des emotionalen und motivationsbezogenen Wertes von Umweltinformationen unter Einbeziehung von Vorwissen und Erwartungen (Aouizerate et al., 2007). Weiterhin ist er für die Bewertung von Stimuli zuständig und spielt eine wichtige Rolle bei der Entscheidungsfindung (Aouizerate et al., 2007). Für die operante Konditionierung übernimmt der orbitofrontale Kortex die Funktion, Verhalten in Hinblick auf Konsequenzen wie Belohnung oder Bestrafung zu regulieren (Wrase et al., 2007). Mithilfe eines DelayDiscounting- Paradigmas konnte gezeigt werden, dass sich Ratten mit Läsionen des orbitofrontalen Kortex weniger impulsiv verhielten und eine größere, aber verzögerte Belohnung einer unmittelbaren Belohnung vorzogen (Winstanley et al., 2004).

Der mediale präfrontale Kortex ist für die kognitive Bewertung komplexer und ambivalenter affektiver Stimuli zuständig (Simmons et al., 2006). Vor allem der ventromediale präfrontale Kortex ist in die Entscheidungsfindung in riskanten Situationen involviert (Clark et al., 2008). Ventromediale Anteile des präfrontalen Kortex haben außerdem zusammen mit dem orbitofrontalen Kortex die Funktion, den emotionalen und motivationalen Wert von Umwelteinflüssen zu beurteilen (Aouizerate et al., 2007) und an Belohnungen gebundene Informationen affektiv zu bewerten (Simmons et al., 2006). Silbersweig et al. (2007) konnten eine Beteiligung des ventromedialen präfrontalen Kortex in der motorischen Inhibition nachweisen. Patienten mit Läsionen des ventromedialen frontalen Kortex, einschließlich des orbitofrontalen Kortex, zeigten eine maladaptive Entscheidungsfindung und abweichendes soziales Verhalten, das oft als impulsiv bezeichnet wird (Winstanley et al., 2006). 
Der laterale präfrontale Kortex ist an impulsunabhängigen kognitiven Prozessen beteiligt (Sommer et al., 2007). Er ist für die kontextabhängige Kodierung von Stimuli, die Wiedergabe kontextueller Informationen und die Verknüpfung kognitiver und motivationsbezogener Kontexte als Grundlage für angepasstes zielgerichtetes Verhalten zuständig (Watanabe M \& Sakagarni, 2007). Außerdem hat der laterale präfrontale Kortex eine Bedeutung für die Verhaltenskontrolle und Reaktionsinhibition (Sommer et al., 2007).

Neurowissenschaftliche Studien belegen die Annahme, dass die Verhaltenstendenz des Menschen, zwischen einer unmittelbaren Belohnung und einem langfristigen Ziel abzuwägen, durch zwei unterschiedliche neuronale Systeme vermittelt wird.

Es konnte gezeigt werden, dass zum einen Regionen des mesolimbischen dopaminergen Systems, darunter insbesondere der Nucleus accumbens (Nacc) und ventrale tegmentale Areale (VTA), eine zunehmende Aktivierung auf Belohnungsprädiktoren zeigten (Schultz, 2000; Knutson et al., 2001a). Studienergebnissen zu Folge stehen der Nacc und VTA auch in einem Zusammenhang zu subjektiven Präferenzen (O’Doherty et al., 2006) und der Chance auf eine unmittelbare Belohnung (McClure et al., 2004; Kable \& Glimcher, 2007). Diese Hirnregionen wurden ebenfalls bei Entscheidungen aktiviert, die entweder eine direkte oder hohe Belohnung favorisierten (McClure et al., 2004; Yacubian et al., 2007; Diekhof \& Gruber, 2010).

Neurophysiologisch zeigten sich als Belohnungsprädiktoren der Impulsivität eine ansteigende neuronale Antwort im Nucleus accumbens und im ventromedialen präfrontalen Kortex (VMPFC) (Hariri et al., 2006; Hahn et al., 2009). Diese Aktivierungen wurden bei nichtklinischen impulsiven Probanden begleitet von Veränderungen in dopaminergen, opioiden und serotonergen Transmissionen in diesen Strukturen (Cools et al., 2005; Oswald et al., 2007; Zald et al., 2008; Lee et al., 2009; Love et al., 2009; Gjedde et al., 2010). Umgekehrt ist die Kompetenz, Verhalten von einer streng wunschorientierten, suboptimalen Belohnungsoption zu entkoppeln, welches das wesentliche Kennzeichen selbstkontrollierten Verhaltens ist, abhängig von der präfrontalen Kontrolle der belohnungsabhängigen neuronalen Aktivierung. Selbstkontrollierte Entscheidungen, die eine übergeordnete Zielsetzung favorisieren und eine unmittelbare Belohnung notwendigerweise ablehnen, werden durch den anteroventralen präfrontalen Kortex vermittelt (avPFC). Dieser reduziert die belohnungsabhängige Aktivierung im Nucleus accumbens (Diekhof \& Gruber, 2010). Auf ähnliche Weise führt die Ablehnung eines beliebten, aber ungesunden Nahrungsmittels zu einer Downregulation der Aktivierung im VMPFC (Hare et al., 2009). 
Weitere Studien beschreiben zum anderen eine Assoziation zum präfrontalen Kortex (PFC). Ihre Ergebnisse zeigen, dass Belohnungssignale im Nacc und der VTA unter der inhibitorischen Kontrolle präfrontaler kortikaler Areale stehen könnten (Duvauchelle et al., 1992; Jackson et al., 2001; Del Arco and Mora, 2008). Der präfrontale Kortex wurde wiederholt mit kognitiver Kontrolle und der Fähigkeit in Verbindung gebracht, zielrelevante Informationen über eine zeitliche Verzögerung hinaus aufrecht zu erhalten, zu verarbeiten und zu integrieren (Owen, 1997; Duncan \& Owen, 2000; Miller EK \& Cohen, 2001).

Es gibt auch überzeugende Daten aus Tierexperimenten, die zeigen, dass präfrontale Aktivierungen die dopaminerge Ausschüttung und die neuronale Aktivität in den mesolimbischen Leitungsbahnen modulieren. Diese wiederum können eine Reduktion der Sensitivität afferenter Aktivierungen durch Belohnungsprädiktoren beeinflussen (Grace, 1991; Carr and Sesack, 2000; Jackson et al., 2001; Grace et al, 2007; Dalley et al., 2008; Del Arco and Mora, 2008; Goto and Grace, 2008). Aus Experimenten an Ratten weiß man, dass der PFC den Output des Nucleus accumbens zum ventralen Pallidum (Grace et al., 2007) entweder durch direkte Projektionen zum Nacc (Sesack and Pickel, 1992) oder indirekt durch GABA- Interneurone in der VTA, die wiederum mesoakkumbiale dopaminerge Neurone beeinflussen (Carr and Sesack, 2000; Del Arco and Mora, 2008), moduliert. Die Ergebnisse von Diekhof und Gruber (2010) liefern eine erste Evidenz dafür, dass beim Menschen ein ähnlicher Mechanismus vorliegen könnte.

fMRT- Daten aus Humanstudien belegen eine zunehmende Aktivierung im avPFC, wenn Menschen eine alternative Belohnungsoption auf Kosten der gerade genutzten Belohnungsoption wählten (Daw et al., 2006).

Insgesamt ist jedoch noch wenig über die funktionellen Mechanismen bekannt, die es den Menschen erlauben, auf eine kurzfristige Belohnung zum Erreichen eines langfristigen Ziels zu verzichten. Man weiß aber, dass der PFC sowohl zum Nacc als auch zu VTA projiziert (Ongür \& Price, 2000; Ferry et al., 2000; Frankle et al., 2006; Haber et al., 2006) und durch kortikostriatale Verschaltungen zielgerichtetes Verhalten fördert (Tzschentke \& Schmidt, 2000; Del Arco \& Mora, 2008; Diekhof \& Gruber, 2010). 
1.6 Neurochemische Grundlage der Impulsivität und der Selbstkontrolle: Das Dopaminsystem

Bezüglich des Verständnisses der Biologie der Impulsivität hat es signifikante Fortschritte in der Forschung gegeben. Es gibt eine Evidenz dafür, dass das dopaminerge Neurotransmittersystem eine Rolle für die Impulsivität spielt. In der vorliegenden Studie soll daher der Hauptfokus auf das Dopamin gelegt werden, da es als neuronales Substrat die Verhaltensinhibition moduliert und die gleichen Hirnstrukturen beinhaltet, die in den fMRTStudien mit der Impulsivität in Verbindung gebracht werden.

Dopamin ist ein biogenes Amin aus der Gruppe der Katecholamine. Es ist nicht nur eine Vorstufe von Noradrenalin, sondern auch seit seinem Nachweis 1957 von Arvid Carlsson selbst als Transmitter des Nervensystems anerkannt.

Dopamin ist ein Zwischenprodukt in der Synthese des Adrenalins. Ausgangsstoff für die Biosynthese ist die Aminosäure Tyrosin. Die Wirkung von Dopamin nach seiner Ausschüttung hängt vom Rezeptortyp an der postsynaptischen Membran ab. Man unterscheidet fünf Dopaminrezeptoren (D1- D5). Am Abbau von Dopamin sind im Wesentlichen 2 Enzyme beteiligt: die Monoaminooxidase und die Catechol- OMethyltransferase. Dopamin wird $\mathrm{zu}$ den Hauptendprodukten 3,4Dihydroxyphenylessigsäure, Methoxytyramin und Homovanillinsäure metabolisiert (Aktories et al., 2009).

Dopaminerge Neurone sind hauptsächlich im Mesenzephalon und Dienzephalon lokalisiert. Es gibt drei wichtige dopaminerge Bahnen, die nachfolgend kurz erklärt werden sollen: Das nigro- striatale Dopaminsystem hat seinen Ursprung in der Pars compacta der Substantia nigra und innerviert das Neostriatum durch Hemmung cholinerger Interneurone. Das Corpus striatum setzt sich aus dem Nucleus caudatus und dem Putamen zusammen. Eine Degeneration von Neuronen im nigro- striatalen System führt zur Parkinson- Krankheit.

Eine zweite Bahn entspringt hauptsächlich in der Area tegmentalis ventralis. Die Zellkörper dieses mesolimbischen Systems liegen im Mittelhirn und haben Projektionen zu Strukturen des limbischen Systems. Dazu zählen der Hippokampus, der Nucleus accumbens, das Tuberculum olfactorium, die Amygdala und der präfrontale, cinguläre und entorhinale Kortex. Die Nervenzellkörper des mesolimbischen Systems werden bei Emotionen wie Lust oder Freude vermehrt aktiviert. Man nennt diese Bahn daher auch das mesolimbische dopaminerge „Belohnungssystem“. Aber auch Stoffe wie Ethanol, Nikotin und Amphetamine, die eine Abhängigkeit erzeugen können, führen $\mathrm{zu}$ einer vermehrten Freisetzung von 
Dopamin im limbischen System. Die dritte dopaminerge Bahn im Zentralnervensystem projiziert vom Nucleus infundibularis zur Eminentia mediana. Freigesetztes Dopamin aus diesem tubero- infundibulären System gelangt zur Hypophyse und steuert die Prolaktinsekretion (Aktories et al., 2009).

In wissenschaftlichen Studien konnte eine signifikante Rolle von Dopamin in einer Vielzahl von neuronalen Prozessen bestätigt werden. Nach derzeitigem Wissen hat Dopamin unter anderem eine Bedeutung für die so genannten exekutiven Funktionen, sowie die Motivation. Diese vorwiegend kognitiven Funktionen werden durch das mesokortikale System vermittelt, das vom ventralen Tegmentum im Mesenzephalon zum Frontallappen des Kortex verläuft. Daher unterliegen Verhaltensweisen, bei denen subkortikale und präfrontale Strukturen mitwirken, dem Einfluss von Dopamin. Es gibt eine umfangreiche Evidenz darüber, dass Dopamin bei seinen im Gehirn unterschiedlich lokalisierten Prozessen einer kognitiven Stabilität und Flexibilität unterliegt. Nach Bilder et al. (2004) gibt es eine komplexe Beziehung zwischen verwandten Proteinen des Dopaminsystems (z.B. Dopaminrezeptoren, Transporter, Enzyme, die für den Abbau zuständig sind) und der Stabilität und Flexibilität der neuronalen Netzwerkaktivität in subkortikalen (striatalen) und präfrontalen Hirnregionen. Die Rolle von Dopamin in der Stabilität und Flexibilität neuronaler Netzwerke ist bekannt als tonisch- phasische Dopaminhypothese, die möglicherweise den Einfluss von Dopaminverwandten genetischen Polymorphismen im Striatum und präfrontalen Kortex auf die Inhibitionskontrolle erklärt (Bilder et al., 2004; Cools, 2006). Somit beeinflusst Dopamin wahrscheinlich viele neuronale und kognitive Prozesse, eine davon ist die Inhibitionskontrolle. Durch Projektionen Dopamin- produzierender Zellen in den präfrontalen Kortex unterstützen Dopamin und GABA die Exzitation präfrontaler neuronaler Netzwerke (Trantham- Davidson et al., 2004). Dopamin ist entscheidend bei der Modulation von Funktionen im präfrontalen Kortex beteiligt, da der substantielle Abbau von Dopamin, nebst der Norepinephrine, signifikant Funktionen im präfrontalen Kortex beeinflusst (Arnsten, 1997). Besonders monoaminerge Neurotransmitter, wie das Dopamin, sind dafür bekannt, spontane neuronale Hintergrundaktivitäten zu unterdrücken, um die Signal- Rausch- Antwort im Gehirn zu verbessern (Bilder et al., 2004; Congdon et Canli, 2005).

Die Bedeutung von Dopamin auf impulsives Verhalten geht auf die Entdeckung psychostimulatorischer Arzneimittel zurück, die das dopaminerge System beeinflussen und effektiv auf Krankheitssymptome z.B. von ADHS wirken (Volkow et al., 2005). Zusätzliche Evidenz für die Rolle von Dopamin auf die Impulsivität kommt von pharmakologischen 
Humanstudien und von pharmakologischen Metabolit-, Läsions-, und Knock- out- Studien an Tieren. Die Gabe von D- Amphetaminen, die als Agonisten die Dopaminausschüttung steigern, reduzierten die impulsiven Wahlmöglichkeiten in Verhaltensinhibitionsaufgaben beim Menschen und in Delay-Discounting- Paradigmen bei Tieren. In einer seriellen, aus fünf Wahlmöglichkeiten bestehenden Reaktionszeitaufgabe bei Tieren jedoch steigerte die Gabe von D- Amphetaminen das impulsive Antwortverhalten. Der Grund, warum Amphetamine die Messung dieser motorischen Impulsivität verbesserten, jedoch die Antwort, die mithilfe der Stopp- Aufgabe gemessen wurde, verschlechterten, ist unklar. Es gibt Hinweise dafür, dass verschiedene Formen impulsiver Handlungen eine verschiedene neuronale Basis haben (Winstanley et al., 2006; Congdon et Canli, 2005).

Zusammenfassend lässt sich sagen, dass viele Variablen Einfluss darauf haben, wie Dopamin auf impulsives Verhalten wirkt. Von besonderer Bedeutung scheinen aber die untersuchten Hirnregionen (frontaler Kortex vs. subkortikale Regionen), das relative Dopaminlevel, die verwendete Messmethode, und/ oder der untersuchte Impulsivitätstyp, die Dosis von DAmphetamin und das Ausgangslevel der Impulsivität zu sein. Im Wesentlichen ist zu sagen, dass es eine Evidenz für eine signifikante Rolle von Dopamin in präfrontal- vermitteltem Verhalten gibt. Aber sowohl die tonische, als auch die phasische Funktion von Dopamin auf das Zentralnervensystem sind komplex (Bilder et al., 2004; Congdon et Canli, 2005).

\section{$\underline{1.7 \quad \text { Ziele dieser Studie }}$}

Ziel der vorliegenden Studie ist es, den Zusammenhang zwischen der Impulsivität als Persönlichkeitseigenschaft und den neuronalen Mechanismen der Fähigkeit der Selbstkontrolle weiter zu erklären. Dafür habe ich gezielt untersucht, welche neuronalen Prozesse es nicht- klinischen, hoch- impulsiven Personen (HI- Probanden) ermöglichen, ihr Verhalten erfolgreich von wunschorientierten Belohnungsoptionen zu entkoppeln, um ein höherwertiges, langfristiges Ziel zu erreichen. Niedrig- und hoch- impulsive Probandengruppen, die mittels der Barratt- Impulsivitätsskala gescreent wurden (BIS- 11; Patton et al., 1995), werden hinsichtlich ihrer Verhaltensleistungen und ihrer Hirnaktivierungen in Situationen miteinander verglichen, in denen sie auf einen unmittelbaren Bonus verzichten müssen, um ein übergeordnetes Ziel zu erreichen (Desire- ReasonDilemma; Diekhof \& Gruber, 2010). 
Die erste Hypothese dieser Studie lautet, dass eine unmittelbar zur Verfügung stehende Belohnung in der Gruppe der hoch- impulsiven Probanden zu einer Interferenz zwischen dem Wunsch nach einer sofortigen Belohnung und der Verfolgung eines langfristigen Ziels führen sollte. Ich erwarte, dass hoch- impulsive Personen, die in der Lage sind, dieses persönlichkeitsspezifische Defizit zu kompensieren und selbstkontrolliert zu handeln, den anteroventralen präfrontalen Kortex stärker aktivieren als niedrig- impulsive Probanden und so die belohnungsabhängige mesolimbische Aktivierung während der Ablehnung einer unmittelbaren Belohnung herunterregulieren (Diekhof \& Gruber, 2010).

Meine zweite Hypothese besagt, dass die zunehmende Wertigkeit einer unmittelbaren Belohnung es den hoch- impulsiven Probanden zunehmend erschweren sollte, selbstkontrolliert zu handeln. HI- Probanden mit einer normalen Verhaltensleistung sollten demnach kompensatorische Hirnmechanismen rekrutieren, um eine suboptimale unmittelbare Belohnung abzuwerten und das Desire- Reason-Dilemma erfolgreich zu lösen.

\section{$\underline{2}$ Material und Methoden}

\section{$\underline{2.1 \quad \text { Die Funktionelle Magnetresonanztomographie (fMRT) }}$}

Im Folgenden werden einzelne Aspekte der funktionellen Magnetresonanztomographie dargestellt, da diese Technik in dieser Studie verwendet wurde.

\subsubsection{Physikalische Grundlagen}

Die Magnetresonanztomographie ist ein bildgebendes Diagnostikverfahren, das auf der Grundlage eines starken Magnetfeldes und hochfrequenter Radiowellen beruht. Die Bildgebung basiert dabei auf den magnetischen Eigenschaften von Wasserstoffatomen.

Wasserstoffatome besitzen als Kern ein Proton und in der Hülle ein Elektron, das um das Proton kreist. Basis der MR-Technik ist der Spin MR-aktiver Kerne. Diese Eigenschaft besitzen Atomkerne mit einer ungeraden Zahl von Protonen. Unter „Kernspin“ versteht man die Eigenrotation von Atomkernen mit einer bestimmten Frequenz um ihre Längsachse. Durch diese Eigenrotation der elektrischen Ladung wird ein geringes Magnetfeld erzeugt, d.h. der Atomkern ist mit einem magnetischen Dipol vergleichbar. 
Ohne äußeres Magnetfeld sind die Kernspins zufällig im Raum orientiert. Werden diese einem elektrischen Magnetfeld ausgesetzt, richten sich die Ladungen, die diffus im menschlichen Körper angeordnet sind, ähnlich einer Kompassnadel aus. Die Ausrichtung der Kerne ist parallel zum äußeren Magnetfeld, kann aber auch zu einem geringen Teil antiparallel erfolgen. Es entsteht eine Summenmagnetisierung, die so genannte Längsmagnetisierung parallel zum äußeren Magnetfeld. Durch die kurzen elektromagnetischen Wellen (Hochfrequenzimpulse) von außen werden die Protonen auf ein höheres Energieniveau gehoben und gleichzeitig in ihrer Kreiselbewegung synchronisiert. Im Extremfall ist die Kreiselbewegung nun quer zum Magnetfeld. Folge ist die so genannte Quermagnetisierung. Sie ist die Ursache für das MR- Signal. Nach Abschalten des Hochfrequenzimpulses gehen die Protonen in ihren Ursprungszustand zurück, d.h. die Quermagnetisierung nimmt langsam ab, die Längsmagnetisierung nimmt wieder zu. Die Protonen geraten wieder ,außer Phase“. Dadurch nimmt das MR- Signal ab. Bei dieser longitudinalen Relaxation wird Energie frei, die gemessen werden kann. Die Energie ist abhängig von der Stärke des Magnetfelds und der Gewebeart. Da die Energie an die Umgebung, das Gitter, abgegeben wird, wird die longitudinale Relaxation auch Spin- GitterRelaxation genannt (Weishaupt et al., 2006). Die Zeit nach Abschalten des Hochfrequenzimpulses bis zum Aufbau der Längsmagnetisierung, also bis die Protonen in ihren Ursprungszustand zurückkehren, nennt man T1- Relaxationszeit. Sie kann zwischen einer halben und mehreren Sekunden betragen.

Neben der longitudinalen Relaxation läuft auch eine transversale Relaxation ab. Die synchron ausgelenkten Protonen verlieren ihre einheitliche Rotation. Durch Wechselwirkung der Teilchen geht die transversale Magnetisierung schließlich verloren. Da jeder Spin selbst ein kleines Magnetfeld erzeugt, das dem äußeren Magnetfeld überlagert ist, entstehen kleine lokale Magnetfeldinhomogenitäten. Unter der transversalen Relaxation ist also der Verlust der transversalen Magnetisierung durch „Außer-Phase- Geraten“ (Dephasierung) der Spins zu verstehen. Es ist dabei wichtig, dass keine Energie an die Umgebung abgegeben wird. Die Spins tauschen vielmehr untereinander Energie aus (Weishaupt et al., 2006). Durch die gegenseitige Beeinflussung der Spins wird die transversale Relaxation auch Spin- SpinRelaxation genannt. Sie ist unabhängig von der Stärke des äußeren Magnetfeldes, jedoch abhängig vom Gewebetyp. Die Dauer der Dephasierung wird ausgedrückt durch die T2-

\section{Relaxationszeit}

In Abhängigkeit von der gemessenen Relaxationszeit stellt das MRT die aktivierten Hirnareale als Bildkontrast dar. 
Gewebe unterscheiden sich in ihren T1- und T2- Werten. Die Qualität eines MRT- Bildes hängt unter anderem von den T1- und T2- Werten und der Protonendichte des untersuchten Gewebes ab.

Während einer Messung werden mehrere Hochfrequenzimpulse ausgestrahlt. Da der Hochfrequenzimpuls in Bruchteilen von Sekunden an- und abgeschaltet wird, empfängt man eine Vielzahl von Signalen. Die Signale werden durch hochempfindliche Antennen gewonnen, in einem komplizierten Auslese- und Messverfahren umgesetzt und in ein Bild umgewandelt.

Für die genaue räumliche Lokalisation der aus dem Körper empfangenen Hochfrequenzimpulse muss eine Ortskodierung stattfinden. Dazu werden Gradientenspulen benötigt, mit deren Hilfe sich kleine Magnetfeldgradienten in allen drei Raumrichtungen zum äußeren Magnetfeld dazuschalten lassen. Durch Überlagerung mit dem Hauptmagnetfeld lässt sich so mit einer bestimmten Frequenz genau eine entsprechende Schicht anregen. Der Rest des Körpers wird nicht beeinflusst. Vorübergehend sind die Protonen in den verschiedenen Schichten somit unterschiedlich starken Magnetfeldern ausgesetzt und weisen dadurch unterschiedliche Frequenzen auf (Weishaupt et al., 2006). Differenzen in der Frequenz, aber auch in der Phase der Nuklei erlauben es, die relative Position der Moleküle entlang der kleinen Magnetfeldgradienten zu messen (Weishaupt et al., 2006).

\subsubsection{Grundlagen des BOLD- Effekts (Blood Oxygenation Level Dependency)}

Das Ziel der funktionellen Kernspintomographie ist es, einen Kontrast zwischen aktiven und inaktiven Hirnregionen zu erzeugen. Die Eigenschaften des BOLD-Effekts sind eine wichtige Voraussetzung dafür. Dabei macht man sich die unterschiedlichen Eigenschaften des Hämoglobins zunutze. Man unterscheidet zwei Arten von Hämoglobin: oxygeniertes und deoxygeniertes Hämoglobin. Oxygeniertes ist diamagnetisch, deoxygeniertes paramagnetisch. Die Grundlage des $B O L D$ - Kontrasts ist also die magnetische Eigenschaft des Hämoglobins im Blut. Verantwortlich dafür ist das an das Hämoglobin gebundene Eisen. Eisen wird für den Sauerstofftransport oxygeniert. Es entsteht Oxyhämoglobin, in dem die magnetischen Eigenschaften des Eisens weitgehend ohne Wirkung bleiben. Nach Sauerstoffabgabe hingegen hat das Eisen im Deoxyhämoglobin seine volle magnetische Wirkung, daher ist es paramagnetisch, d.h. leichter magnetisierbar.

Deoxyhämoglobin induziert in seinem Umfeld Inhomogenitäten im Magnetfeld und in der Umgebung von Gefäßen Magnetfeldgradienten. Paramagnetische Moleküle führen auf diese 
Weise zu einer Veränderung der Suszeptibilität zwischen Blutgefäßen und dem umgebenden Gewebe.

Je größer also der paramagnetische Anteil im aktivierten Hirnareal, desto inhomogener ist das regionale Magnetfeld und desto stärker interferiert das Magnetfeld des deoxygenierten Hämoglobins mit dem des MR- Scanners und die Spin- Spin- Relaxation wird verändert (Thulborn et al., 1982). Die T2- Relaxation wird demzufolge kürzer als bei einem Hirnareal mit einer niedrigen Konzentration an deoxygeniertem Hämoglobin. Das fMRT- Signal ist daher bei deoxygeniertem Hämoglobin abgeschwächt und bei oxygeniertem Hämoglobin stärker. Deoxyhämoglobin wirkt quasi „als körpereigenes Kontrastmittel“. Blut besitzt also aufgrund seines Anteils von Deoxyhämoglobin zu Oxyhämoglobin intrinsische Kontrasteigenschaften.

Zur Darstellung neuronaler Aktivierungen macht man sich die neurovaskuläre Kopplung zunutze. Damit ist gemeint, dass sich der regionale zerebrale Blutfluss den metabolischen Anforderungen der neuronalen Aktivität anpasst. Bei der Stimulation von Kortexarealen kommt es zur Erhöhung der Nervenzellaktivität und damit verbunden zur Energieproduktion. Dies führt zu einem gesteigerten Metabolismus und damit zu einem erhöhten Sauerstoffbedarf und -verbrauch. Durch die erhöhte Sauerstoffausschöpfung des Blutes kommt es zu einem Anstieg des Deoxyhämoglobins. Die absolute Menge des Deoxyhämoglobins steigt also im Vergleich zum Ruhezustand an. In der Theorie müsste das fMRT- Signal abgeschwächt sein. Beim Vergleich der fMRT- Bilder aus Ruhephase und stimuliertem Zustand sieht man aber einen Anstieg des fMRT- Signals. Die Erklärung dafür ist in der Physiologie des Zentralnervensystems bei Aktivität begründet. Durch den Anstieg der Nervenzellaktivität steigen der zerebrale Blutfluss und das zerebrale Blutvolumen überproportional an. Die Folge ist eine Abnahme der Deoxyhämoglobinkonzentration, obwohl die absolute Menge ansteigt. Es kommt nämlich durch lokal chemische Reaktionen zu einer Gefäßerweiterung in der durch das Gefäß versorgten Region. Durch diese Überkompensation wird die Interferenz mit dem Magnetfeld geringer. Dies bedeutet eine langsamere Dephasierung der Protonenspins in der angeregten Schicht und bewirkt damit einen Signalanstieg. Dementsprechend führt neuronale Aktivität mittels der oben beschriebenen Änderung des zerebralen Blutflusses über eine Abnahme der Konzentration an deoxygeniertem Hämoglobin zu einer Zunahme des BOLDSignals (Kwong et al., 1992; Ogawa et al., 1992).

Die dynamischen Veränderungen der Signalintensität in T2- gewichteten Bildern lassen sich im Zeitverlauf als Kurve darstellen (siehe Abb. 2). 


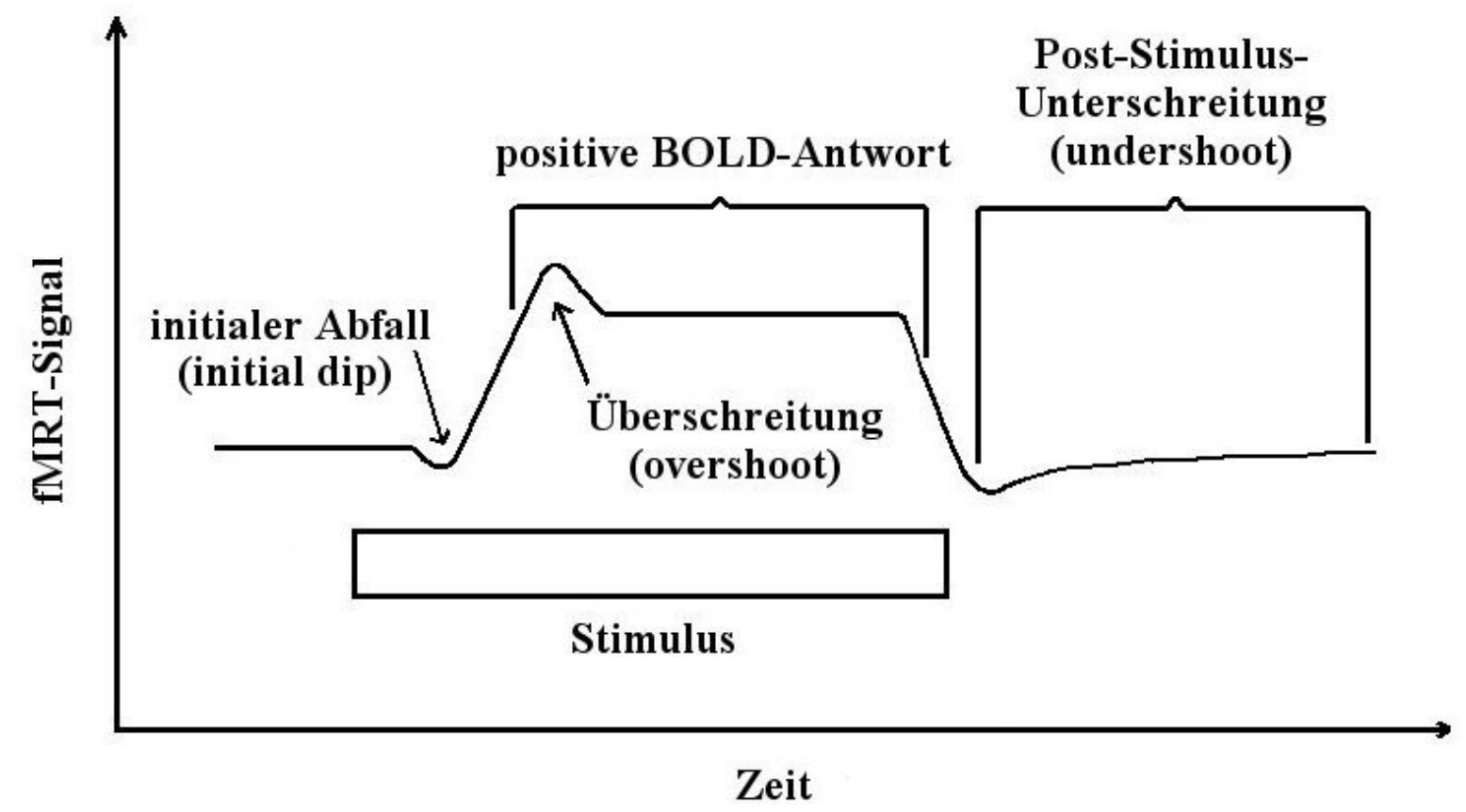

\begin{abstract}
Abbildung 2: Zeitlicher Verlauf des BOLD- Signals: Das hämodynamische Signal beginnt mit einem initialen Abfall (initial dip). Zu Beginn der neuronalen Antwort kommt es zu einem geringen Abfall des MRT- Signals. Mit dem Beginn der positiven Antwort steigt das Signal auf ein Maximalniveau (overshoot). Danach sinkt es auf ein konstantes Niveau ab. Am Ende der Stimulation sinkt das Signal unter sein Ursprungsniveau (undershoot) und kehrt anschließend auf dieses zurück.
\end{abstract}

Quelle: Goebel und Kriegeskorte 2005, S.27

Man weiß, dass die $B O L D$ - Antwort nicht unmittelbar mit der Stimuluspräsentation ansteigt. Aufgrund der Trägheit der Hämodynamik ist das Maximum der BOLD-Antwort erst 5-6 Sekunden nach Stimulusbeginn zu erwarten und folgt einem charakteristischen Verlauf:

Die hämodynamische Antwort beginnt mit einem initialen Abfall (initial dip). Der geringfügige Abfall des MRT- Signals zu Beginn der neuronalen Aktivität ist bedingt durch die lokale Sauerstoffabnahme. Durch Zunahme der Gefäßdurchblutung kommt es 2-5 Sekunden nach der Stimulation zu einem Signalanstieg (overshoot), der in der Phase der Progression beschrieben wird. Der Blutfluss steigt um 50-70 \% in Bezug auf seinen Ausgangswert an. Begleitend kommt es auch zu einem Anstieg des Verhältnisses von Oxyhämoglobin zu Deoxyhämoglobin. In der letzten Phase, der Relaxation, kehrt das Signal nach Beendigung des Stimulus auf sein Ausgangsniveau zurück. Dabei unterschreitet der Signalabfall in der Regel für mehrere Sekunden seinen Ausgangswert (undershoot). 
Der $B O L D$ - Kontrast bildet die Änderung der Sauerstoffsättigung im Blut ab. Auf diese Weise lassen sich aktivitätsbedingte Signalveränderungen in der grauen Substanz des Gehirns identifizieren.

\section{$\underline{2.2}$ Stichprobenerhebung und-zusammensetzung}

Die Studie wurde an einer nicht- klinischen Stichprobe durchgeführt. Als Probanden kamen freiwillige und gesunde Personen aller Altersgruppen in Betracht. Die Probandenrekrutierung erfolgte durch verschiedene Vorgehensweisen: Ein Teil der Stichprobe wurde aus einer bereits bestehenden Probandendatei rekrutiert, die aus vorherigen Studienprobanden der Abteilung Psychiatrie und Psychotherapie der Universität Göttingen angelegt worden war. Ein weiterer Teil wurde durch Aushänge an der Universität und durch ein Rundschreiben über die Semesterverteiler der medizinischen Fakultät gewonnen. Auf den Aushängen wurde für eine Untersuchung zur Entscheidungsfindung geworben. Erste Informationen über den Ablauf der Studie, den Zeitrahmen und die Anforderungen an die Probanden wurden dort beschrieben.

Unbedingte Voraussetzung für die Teilnahme an der Studie war das Ausfüllen der deutschsprachigen Version der BIS-11. Anhand der Werte der einzelnen Personen in der BIS11 wurden die beiden Gruppen innerhalb der Studie gebildet. Personen, deren Werte über dem Mittelwert lagen, wurden als impulsiv bezeichnet (Mittelwert 71,0; Standardabweichung 4,4; p- Wert $<0,0001$ ). Personen, deren Werte darunter lagen als kontrolliert (Mittelwert 52,8; Standardabweichung 3,2; p-Wert <0,0001). In dieser Arbeit habe ich mich dafür entschieden, vor allem die Probanden in die Studie einzuschließen, deren Werte extrem über und unter dem Mittelwert lagen. Die Probanden wurden für diese Studie somit streng nach ihrer Impulsivität eingestuft. Dieses Vorgehen sollte die Wahrscheinlichkeit erhöhen, dass die Probanden auch tatsächlich die entsprechende gesuchte Eigenschaft aufwiesen.

Der Zeitraum der Rekrutierung erstreckte sich von Januar bis April 2008. Für die vorliegende Studie wurden insgesamt 67 Personen rekrutiert. 24 rechtshändige Personen erwiesen sich im Vorfeld als geeignet für die Studienteilnahme und wurden mittels fMRT untersucht. Nach Anwendung der Ausschlusskriterien wurden für diese Studie aber nur die Daten von 19 Studienteilnehmern ausgewertet (siehe Ausschlusskriterien). 10 Probanden wurden als hochimpulsiv (HI- Probanden) eingestuft, 9 Probanden als extrem- kontrolliert (LO- Probanden) (Mittelwerte der BIS-11 beider Extremgruppen sind in Tabelle 1 dargestellt). Unter den 19 Probanden waren 10 weibliche und 9 männliche Studienteilnehmer. Es wurde eine etwa gleiche Anzahl an weiblichen und männlichen Probanden gewählt, um geschlechtsspezifische 
Effekte auf die neuronale Antwort zu vermeiden. Sowohl in der impulsiven als auch in der kontrollierten Gruppe waren 5 Frauen. Lediglich die Anzahl der Männer variierte. Die impulsive Gruppe enthielt 5 männliche Probanden, die kontrollierte Gruppe nur 4. Die Gruppen waren hinsichtlich Alter, Ausbildung und Geschlecht gematcht, die Altersspanne lag zwischen 21 - 28 Jahren. Ein statistischer Vergleich in Bezug auf Alter und Geschlecht zeigte keine signifikanten Unterschiede. In Bezug auf den Grad der Impulsivität unterschieden sich die Probanden jedoch signifikant. Alle Probanden waren Studenten oder hatten ein Studium abgeschlossen. Sie hatten somit ein vergleichbares Bildungsniveau. Alle Studienteilnehmer waren zuvor mit dem Stimulusmaterial nicht vertraut.

Einschlusskriterien für die Studienteilnahme:

- Freiwillige gesunde Probanden

- Laufendes oder abgeschlossenes Studium

- $\quad$ Alter 21 - 28 Jahre.

Ausschlusskriterien für die Studienteilnahme:

- Psychiatrische, neurologische, kardiologische Vorerkrankungen

- Operationen an Kopf, Herz, Augen

- Metallteile im Körper (Implantate), Gefäßclips

- Einnahme bestimmter Medikamente, vor allem Psychopharmaka

- Intrauterinpessar

- Bestehende oder mögliche Schwangerschaft

- Schwere Allergien

- Klaustrophobie

- $\quad$ Zu starke Kopfbewegungen während der Messung im MRT

- Fehlerrate von mehr als $15 \%$ im gesamten Experiment.

Von der Studienteilnahme mussten insgesamt 5 der 24 Probanden ausgeschlossen werden. Darunter waren 3 kontrollierte und 2 impulsive Probanden. Eine kontrollierte Probandin musste faktisch von der Studie ausgeschlossen werden, da sie regelmäßig antidepressive Selektive- Serotonin- Wiederaufnahmehemmer einnahm. Bei 2 weiteren männlichen Probanden wurde die Konditionierung aufgrund von Computerproblemen nicht korrekt 
durchgeführt. Jeweils einer dieser Probanden gehörte der kontrollierter und der impulsiven Gruppe an. Bei dem vierten männlichen, kontrollierten Probanden kam es nicht zur Studienteilnahme, da der 10er Bonus während des Experiments nie angenommen wurde. Es ist davon auszugehen, dass der Proband diesen nicht als solchen erkannt hat. Die fünfte Studienteilnehmerin gehörte der impulsiven Gruppe an und wurde ausgeschlossen, um eine gematchte Gruppe zu erhalten.

\section{$\underline{2.3}$ Beschreibung des Experiments}

Die Studie wurde im Mai und Juni 2008 am Universitätsklinikum Göttingen durchgeführt.

Die Probanden wurden zu Beginn der Studie persönlich und anhand von Informationsmaterial (siehe Anhang) über die Zielsetzung und den Ablauf der Studie informiert. Durch das Unterschreiben der Einverständniserklärung wurde die Einwilligung zur Studienteilnahme abgegeben. Die Probanden wurden für ihre Teilnahme am Experiment bezahlt. Die Studienteilnehmer wurden darüber aufgeklärt, dass die Teilnahme an der Studie vollkommen freiwillig ist. Sie hatten die Möglichkeit, jeder Zeit ohne Angabe von Gründen das Experiment abzubrechen bzw. aus der Studie auszuscheiden, ohne dass sie Nachteile zu erwarten hatten oder dass es eine Auswirkung auf ihre Bezahlung hatte. Den Probanden wurde erklärt, dass ihre personenbezogenen Daten vertraulich nach den Richtlinien der Datenschutzbestimmungen gespeichert und ausgewertet werden. Für die wissenschaftliche Auswertung wurden die persönlichen Angaben anonymisiert, das heißt ohne Namen und Geburtsdatum ausgewertet.

Die Studie entspricht den Richtlinien der Ethikkommission der Georg- August- Universität Göttingen und wurde von dieser vor Studienbeginn genehmigt.

\subsubsection{Konditionierung}

Das Experiment begann mit einer operanten Konditionierungsphase außerhalb des Kernspins zum Erlernen von Reiz-Reaktionsmustern.

Die Probanden wurden in der Regel einen Tag vor der Messung im Scanner an einem handelsüblichen Computer konditioniert. Nach der Aufklärung und Einwilligung wurden die Probanden standardisiert mündlich und schriftlich instruiert (siehe Anhang). Im Anschluss daran absolvierten sie einen kurzen Probedurchgang, um sich mit der Aufgabe und dem 
Stimulusmaterial vertraut $\mathrm{zu}$ machen. Die Probanden hatten keine Schwierigkeiten, die Aufgabe zu verstehen.

In diesem ersten Teil des Experimentes wurden den Teilnehmern Quadrate in sechs verschiedenen Farben gezeigt. Jedes der 6 Quadrate wurde den Probanden in einer zufälligen Reihenfolge 30-mal präsentiert.

Sobald ein neues Quadrat auf dem Bildschirm erschien, waren die Probanden aufgefordert, nach eigenem Belieben, eine von zwei möglichen Antworttasten auf der Tastatur des Computers zu drücken und zu sehen, was die unmittelbare Folge ihrer freien Entscheidung war. Die beiden Antworttasten auf der Tastatur hatten dabei unterschiedliche Bedeutungen:

Drücken der linken Taste (Alt-Taste) bedeutete, dieses Quadrat annehmen (d.h. dass sich die Probanden für dieses Quadrat entschieden).

Drücken der rechten Taste (Alt Gr- Taste) bedeutete dagegen, dieses Quadrat ablehnen (d.h. dass die Probanden dieses Quadrat nicht annehmen möchten und sich dagegen entschieden).

Die Bedeutung der Antworttasten war insofern wichtig, da die Probanden direkt nach dem Tastendruck eine Rückmeldung (bzw. ein Feedback) erhielten, ob die Entscheidung für oder gegen ein bestimmtes Quadrat zu einem Gewinn von Punkten (Belohnung) geführt hat oder aber ob ihre Entscheidung von einem neutralen Ergebnis (0 Punkte), also weder zu einem Gewinn noch zu einem Verlust geführt hat.

Das Feedback wurde dabei immer durch eines der folgenden Symbole dargestellt:

$0 \quad=$ neutrales Ergebnis, kein Zugewinn oder Verlust von Punkten

$10=$ kleine Belohnung, die Probanden gewannen 10 Punkte

$25=$ mittlere Belohnung, die Probanden gewannen 25 Punkte

$40=$ große Belohnung, die Probanden gewannen 40 Punkte.

Die meisten Quadrate des Experimentes hatten ein neutrales Feedback zur Folge, das unabhängig von der Wahl der gedrückten Antworttaste war. Die Aufgabe der Probanden war es, bei dieser Aufgabe durch Ausprobieren herauszufinden, welche der sechs farbigen Quadrate eine direkte Belohnung zur Folge hatten und diese Quadrate dann im weiteren Verlauf des Experimentes anzunehmen (siehe auch Diekhof \& Gruber, 2010). 
Die Probanden wurden darum gebeten, während des Experimentes nicht mitzuzählen, wie oft sie ein Feedback einer bestimmten Sorte bekommen haben. Die Punkte, die die Probanden in diesem Teil des Experimentes erhalten hatten, wurden ihnen gutgeschrieben und später in einen Geldwert umgewandelt.

Das Ziel der operanten Konditionierung war es, bei den Probanden ein bestimmtes Antwortverhalten in Bezug auf die Bonusstimuli zu etablieren.

\subsubsection{Messung im MRT}

Vor dem Beginn des neuropsychologischen Experimentes im MRT haben die Probanden 2 allgemeine Fragebögen ausgefüllt, in denen nach der Einnahme von (regelmäßigen) Medikamenten und von stimulierenden Substanzen (z.B. Alkohol, Kaffee) vor der Testung gefragt wurde. Des Weiteren wurden die generellen Ausschlusskriterien für die Teilnahme an fMRT- Studien überprüft. Vor der Messung im Kernspintomographen wurden die Probanden mit dem MR-Gerät und den Räumlichkeiten vertraut gemacht, um während der Untersuchungen eventuell auftretende Einflüsse durch die unbekannte Umgebung zu reduzieren. Um unerwünschte Artefakte durch die Kopfbewegung der Probanden von vornherein $\mathrm{zu}$ minimieren, wurden die Probanden in einer speziell entwickelten Kopfhalterung gelagert. Das Experiment bestand aus 3 Teilen. Zwischen den Scans konnten die Probanden 2 kurze Pausen von jeweils ein paar Minuten machen, um sich zu erholen. Die Untersuchung wurde dann mit Zustimmung der Probanden fortgesetzt. Außerdem hatten die Studienteilnehmer die Möglichkeit über eine Notfallklingel und eine Gegensprechanlage jederzeit mit dem Untersuchungsteam Kontakt aufzunehmen. Keiner der Probanden beendete das Experiment vorzeitig.

In diesem zweiten Teil des Experimentes hatten die Probanden im MRT eine modifizierte Version der sequentiellen Forced-Choice-Aufgabe aus der Studie von Diekhof \& Gruber (2010) zu bearbeiten (siehe Anhang). Die Entscheidungsfindungsaufgabe bestand aus zwei Aufgabentypen, die entweder als Bonusrunde (Free- Choice- Aufgabe) oder als Zielverfolgung (Forced-Choice- Aufgabe) bezeichnet wurden. Das Stimulusmaterial der Aufgabentypen entsprach dem der Konditionierung.

Den Probanden wurden verschiedenfarbige Quadrate in einer Sequenz von entweder 4 oder 7 Quadraten präsentiert. Sie wurden aufgefordert, in einer Sequenz immer nur die beiden farbigen Quadrate mit der linken Taste anzunehmen, die ihnen vor jeder Sequenz durch einen Hinweisstimulus als zielrelevant ausgewiesen wurden, und dafür anders farbige Quadrate 
gegebenenfalls auch abzulehnen, wenn diese nicht Teil der Zielvorgabe waren. Das erfolgreiche Erreichen des langfristigen Ziels nach den Regeln des jeweiligen Aufgabentyps wurde dabei am Ende eines Blockes mit 50 Punkten belohnt. Je nach konkreter Aufgabenstellung hatten die Probanden in einigen Durchgängen jedoch die Möglichkeit, einen zusätzlichen Bonus über die direkt belohnten Farben zu bekommen. Die direkt belohnenden Farben hatten die Probanden in der Konditionierung durch Ausprobieren erlernt.

Die Struktur des Experimentes der vorliegenden Studie unterschied sich von der, die in der Studie von Diekhof \& Gruber (2010) verwendet wurde, um den Probanden die korrekte Durchführung des Experimentes nach den Regeln des jeweiligen Aufgabentyps zu ermöglichen und den HI- Studienteilnehmern die Ablehnung einer direkt belohnten Farbe zu erleichtern.

Die Regeln des jeweiligen Aufgabentyps galten für 10 aufeinander folgende Blöcke. Ein „Zehnerblock“ begann immer mit 5 kurzen Blöcken (siehe Abb. 3), gefolgt von 5 langen (nicht dargestellt). Die kurzen Blöcke bestanden aus jeweils 4 aufeinander folgenden Quadraten bis zum Erreichen des Ziels, lange Blöcke enthielten 7 aufeinander folgende Quadrate. Bonusrunde und Zielverfolgung wechseln sich während des Experimentes jeweils nach 10 Blöcken eines Aufgabentyps ab.

Der gegenwärtig geltende Aufgabentyp wurde den Probanden dabei immer zu Anfang eines solchen ,Zehnerblockes“ angezeigt.

Erschien der Hinweis „Bonusrunde“ vor einer Sequenz, galten folgende Verhaltensregeln für die Probanden:

- zielrelevante Farben immer annehmen

- nicht-zielrelevante Farben (fast) immer ablehnen (s.u.)

- nicht-zielrelevante Farben mit einer direkten Belohnungsassoziation von 10, 25 oder 40 Punkten durften auch als zusätzlicher Bonus angenommen werden, der dann zur Gesamtbelohnung des Blockes hinzuaddiert wurde, während neutrale Farben, die nicht Teil der Zielvorgabe waren, immer abgelehnt werden mussten, da ansonsten das Ziel als verfehlt galt.

Bei der so genannten ,Zielverfolgung“ mussten sich die Probanden stattdessen wie folgt verhalten: 
- zielrelevante Farben immer annehmen

- nicht-zielrelevante Farben immer ablehnen (dies galt auch für nicht-zielrelevante Farben mit einer Belohnungsassoziation, da ansonsten das Ziel als verfehlt galt und der Block vorzeitig ohne Belohnung abgebrochen wurde).

Da die Entscheidung der Probanden über die Annahme oder Ablehnung einer direkt belohnten Farbe in der Bonusrunde frei war, wäre es bei diesem Aufgabentyp die beste Strategie für die Probanden gewesen, alle direkt belohnten Farben zusätzlich einzusammeln, um den Gewinn zu maximieren. Während der Zielverfolgung hingegen waren die Probanden gezwungen, ihre Tendenz zu überwinden, eine direkt belohnte Farbe anzunehmen, da dies der übergeordneten Zielsetzung widersprach (diese Bedingung erzeugte ein Desire- Reason- Dilemma, siehe Diekhof \& Gruber, 2010). Da die drei konditionierten Belohnungsstimuli mit einer parametrisch zunehmenden Wertigkeit assoziiert waren, war zu erwarten, dass diese mit der zunehmenden Sensitivität der HI- Studienteilnehmer für die Wertigkeit einer unmittelbaren Belohnung interferiert (Hariri et al., 2006). Diese Tatsache sollte es den HI- Probanden während der Zielverfolgung zunehmend erschweren, eine unmittelbare Belohnung erfolgreich abzulehnen.
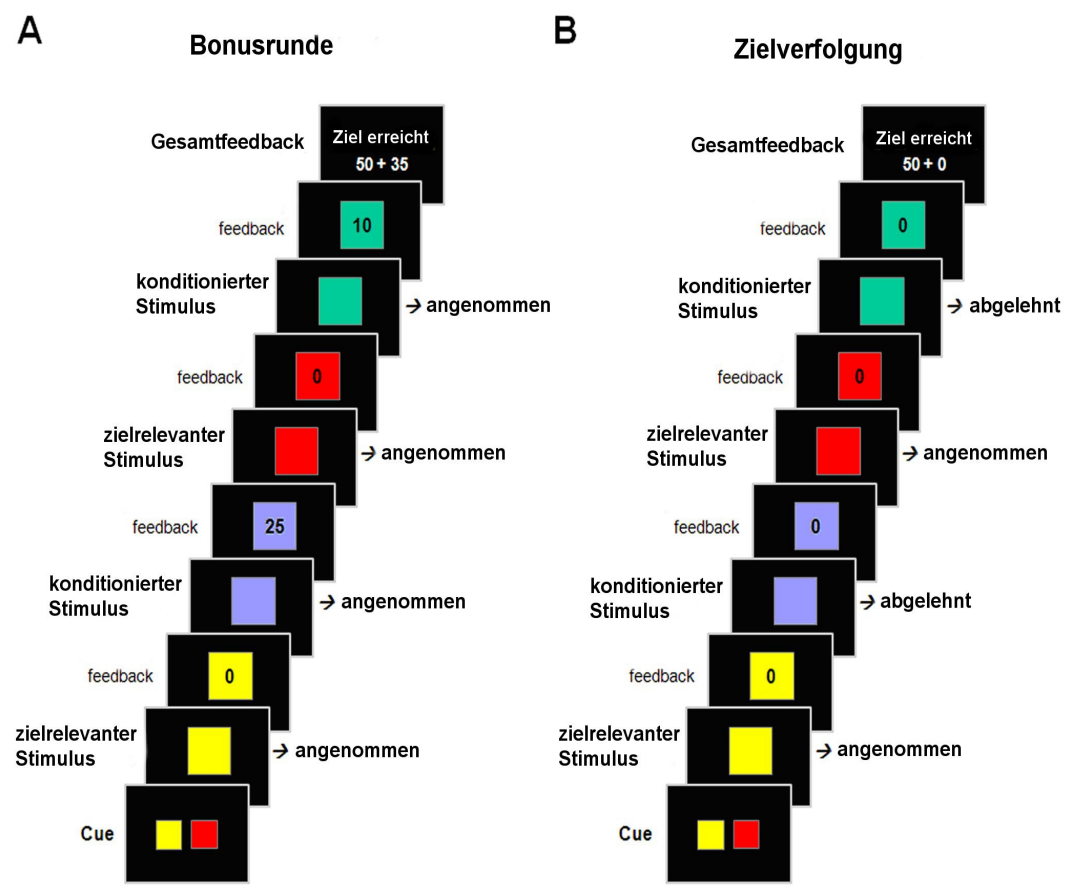

\section{Abbildung 3: Experimentelles Design der modifizierten Forced-Choice-Aufgabe}


(A) Bonusrunde (Desire- Kontext): Die Probanden sollten alle zielrelevanten Stimuli annehmen und alle neutralen, nicht- zielrelevanten Farben ablehnen. Nicht-zielrelevante Farben mit einer direkten Belohnungsassoziation von 10, 25 oder 40 Punkten durften als zusätzlicher Bonus angenommen werden, der dann zur Gesamtbelohnung des Blockes hinzuaddiert wurde.

(B) Zielverfolgung (Reason- Kontext): Die Probanden sollten alle zielrelevanten Farben annehmen und alle nicht- zielrelevanten Farben ablehnen. Dies galt auch für nicht-zielrelevante Farben mit einer direkten Belohnungsassoziation. Dies führte zu einem Desire- Reason-Dilemma, in dem das Verlangen, die potentielle direkte Belohnung anzunehmen, mit dem Erreichen der übergeordneten Zielsetzung konkurrierte.

Während der drei Durchgänge im MRT bearbeiteten die Probanden insgesamt 180 Blöcke. Von diesen erfolgte die Hälfte der Blöcke nach den Vorgaben der Bonusrunde, die andere Hälfte nach den Regeln der Zielverfolgung (siehe Abb. 3). Das Experiment im MRT dauerte ohne Pausen etwa 50 Minuten.

Der Hinweisstimulus, der die Änderung des Aufgabentyps anzeigte, erschien für $2600 \mathrm{~ms}$. Die zielrelevanten Farben wechselten von Block zu Block. Ein Block begann mit einem schwarzen Bildschirm für 200 ms, gefolgt von dem Hinweisstimulus, der den Probanden die beiden zielrelevanten farbigen Quadrate vor jeder Sequenz anzeigte (Dauer $=1500 \mathrm{~ms}$ ) und einem erneuten schwarzen Bildschirm von 200 ms. Die einzelnen Quadrate in einem Block erschienen jeweils für $900 \mathrm{~ms}$. Anschließend folgte ein schwarzer Bildschirm für $200 \mathrm{~ms}$, bevor nach dem Drücken einer Antworttaste ein Feedback von der Dauer von 700 ms angezeigt wurde, wieder gefolgt von einem schwarzen Bildschirm von einer Dauer von 100 ms. Das Gesamtfeedback für die einzelnen Durchgänge wurde den Probanden am Ende jeden erfolgreich erreichten Blocks als Gesamtpunktzahl für $3900 \mathrm{~ms}$ angezeigt, bevor der neue Block begann. Das Gesamtfeedback erschien auch direkt nach dem Abbruch eines Blocks bei Verfehlen des Ziels.

Wie schon in der Konditionierung mussten sich die Probanden innerhalb von 900 ms entschieden und eine Antworttaste gedrückt haben, da ansonsten das Ziel als verfehlt galt und der Block sofort abbrach. Das Ziel wurde außerdem verfehlt, wenn die Probanden falsch oder gar nicht gedrückt hatten. Dies bedeutete dann für die Probanden, dass sie keine Punkte für den jeweiligen Block erhielten. Auch die zusätzlich gesammelten Bonuspunkte aus der Bonusrunde gingen verloren. Wurde der Block erfolgreich beendet, wurde den Probanden ihre Gesamtpunktzahl für den Block angezeigt (siehe Abb. 3). Es gab insgesamt 180 Trials, die die Gesamtpunktzahl eines Blocks anzeigten. Die Anzahl der Trials, die nach der Verfehlung des Ziels erschienen, war abhängig von der Leistung der Probanden. Die Trials innerhalb der 
Blöcke wurden den Studienteilnehmern pseudorandomisiert präsentiert. Die Trial-Übergänge waren ausbalanciert.

Den Probanden wurden insgesamt 180 Hinweisstimuli mit den beiden zielrelevanten Farben vor dem Beginn jeden Blocks präsentiert. Innerhalb der Aufgabentypen umfassten die einzelnen präsentierten Trials maximal 279 zielrelevante Trials, 90 Trials mit einem neutralen, nicht- zielrelevanten Feedback und 126 Trials mit konditioniertem, nichtzielrelevanten Feedback, darunter 42 Trials mit 10 Belohnungspunkten, 42 Trials mit 25 Belohnungspunkten und 42 Trials mit einem Feedback von 40 Belohnungspunkten.

Punkte, die in den Bonusrunden und Zielverfolgungen erworben wurden, wurden anschließend mit denen aus der Konditionierung zusammengerechnet und in einen Geldwert umgewandelt. Die Probanden wurden mit 15 Euro für ihre Teilnahme an der Studie bezahlt. Durch die zusätzlichen Bonusstimuli konnten insgesamt bis zu 30 Euro erzielt werden.

\section{$\underline{2.4}$ Barratt- Impulsivitätsskala, 11. Revision (BIS- 11)}

Um interindividuelle Unterschiede der Impulsivität an einer nicht- klinischen Stichprobe von Studenten zu erfassen, füllten die Studienteilnehmer vor der Teilnahme am Experiment die deutschsprachige Version der Barratt- Impulsivitätsskala in der 11. Revision aus.

Die Teilnehmer der vorliegenden Studie wurden aus einem Studentenkollektiv der GeorgAugust- Universität zu Göttingen ( $\mathrm{n}=67)$ ausgewählt und anhand der BIS- 11 gescreent. Sie hatten einen vergleichbaren sozioökonomischen Status und Bildungsgrad.

Der mittlere BIS-11- Gesamtscore des Studentenkollektivs betrug 62,4 $\pm 8,6$. Diese Werte sind vergleichbar mit dem Durchschnittswert der Population, die Patton et al. (1995) untersucht haben. Sie gleichen auch dem Durchschnittswert der Gruppe aus der Studie von Diekhof \& Gruber (2010), deren Werte 61,9 \pm 7,2 $(\mathrm{n}=18)$ betrugen.

In der vorliegenden Studie wurden aus dem Gesamtkollektiv von 67 Studenten zwei Probandengruppen gebildet, streng gematcht nach Alter und Geschlecht. Es wurden nur diejenigen Studenten in die Studie eingeschlossen, deren BIS-11- Werte eine Standardabweichung über oder unter dem Mittelwert des Studentenkollektivs lagen, um 2 Extremgruppen der Impulsivität miteinander zu vergleichen (siehe Tabelle 1). 
Tabelle 1: Persönlichkeits- und demographische Merkmale der Studienteilnehmer

\begin{tabular}{|c|c|c|c|}
\hline & $\begin{array}{l}\text { HI } \\
(\mathbf{n}=10)\end{array}$ & $\begin{array}{l}\mathbf{L O} \\
(\mathrm{n}=9)\end{array}$ & p-Wert \\
\hline $\begin{array}{l}\text { BIS-11 Gesamtpunktzahl } \\
\text { (Mittelwert }{ }_{93}^{23} \text { Standardabweichung) }\end{array}$ & $71,0{ }_{93}^{238} 4,4$ & $52,8 \underset{93}{238}, 2$ & $<0,0001$ \\
\hline $\begin{array}{l}\text { BIS-11 Kognitive Impulsivität } \\
\text { (Mittelwert }{ }_{938}^{23} \text { tandardabweichung) }\end{array}$ & $19,3 \underset{932,8}{232}$ & $12,9{ }_{93}^{238} 1,7$ & $<0,0001$ \\
\hline $\begin{array}{l}\text { BIS-11 Motorische Impulsivität } \\
\text { (Mittelwert }{ }_{93}^{23} \text { Standardabweichung) }\end{array}$ & $24,6{ }_{93}^{232}, 1$ & $20,4{ }_{93}^{238} 1,8$ & 0,0003 \\
\hline $\begin{array}{l}\text { BIS-11 Nicht- planende Impulsivität } \\
\text { (Mittelwert }{ }_{93}^{23} \text { Standardabweichung) }\end{array}$ & $27,1_{93}^{232}, 2$ & $19,44_{93}^{232} 2,4$ & $<0,0001$ \\
\hline $\begin{array}{l}\text { Alter in Jahren } \\
\text { (Mittelwert }{ }_{93}^{23} \text { Standardabweichung) }\end{array}$ & $23,9 \underset{93}{232}, 0$ & $24,7{ }_{93}^{238} 1,8$ & 0,398 \\
\hline Geschlecht & $5 \mathrm{w} / 5 \mathrm{~m}$ & $5 \mathrm{w} / 4 \mathrm{~m}$ & 0,809 \\
\hline
\end{tabular}

\section{$\underline{2.5}$ Analyse der Verhaltensdaten}

Für die statistische Analyse der Verhaltensdaten wurde das Softwarepaket Statistical Package for the Social Sciences Version 17.0 für Windows von SPSS Inc. verwendet (SPSS, Chicago, IL, USA). Als Verhaltensdaten des fMRT- Experimentes wurden die Reaktionszeiten der korrekt beantworteten Aufgaben und der durchschnittliche prozentuale Anteil der korrekten Antworten auf die konditionierten Belohnungsstimuli getrennt für die Bonusrunde und während der Zielverfolgung registriert. Die Reaktionszeiten und der durchschnittliche prozentuale Anteil der korrekten Antworten auf die konditionierten Belohnungsstimuli wurden mit einer zweifaktoriellen Varianzanalyse ausgewertet (Abk. ANOVA). Die ANOVA wurde anhand der Deltawerte der Reaktionszeiten und die des durchschnittlichen prozentualen Anteils der korrekten Antworten auf die konditionierten Belohnungsstimuli durchgeführt. Bei den Deltawerten handelte es sich um die Differenz der Reaktionszeiten und die Differenz des prozentualen Anteils korrekter Antworten, die in der Bonusrunde und während der Zielverfolgung registriert wurden. Sie entsprechen den jeweiligen Subtraktionskontrasten aus der fMRT- Analyse, die die Wertigkeit der unmittelbaren Belohnung (10, 25, 40), Faktoren zwischen den Probanden und der Gruppe (HI vs. LO) und Faktoren innerhalb der einzelnen Probanden berücksichtigen.

ANOVA ist eine parametrische Analyse, mit der man signifikante Unterschiede zwischen zwei und mehr Gruppen testen kann. ANOVA gibt aber nur an, ob ein signifikanter 
Unterschied zwischen den Bedingungen vorliegt. Es kann keine Aussage darüber getroffen werden, welche Bedingungen sich signifikant voneinander unterscheiden.

\section{$\underline{2.6}$ Datenakquisition}

Die Studie wurde an einem MRT- Scanner (Magnetom TRIO, Siemens Healthcare, Erlangen) mit einer Magnetfeldstärke von 3 Tesla und einer phasengesteuerten 8- Kanal- Kopfspule am Universitätsklinikum Göttingen durchgeführt. Vor Beginn der Messung wurde für die Zuordnung der aktivierten Areale zu morphologischen Strukturen ein T1- gewichteter anatomischer Datensatz mit $1 \mathrm{~mm}$ isotropischer Auflösung generiert. Für den fMRTDatensatz wurden anschließend in aufsteigender Richtung 27 axiale Schichten (slices) mit drei Millimeter Schichtdicke und einer Schichtlücke (gap) von 0,6 mm parallel zur anteriorenposterioren Komissurebene akquiriert. Mit einer Gradientenechosequenz (echo planar imaging, EPI) wurde im Verlauf der 3 Sessions insgesamt eine Datenmenge von 1602 Bildern erhoben. Zur Optimierung der räumlichen und zeitlichen Auflösung dauerte ein Intervall zwischen den Scans, also die Repetitionszeit (TR), 2000 ms. Die Echozeit betrug 33 ms und der Anregungswinkel (flip angle) 70. Das Sichtfeld (field of view) war $192 \mathrm{~mm}$ groß. Zu Beginn jeder Messung wurde ein Fixationskreuz für die Dauer von 4 TRs präsentiert, damit das Magnetfeld einen stabilen Zustand erreichen konnte. Die während dieser Zeit gewonnenen Bilder wurden aus der Datenanalyse ausgeschlossen.

Die Präsentation der Stimuli, sowie die Registrierung der Reaktionszeiten und Fehlerraten wurden mit der Software Presentation ${ }^{\circledR}$ Software (Neurobehavioral Systems, Albany, USA) durchgeführt. Die einzelnen Stimuli wurden den Probanden über eine Brille (Resonance Technology, Northridge, USA) präsentiert, in der die Stimuli über einen lichtdurchlässigen Bildschirm auf einen Spiegel reflektiert wurden. Die Probanden antworteten durch Tastendruck auf elektronische Antwortpads (Current Designs Inc., Philadelphia, USA).

\section{$\underline{2.7 \quad \text { Analyse der fMRT- Daten }}$}

Die funktionellen fMRT- Bilder wurden mit den Programmen Matlab (Matrix Laboratory, MathWorks, Natick, Massachusetts, USA) und dem Softwareprogramm „statistical parametric mapping 2“, (SPM2, Wellcome Department of Cognitive Neurology, University College London, London, UK) vorverarbeitet und statistisch analysiert. 


\subsubsection{Vorverarbeitung}

Die Vorverarbeitung diente der Aufbereitung der Daten für die statistische Analyse. Die im Experiment erhobenen funktionellen Bilder wurden konvertiert und auf das anatomische T1Bild jedes einzelnen Probanden reorientiert, um die T1- Bilder danach in SPM2 weiterbearbeiten zu können. Im Anschluss daran wurden alle T1- und EPI- Bilder aller Probanden von der radiologischen in die neurologische Bildorientierung geflippt. Die ersten 4 Bilder jedes Scans, die die Anlaufzeit und die T1- Equilibrierungseffekte erfassten, waren für die weitere Analyse nicht von Interesse und wurden gelöscht. Im nächsten Schritt wurde bei allen T1- und EPI- Bildern jedes Probanden der Ursprung im dreidimensionellen Raum ( $\mathrm{x}=0$; $\mathrm{y}=0 ; \mathrm{z}=0$ ) im Koordinatensystem an die ,unterste vorderste“ Ecke der anterioren Kommissur in der median- sagittal- Ebene als Referenzpunkt positioniert. Die Positionierung des Referenzpunktes war notwendig, um die Koregistrierung des T1- Bildes auf das erste EPIBild durchzuführen. Als letztes wurden auch die übrigen EPI- Bilder, analog zur Orientierung des ersten EPI- Bildes, reorientiert.

Nach der beschriebenen ersten Bearbeitung der funktionellen Bilder umfasste die Vorverarbeitung folgende Schritte:

- eine Koregistrierung der anatomischen und funktionellen Bilder

- eine Bewegungskorrektur (Realignment \& Unwarping).

Die Korrektur von Bewegungen war notwendig, da Kopfbewegungen Änderungen in der Signalintensität hervorrufen können, die die durch das Experiment hervorgerufenen Aktivierungen im Gehirn stören können (Friston et al., 2003).

- $\quad$ eine Korrektur des zeitlichen Verlaufs über die Schichtfolge (Slice Timing)

Als Referenzschicht diente die erste und somit die unterste Schicht.

- eine Normalisierung der EPIs auf ein Standardgehirn, um die Daten der Probanden miteinander vergleichen zu können. In der vorliegenden Studie wurde das in SPM 2 MNI (Montreal Neurological Institute)- EPI- Template verwendet.

- $\quad$ eine Glättung der Daten (Smoothing) mit einem Gauss'schen Filter (FWHM: 9mm).

\subsubsection{Statistische Analyse der fMRT- Daten}

Für die statistische Analyse der fMRT- Daten wurde das allgemeine lineare Modell (Abk. ALM) angewendet. Das Prinzip der im ALM verwendeten statistischen Tests besteht darin, beobachtete Daten in verschiedene Varianzanteile $\mathrm{zu}$ zerlegen, um diese miteinander 
vergleichen zu können (Friston et al., 1995a,b). Hierzu wurden statistische Karten (engl. statistical parametric maps (SPMs)) der Gehirnaktivierung errechnet (Friston et al., 1996). Das ALM beinhaltete für die Bonusrunde und die Zielverfolgung jeweils drei Regressoren: einen für die zielrelevanten Stimuli, einen für die neutralen, nicht- zielrelevanten und einen für die konditionierten, nicht- zielrelevanten Stimuli. Die einzelnen Cues und das Feedback, das den Probanden nach jedem Block angezeigt wurde, unabhängig davon, ob der Block erfolgreich beendet wurde oder das Ziel als verfehlt galt, wurden als unabhängige Variablen angesehen. In der Summe gab es 9 Regressoren. Weiterhin gab es zwei lineare parametrische Modulatoren, die die einzelnen Wertigkeiten $(10,25,40)$ der unmittelbaren, nichtzielrelevanten Belohnungsoptionen getrennt für die Bonusrunde und Zielverfolgung erfassten. Diese parametrischen Modulatoren gaben an, wie gut das BOLD-Signal mit der konstanten Variablen, der Wertigkeit einer Belohnungsoption, auf Trial- By- Trial- Basis korrelierte. Die Fehlertrials und die Trials der konditionierten Belohnungsstimuli aus der Bonusrunde, die die Probanden nicht eingesammelt hatten, wurden aus der Analyse ausgeschlossen.

Es wurde ein Vektor generiert, der den zeitlichen Beginn der Stimuluspräsentation für jeden Stimulustyp darstellte. Dieser Vektor wurde mit der kanonischen hämodynamischen Antwortfunktion (hrf) verknüpft, um eine hämodynamische Antwort für jede experimentelle Bedingung und jeden parametrischen Modulator vorhersagen zu können. Außerdem wurde ein linearer t- Kontrast definiert, um die spezifischen Effekte ausgewählter konditionierter, nicht- zielrelevanter Stimuli und die parametrischen Modulatoren der beiden Aufgabentypen und die der beiden Probandengruppen getrennt voneinander beurteilen zu können. Mithilfe der Kontraste konnte man für jeden Probanden einzeln überprüfen, wie sich das fMRT- Signal in einer experimentellen Bedingung von der neuronalen Aktivierung in Ruhe unterschied. Mit differentiellen Kontrasten konnte außerdem getestet werden, ob sich das fMRT- Signal und damit die neuronale Aktivierung in verschiedenen Bedingungen voneinander unterschieden.

Um Unterschiede in den belohnungsabhängigen Aktivierungen des Gehirns in den beiden Aufgabentypen zu untersuchen, wurden ausgewählte konditionierte Belohnungsstimuli aus der Bonusrunde mit denen aus der Zielverfolgung verglichen, und zwar dann, wenn diese Stimuli nicht Teil der Zielvorgabe waren. Anhand dieses Kontrastes konnte die Herabregulation der neuronalen Aktivität während des Konflikts zwischen der übergeordneten Zielsetzung und der unmittelbaren Belohnung während der Zielverfolgung beurteilt werden (d.h. während des Desire- Reason- Dilemmas, welches die Ablehnung einer direkten Belohnung zum Erreichen eines langfristigen Ziels erforderte; siehe auch Diekhof \& Gruber, 2010). Um den Effekt des linearen Anstiegs der Wertigkeit der Belohnung der 
konditionierten, nicht- zielrelevanten Stimuli auf die Hirnaktivität in beiden Aufgabentypen zu untersuchen, wurde jeder parametrische Modulator mit der impliziten Baseline verglichen. Weiterhin wurde ein direkter Kontrast zwischen den beiden parametrischen Modulatoren berechnet. Dadurch wurde versucht, Hirnregionen zu identifizieren, die mit der Wertigkeit einer Belohnungsoption in der Bonusrunde und während der Zielverfolgung unterschiedlich stark mit Trial-By- Trial- Veränderungen korrelierten.

Um die Parameterschätzer der drei Regressoren, die die Wertigkeit der unmittelbaren Belohnung $(10,25,40)$ repräsentierten, analysieren zu können, war es notwendig, ein zweites ALM zu erstellen und zu schätzen. Dieses Modell beinhaltete für jede Wertigkeit in der Bonusrunde und während der Zielverfolgung drei Onset- Regressoren. Parameterschätzer für das lokale Aktivierungsmaximum im VMPFC ( $\left.\begin{array}{lll}0 & 24 & -9\end{array}\right)$ wurden für jeden dieser sechs Regressoren mit der Funktion Marsbar gewonnen (http://marsbar. Sourceforge.net/).

Um in einem zweiten Schritt Gruppeneffekte analysieren zu können, war zusätzlich eine so genannte Second Level Analyse erforderlich. Dazu wurden Random-effect- Analysen auf der Basis der kontrastierten Bilder einzelner Probanden erstellt. Es wurde eine zweifaktorielle Varianzanalyse durchgeführt, um Differenzen zwischen HI- und LO- Studienteilnehmern zu testen. So konnte man Aktivierungsunterschiede für eine Gruppe von Probanden gemäß den experimentellen Bedingungen überprüfen. Als Standardstatistikkriterium der Gruppenstatistik wurde eine Schwelle von $\mathrm{p}<0,001$, unkorrigiert mit einer minimalen Clustergröße von 10 Voxel, wenn dies nicht anderweitig beschrieben ist, gewählt. Für Hirnregionen mit einer spezifischen a priori Hypothese ist es aufgrund früherer Studien zu rechtfertigen (Hare et al., 2009; Diekhof \& Gruber, 2010), kleine Volumenkorrekturen (Worsley et al., 1996) mit einer Wahrscheinlichkeit von $\mathrm{p}<0,05$ mit einer Family- wise- Fehlerrate (FWE) durchzuführen. Für alle Abbildungen in dieser Arbeit wurde ein abgeschwächteres statistisches Kriterium mit $\mathrm{p}<0,005$, unkorrigiert verwendet.

\subsubsection{Psychophysiologische Interaktionsanalyse (PPI)}

Mit einer psychophysiologischen Interaktionsanalyse (PPI) kann man den Einfluss einer experimentellen Bedingung auf die funktionelle Konnektivität zweier Hirnareale beschreiben. Um die erste Hypothese dieser Studie zu testen und in Replikation zur Studie von Diekhof und Gruber (2010) wurde mithilfe der nachfolgenden psychophysiologischen Interaktionsanalysen (Friston et al., 1997) als erstes die funktionellen Interaktionen zwischen dem rechten Nacc und dem avPFC untersucht, und zwar unter der Bedingung, dass die 
unmittelbare Belohnungskontingenz und die übergeordnete Zielsetzung bei der Handlungskontrolle miteinander konkurrierten (d.h. während des Desire- Reason-Dilemmas). Das lokale Maximum des rechten Nacc (15 12 -6), das eine signifikante Reduktion der belohnungsabhängigen Aktivierung während der Zielverfolgung zeigte (Tabelle 3, Abb. 4A), wurde als Seed- Area für die erste PPI- Analyse ausgewählt (für ein ähnliches Vorgehen siehe Diekhof \& Gruber, 2010).

In einer zweiten PPI- Analyse wurden Veränderungen in den neuronalen Konnektivitätsmustern untersucht, die während der erfolgreichen Lösung des Desire- ReasonDilemmas vom VMPFC ausgingen. Der VMPFC spielt eine wichtige Rolle für die Repräsentation der Wertigkeit einer Belohnung während der Entscheidungsfindung (Hare et al., 2008; Plassmann et al., 2008). Sowohl in der vorliegenden Studie (siehe Tabelle 6) als auch in vorherigen (Hare et al., 2009) wurde beobachtet, dass die Aktivität des VMPFC signifikant abgeschwächt wird, wenn impulsive Probanden in Hinblick auf in der Wertigkeit zunehmende Belohnungen selbstkontrolliert handeln. Mit der zweiten PPI- Analyse wurde nach denjenigen Hirnregionen gesucht, deren funktionelle Konnektivität mit dem VMPFC durch die Wertigkeit einer unmittelbaren Belohnungsoption beeinflusst werden, wenn diese während des Desire-Reason-Dilemmas abgelehnt werden mussten. Als Seed- Area für diese Analyse wurde das Aktivitätsmaximum des VMPFC (l $\left.\begin{array}{lll}0 & 24 & -9\end{array}\right)$ gewählt, welches einen signifikanten Abfall der neuronalen Aktivität mit zunehmender Wertigkeit einer unmittelbaren Belohnungsoption während der Zielverfolgung zeigte (siehe Tabelle 6).

Die einzelnen Zeitverläufe des BOLD- Signals wurden von den beiden lokalen Aktivierungsmaxima abgeleitet, welche in den beiden PPI als physiologische Vektoren dienten (siehe oben). In der ersten PPI- Analyse bestand der psychologische Vektor aus dem oben beschriebenen Kontrast, der die konditionierten Belohnungsstimuli aus der Bonusrunde mit denen aus der Zielverfolgung verglich. In der zweiten PPI- Analyse bestand der psychologische Vektor aus dem Vergleich zwischen den beiden parametrischen Modulatoren, die die Trial- By- Trial- Veränderungen der Wertigkeit der unmittelbaren Belohnungsoption in den beiden Aufgabentypen reflektierten. Es wurde also ein Vergleich zwischen dem parametrischen Modulator durchgeführt, der die zunehmende Wertigkeit der Belohnungsoption in der Bonusrunde repräsentierte mit dem aus der Zielverfolgung.

Unter zur Hilfenahme von Matlab und SPM 2 wurden die hämodynamischen Signale zuerst mit einer empirischen parametrischen Bayes'schen Formulierung entfaltet (Gitelman et al., 2003) und über den Mittelwert korrigiert. Danach wurde für jede Region separat ein PPITerm durch Multiplikation des entfalteten und über den Mittelwert korrigierten BOLD- 
Signals mit dem jeweiligen psychologischen Vektor gebildet. Nach der Faltung mit der hrf (hämodynamischen Antwortfunktion), der Mittelwertkorrektur und der Orthogonalisierung wurden die drei Regressoren, also der PPI- Term, der physiologische Vektor und der psychologische Vektor, in die statistische Analyse überführt, um kontextabhängige Veränderungen der funktionellen Konnektivität und darüber hinaus Haupteffekte der Aufgabe oder Haupteffekte der Aktivierungen in den korrespondierenden Gehirnarealen zu bestimmen. In den beiden PPI- Kontrasten wurde der PPI- Term gegen die implizite Baseline berechnet. Im Anschluss daran wurden für jeden Probanden Random- effekt- Analysen mit $p<0,001$, unkorrigiert an den Kontrastbildern durchgeführt. Um Differenzen in den funktionellen Interaktionen der HI- und LO- Studienteilnehmer $\mathrm{zu}$ testen, wurde eine ANOVA durchgeführt.

Es wurden weiterhin zwei zusätzliche PPI- Analysen durchgeführt, in denen separat die funktionellen Interaktionen zwischen dem rechten Nacc (als Seed- Area) und dem linken avPFC untersucht wurden, und zwar entweder wenn die konditionierten Belohnungsstimuli während der Zielverfolgung präsentiert wurden oder in der Bonusrunde. Es wurden die Zeitverläufe des Signals des Nacc berechnet und entsprechende Vergleiche gegen die implizite Baseline als psychologischen Vektor (d.h. den Kontrast der Bonusannahme vs. implizite Baseline in der Bonusrunde) vorgenommen. Das weitere Vorgehen war wie oben beschrieben. Diese zusätzlichen Analysen waren erforderlich, um zu untersuchen, ob die Differenz in der funktionellen Konnektivität in den beiden Aufgabentypen (1.) entweder aus einer stärker positiven PPI- Analyse in der Bonusrunde resultierte, das heißt, dass die Steigung der Regressionsgeraden in der Bonusrunde stärker positiv war als die allgemeine Konnektivität der impliziten Baseline. Oder aber, ob der Konnektivitätsunterschied (2.) auf eine stärker negative PPI- Analyse während der Zielverfolgung zurückzuführen war.

Die Parameterschätzer der Probanden- spezifischen Stärke der Kopplung zwischen dem ventralen Striatum/ Nacc und dem VMPFC für die drei Wertigkeiten der unmittelbaren, aber abgelehnten Belohnungsoptionen sind die Ergebnisse der drei zusätzlichen PPI- Analysen.

Diese Analysen liefern eine Erklärung für die Konnektivität des VMPFC in den einzelnen Vergleichen der drei Regressoren der Wertigkeit während der Zielverfolgung und der Bonusrunde, die im zweiten ALM erstellt wurden (siehe oben). Das bedeutet, der psychologische Vektor der ersten PPI- Analyse besteht aus dem Kontrast, mit dem die neuronale Aktivierung getestet wurde, die bei Ablehnung einer unmittelbaren 10er Belohnungsoption während der Zielverfolgung versus der Annahme des 10er Bonus in der Bonusrunde gemessen wurde. Die zweite und dritte PPI- Analyse basierte ebenfalls auf einen 
Vergleich zwischen den beiden Aufgabentypen, jedoch jeweils für eine unmittelbare Belohnungsoption von 25 bzw. 40 Bonuspunkten. Als Seed- Area dieser drei Analysen wurde wieder das Aktivitätsmaximum des VMPFC gewählt ( $\begin{aligned} & 0 \\ & 2\end{aligned} 4$-9).

\section{$\underline{3}$ Ergebnisse}

\section{$\underline{3.1 \quad \text { Ergebnisse der Verhaltensdaten }}$}

In der Tabelle 2 sind die durchschnittlichen Reaktionszeiten in Millisekunden und der durchschnittliche prozentuale Anteil der korrekten Antworten auf die konditionierten Belohnungsstimuli dargestellt. Es sind jeweils die Mittelwerte und Standardabweichungen getrennt für beide Probandengruppen (HI versus LO) und beide Aufgabentypen (Bonusrunde versus Zielverfolgung) angegeben und nach der Wertigkeit der Belohnungspunkte aufgezeigt. Die Analyse der Delta- Werte (d.h. die Differenz der Reaktionszeiten und die Differenz des Anteils der korrekten Antworten getrennt betrachtet für die Bonusrunde und die Zielverfolgung), der Reaktionszeiten und der Fehlerraten beider Kontexte zeigte einen signifikanten relativen Leistungsabfall in beiden Gruppen während des Desire- ReasonDilemmas. Während der Zielverfolgung, in der die Teilnehmer eine unmittelbare Belohnungsoption für die Verfolgung einer langfristigen Zielsetzung ablehnen mussten, zeigte sich der Abfall der Verhaltensleistung (i.e.S. der relative Anstieg der Reaktionszeiten und der Fehlerraten) mit zunehmender Wertigkeit der unmittelbaren Belohnung. Dieser mit ansteigender Wertigkeit zunehmende Leistungsabfall verhielt sich signifikant (Haupteffekt der Leistungsmesswerte: FRTs $\left.=15,92, \mathrm{p}<0,0001 ; \mathrm{F}_{\text {error }}=4,00, \mathrm{p}=0,025\right)$. Ein signifikanter Haupteffekt auf Gruppenebene ( $\left.F_{R T s}=1,12, p=0,296 ; F_{\text {error }}=0,35, p=0,555\right)$ sowie eine signifikante „Wertigkeitsinteraktion“ zwischen den Gruppen (FRTs $=0,05, \mathrm{p}=0,960$; Ferror $=$ $0,55, \mathrm{p}=0,583$ ) konnte nicht nachgewiesen werden.

Diese Ergebnisse weisen darauf hin, dass es sowohl für die hoch-impulsiven als auch für die extrem- kontrollierten Probanden zunehmend schwieriger geworden ist, auf eine unmittelbare Belohnungsoption zunehmender Wertigkeit während der Verfolgung der übergeordneten Zielsetzung zu verzichten. 
Tabelle 2: Verhaltensdaten

\begin{tabular}{|c|c|c|c|c|c|c|}
\hline & \multicolumn{3}{|c|}{$\begin{array}{l}\text { Reaktionszeiten (ms) } \\
\text { Mittelwert } \pm \text { Standardabweichung }\end{array}$} & \multicolumn{3}{|c|}{$\begin{array}{l}\text { Anteil der korrekten Antworten (\%) } \\
\text { Mittelwert } \pm \text { Standardabweichung }\end{array}$} \\
\hline & HI & LO & HI \& LO & HI & LO & HI \& LO \\
\hline (A) Bonusrunde & & & & & & \\
\hline $\begin{array}{l}\text { Annahme von ... } \\
10 \text { Bonuspunkten } \\
25 \text { Bonuspunkten } \\
40 \text { Bonuspunkten }\end{array}$ & $\begin{array}{l}511 \pm 9 \mathrm{~ms} \\
503 \pm 9 \mathrm{~ms} \\
509 \pm 16 \mathrm{~ms} \\
\end{array}$ & $\begin{array}{l}488 \pm 9 \mathrm{~ms} \\
477 \pm 12 \mathrm{~ms} \\
488 \pm 14 \mathrm{~ms} \\
\end{array}$ & $\begin{array}{l}500 \pm 9 \mathrm{~ms} \\
491 \pm 8 \mathrm{~ms} \\
499 \pm 11 \mathrm{~ms} \\
\end{array}$ & $\begin{array}{l}88,3 \pm 2,3 \% \\
90,8 \pm 2,8 \% \\
91,1 \pm 1,9 \% \\
\end{array}$ & $\begin{array}{l}88,8 \pm 4,3 \% \\
96,1 \pm 1,1 \% \\
93,5 \pm 1,5 \% \\
\end{array}$ & $\begin{array}{l}88,6 \pm 2,3 \% \\
93,3 \pm 1,6 \% \\
92,2 \pm 1,2 \% \\
\end{array}$ \\
\hline (B) Zielverfolgung & & & & & & \\
\hline $\begin{array}{l}\text { Ablehnung von ... } \\
10 \text { Bonuspunkten } \\
25 \text { Bonuspunkten } \\
40 \text { Bonuspunkten }\end{array}$ & $\begin{array}{l}446 \pm 12 \mathrm{~ms} \\
457 \pm 12 \mathrm{~ms} \\
502 \pm 12 \mathrm{~ms}\end{array}$ & $\begin{array}{l}434 \pm 8 \mathrm{~ms} \\
436 \pm 7 \mathrm{~ms} \\
489 \pm 8 \mathrm{~ms}\end{array}$ & $\begin{array}{l}440 \pm 7 \mathrm{~ms} \\
447 \pm 7 \mathrm{~ms} \\
496 \pm 7 \mathrm{~ms}\end{array}$ & $\begin{array}{l}99,0 \pm 0,4 \% \\
98,7 \pm 0,7 \% \\
94,7 \pm 2,0 \% \\
\end{array}$ & $\begin{array}{l}100,0 \pm 0,0 \% \\
99,5 \pm 0,4 \% \\
97,1 \pm 0,8 \%\end{array}$ & $\begin{array}{l}99,5 \pm 0,3 \% \\
99,0 \pm 0,4 \% \\
95,8 \pm 1,1 \%\end{array}$ \\
\hline
\end{tabular}

\section{$\underline{3.2 \quad \text { Ergebnisse der fMRT- Daten }}$}

Auf neuronaler Ebene führten Entscheidungen, die auf ein langfristiges Ziel mit Verzicht auf eine unmittelbare Belohnung ausgerichtet waren, in der Gruppe der HI- Studienteilnehmer zu einer signifikanten Abschwächung der hämodynamischen Antwort auf die konditionierten Belohnungsstimuli im rechten Nucleus accumbens (Nacc) und in der Area tegmentalis ventralis (VTA) (Tabelle 3, Abb. 4A). Insbesondere in der HI- Gruppe konnte in der Bonusrunde in Relation zur impliziten Baseline eine relative Abnahme der belohnungsabhängigen Aktivierung im Nacc nachgewiesen werden (Abb. 4B). Das Dilemma führte zu einer weiteren signifikanten Suppression der belohnungsabhängigen neuronalen Antwort. In Übereinstimmung mit den Ergebnissen der vorangegangenen Studie von Diekhof \& Gruber (2010) ging diese Downregulation der belohnungsabhängigen Aktivierung während des Dilemmas mit einer Abnahme der positiven funktionellen Konnektivität im Vergleich zur impliziten Baseline (inverse Konnektivität) zwischen dem linken anteroventralen PFC (avPFC) und dem rechten Nacc einher (Tabelle 4; Abb. 4C). Dieses Ergebnis zeigte sich ebenso im Vergleich mit der Gruppe der LO- Probanden (Abb. 4D). Bei einem Vergleich von Bonusrunde und Zielverfolgung zeigten die hoch- impulsiven Probanden eine signifikante Veränderung (d.h. eine Abnahme) in der frontostriatalen Konnektivität (Tabelle 7, Abb. 6).

Tabelle 3: Downregulation der belohnungsabhängigen Aktivierung während des Desire-Reason-Dilemmas 


\begin{tabular}{lll}
\hline & $\begin{array}{l}\text { Hirnregionen, die während des Desire- Reason- Dilemmas eine } \\
\text { abnehmende Aktivierung zeigten }\end{array}$ \\
& $\begin{array}{l}\text { [konditionierte (nicht- zielführende) } \\
\text { Zielverfolgung vs. der Bonusrunde] }\end{array}$ & \\
& HI & LO \\
& MNI-Koordinaten & MNI-Koordinaten \\
Region & (t-Wert) & (t-Wert) \\
\hline R Nacc & $1512-6(-3,80)$ & n.s. \\
L/R VTA/ Mittelhirn & $-6-18-21(-3,87)^{1}$ & n.s. \\
\hline
\end{tabular}

Aktivierungen sind mit $\mathrm{p}<0,05$, korrigiert für kleine Volumina dargestellt, wenn nicht anderweitig beschrieben. ${ }^{1}$ Aktivierungen sind mit $\mathrm{p}<0,001$, unkorrigiert dargestellt.

Tabelle 4: Abnahme der positiven funktionellen Konnektivität im Vergleich zur impliziten Baseline (inverse funktionelle Konnektivität) zwischen dem rechten Nacc und dem linken avPFC während des Desire-Reason-Dilemmas in der Gruppe der HI- Probanden

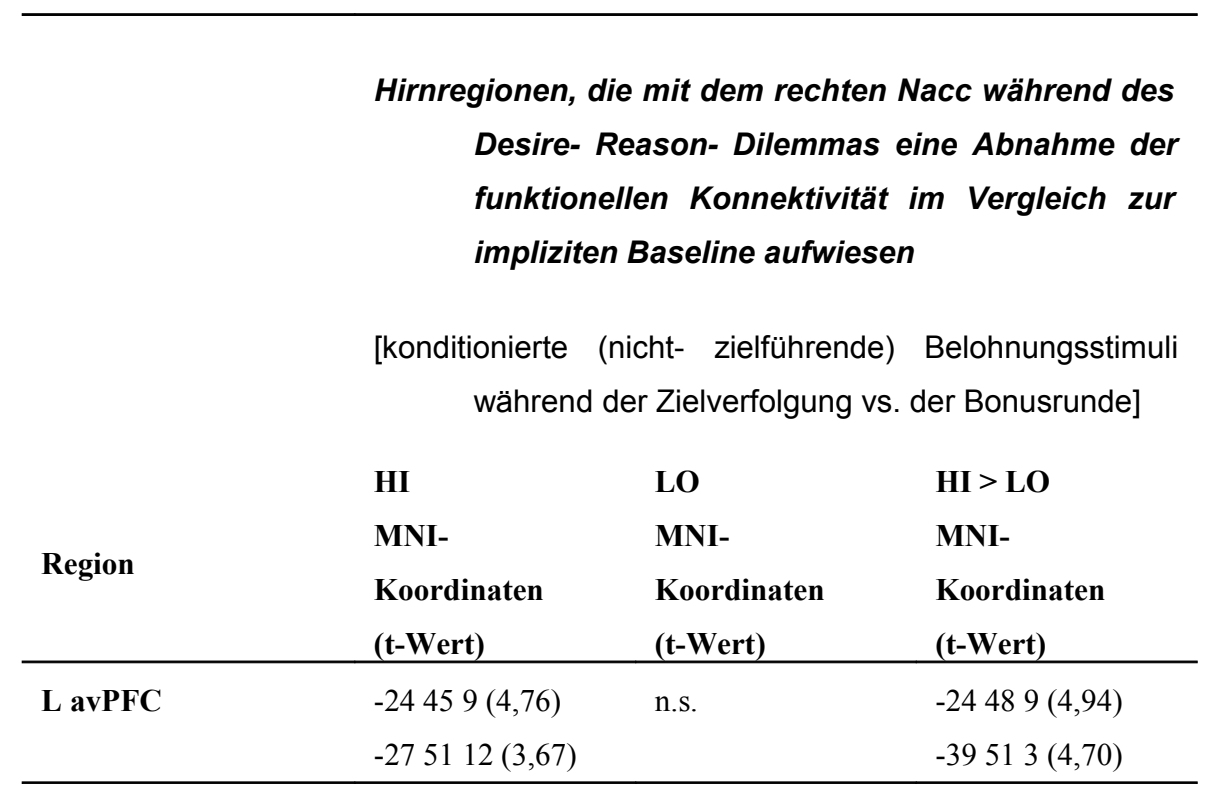

Aktivierungen sind mit $\mathrm{p}<0,001$, unkorrigiert dargestellt, mit einer minimalen Clustergröße von 10 Voxel. 
A

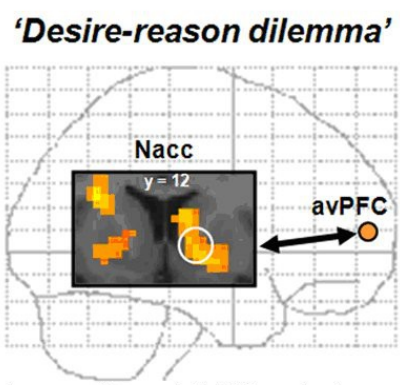

Inverse Konnektivität zwischen dem re. NACC und dem Ii. avPFC

C

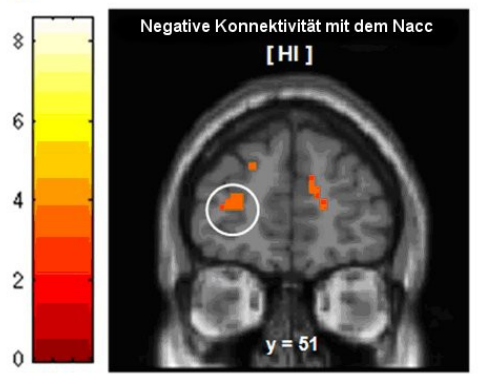

B

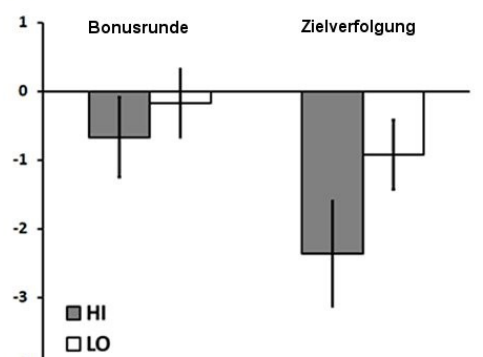

D

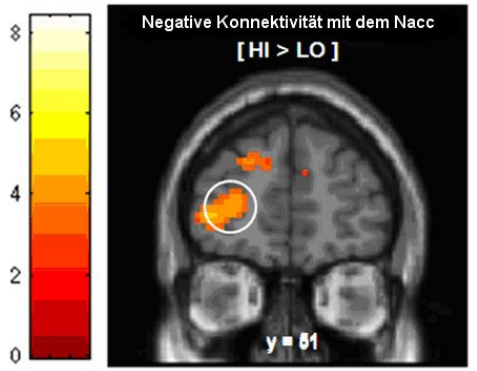

Abbildung 4: Downregulation der belohnungsabhängigen Aktivierung und Veränderungen in der präfrontostriatalen Konnektivität bei hochimpulsiven Probanden während des Desire- Reason- Dilemmas

(A) Signifikante Downregulation der Aktivierung im rechten Nacc während des Desire- ReasonDilemmas in der Gruppe der HI- Probanden (siehe auch Tabelle 3). (B) Parameterschätzer für das belohnungsabhängige Signal im rechten Nacc (im Vergleich zur impliziten Baseline) während der Bonusrunde, in der die konditionierten, nicht- zielführenden Belohnungsstimuli zusätzlich angenommen werden durften, und während der Zielverfolgung, in der die konditionierten, nichtzielführenden Belohnungsstimuli abgelehnt werden mussten (Desire-Reason-Dilemma). Die Fehlerbalken zeigen den Standardfehler des Mittelwerts. In der HI- Gruppe wurden die Parameterschätzer während des Dilemmas signifikant herabreguliert. (C) Zunahme der negativen Konnektivität (i.e.S. Abnahme der positiven funktionellen Konnektivität im Vergleich zur impliziten Baseline) zwischen dem rechten Nacc und dem linken avPFC während des DesireReason- Dilemmas in der HI-Gruppe (siehe auch Tabelle 4). (D) Zunahme der negativen Konnektivität (i.e.S. Abnahme der positiven funktionellen Konnektivität im Vergleich zur impliziten Baseline) zwischen dem rechten Nacc und dem linken avPFC während des Dilemmas, HI - und LO- Probanden im Vergleich (siehe auch Tabelle 4). 
A

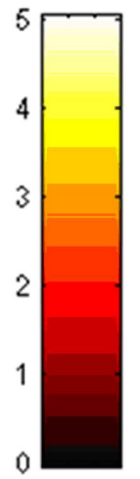

B

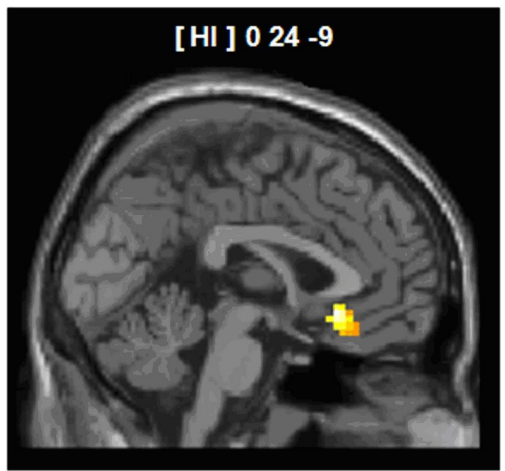

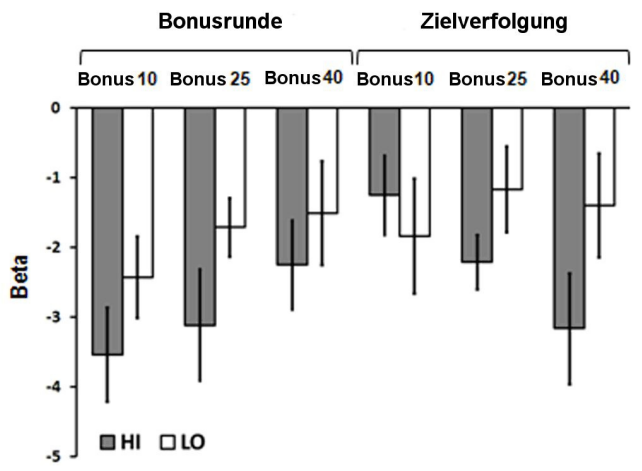

Abbildung 5: Parametrische Deaktivierung des VMPFC während der Ablehnung einer unmittelbaren Belohnungsoption zunehmender Wertigkeit während des Desire- Reason- Dilemmas in der Gruppe der HI- Probanden

(A) Signifikante parametrische Downregulation der wertigkeitsabhängigen Aktivierung im VMPFC während des Desire- Reason- Dilemmas in der HI- Gruppe (siehe auch Tabelle 6). (B) Parameterschätzer des belohnungsabhängigen Signals im VMPFC in Abhängigkeit von der Wertigkeit der Belohnungsoption (im Vergleich zur impliziten Baseline). In der HI- Gruppe zeigten die Parameterschätzer während der Zielverfolgung eine signifikante Abnahme mit zunehmender Wertigkeit der Belohnungsoption.

In der Gruppe der extrem- kontrollierten Studienteilnehmer wurde eine Downregulation der belohnungsabhängigen Aktivierung im rechten Nacc und der VTA während des Dilemmas nur nach Absenken der statistischen Schwelle auf p $<0,05$, unkorrigiert für multiple Vergleiche beobachtet [MNI- Koordinaten x y z (t-Wert): Nacc 1212 -6 (-1,89); VTA -9 -18 -24 (- 2,21)]. Bei den kontrollierten Probanden konnte außerdem während der Zielverfolgung, in der sie eine unmittelbare Belohnung für das Erreichen eines langfristigen Ziels ablehnen mussten, der relative Abfall der funktionellen Interaktion zwischen dem Nacc und dem avPFC nicht nachgewiesen werden (Tabelle 3 und 4). Diese Ergebnisse führen zu der Annahme, dass sich extrem- kontrollierte und hoch- impulsive Probanden in ihren neuronalen Mechanismen unterscheiden, einen Konflikt zwischen wunsch- und zielorientierten Entscheidungen zu lösen (d.h. während des Desire-Reason-Dilemmas). 
Tabelle 5: Positive funktionelle Konnektivität zwischen dem rechten Nacc und dem linken avPFC während der Verarbeitung konditionierter (Belohnungs-) Stimuli

\begin{tabular}{|c|c|c|c|c|}
\hline & \multicolumn{2}{|c|}{$\begin{array}{l}\text { Hirnregionen, die mit dem rechten Nacc in } \\
\text { der „Bonusrunde“ eine positive } \\
\text { Konnektivität aufwiesen }\end{array}$} & \multicolumn{2}{|c|}{$\begin{array}{l}\text { Hirnregionen, die mit dem rechten Nacc } \\
\text { während der „Zielverfolgung“ eine positive } \\
\text { Konnektivität aufwiesen }\end{array}$} \\
\hline & \multicolumn{2}{|c|}{ [Bonus > implizite Baseline] } & \multicolumn{2}{|c|}{ [Dilemma $>$ implizite Baseline] } \\
\hline & HI & LO & HI & LO \\
\hline Region & $\begin{array}{l}\text { MNI-Koordinaten } \\
\text { (t-Wert) }\end{array}$ & $\begin{array}{l}\text { MNI-Koordinaten } \\
\text { (t-Wert) }\end{array}$ & $\begin{array}{l}\text { MNI-Koordinaten } \\
\text { (t-Wert) }\end{array}$ & $\begin{array}{l}\text { MNI-Koordinaten } \\
\text { (t-Wert) }\end{array}$ \\
\hline \multirow[t]{2}{*}{$L$ avPFC } & $-30546(3,78)$ & $-30606(3,09)^{1}$ & - & $-30606(3,70)$ \\
\hline & $-27513(2.93)^{1}$ & & & $-24513(3.97)$ \\
\hline
\end{tabular}

Zur Überprüfung der zweiten Hypothese, dass besonders die HI- Probanden die Interferenz der zunehmenden Wertigkeit der unmittelbaren Belohnung mittels Selbstkontrolle regulieren müssen, wurde der Effekt der linear ansteigenden Wertigkeit der Belohnung auf die neuronale Verarbeitung während des Desire- Reason-Dilemmas berechnet. Ich hatte angenommen, dass die Hirnaktivierung, die die Wertigkeit der unmittelbaren Belohnung repräsentiert, signifikant herunterreguliert werden wird, wenn die HI- Probanden einen konditionierten Belohnungsstimulus während der Zielverfolgung erfolgreich abgelehnt haben (siehe z.B. Hare et al., 2009). Durch die durchgeführte Analyse konnte eine Hirnregion identifiziert werden, die mit zunehmender Wertigkeit der Belohnung eine signifikante parametrische Downregulation während des Dilemmas zeigte. Dementsprechend führte in der Gruppe der HI- Probanden eine Ablehnung der konditionierten Belohnungsstimuli mit zunehmender Wertigkeit der Belohnung zu einer parametrischen Downregulation der Aktivierung im subgenualen anterioren cingulären Kortex und dem benachbarten Gyrus rectus (Tabelle 6, Abb. 5A \& B). Im weiteren Verlauf der vorliegenden Arbeit wird für diese Hirnregion die Bezeichnung ventromedialer präfrontaler Kortex mit der Abkürzung „VMPFC“ verwendet. Interessanterweise konnte nach Absenken der statistischen Schwelle auf $\mathrm{p}<0,05$, unkorrigiert in der Gruppe der HI- Probanden während der Bonusrunde eine relative Zunahme des ventromedialen präfrontalen Signals mit der Wertigkeit der unmittelbaren Belohnung beobachtet werden (d.h. eine Reduktion des Deaktivierungsgrades im VMPFC) [MNIKoordinaten x y z ( $\mathrm{t}$-Wert): $0270(2,84)]$. 
Im Gegensatz dazu konnte diese wertigkeitssensitive Abnahme der Aktivierung im VMPFC in der Gruppe der LO- Probanden während des Dilemmas nicht nachgewiesen werden. Den linearen wertigkeitsabhängigen Anstieg während der erfolgreichen Annahme der Bonusstimuli zeigten die extrem- kontrollierten Probanden nur nach einem Absenken des statistischen Schwellenwertes auf $p<0,05$ unkorrigiert (Abb. 5B).

\section{Tabelle 6: Parametrische Downregulation der wertigkeitsabhängigen Aktivierung} während des Desire-Reason- Dilemmas

\section{Abnahme der Aktivierung mit linearem Anstieg der Wertigkeit einer unmittelbaren Belohnung während des Desire- Reason- Dilemmas}

[konditionierte (nicht-

Belohnungsstimuli

Zielverfolgung vs. der Bonusrunde]
Parametrischer Kontrast

Parametrischer Kontrast

[konditionierte (nicht- zielführende) Belohnungsstimuli während der

Zielverfolgung vs. implizite Baseline]

\begin{tabular}{|c|c|c|c|c|c|c|}
\hline & HI & LO & HI $>$ LO & HI & LO & $\mathrm{HI}>\mathrm{LO}$ \\
\hline Region & $\begin{array}{l}\text { MNI- } \\
\text { Koordinaten } \\
\text { (t-Wert) } \\
\end{array}$ & $\begin{array}{l}\text { MNI- } \\
\text { Koordinaten } \\
\text { (t-Wert) } \\
\end{array}$ & $\begin{array}{l}\text { MNI- } \\
\text { Koordinaten } \\
\text { (t-Wert) } \\
\end{array}$ & $\begin{array}{l}\text { MNI- } \\
\text { Koordinaten } \\
\text { (t-Wert) }\end{array}$ & $\begin{array}{l}\text { MNI- } \\
\text { Koordinaten } \\
\text { (t-Wert) } \\
\end{array}$ & $\begin{array}{l}\text { MNI- } \\
\text { Koordinaten } \\
\text { (t-Wert) }\end{array}$ \\
\hline L/R VMPFC & $\begin{array}{l}033-12 \\
(-4,33)\end{array}$ & n.s. & $\begin{array}{l}030-12 \\
(-3,33)^{2}\end{array}$ & $\begin{array}{l}024-9 \\
(-5,04)^{1}\end{array}$ & n.s. & $\begin{array}{l}-324-9 \\
(-4,94)^{1}\end{array}$ \\
\hline
\end{tabular}

Aktivierungen sind mit $\mathrm{p}<0,05$, korrigiert für kleine Volumina, dargestellt, wenn nicht anderweitig beschrieben.

${ }^{1}$ Aktivierungen sind mit $\mathrm{p}<0,001$, unkorrigiert, mit einer minimalen Clustergröße von 10 Voxel.

${ }^{2}$ Aktivierungen sind mit $\mathrm{p}<0,005$, unkorrigiert dargestellt. 


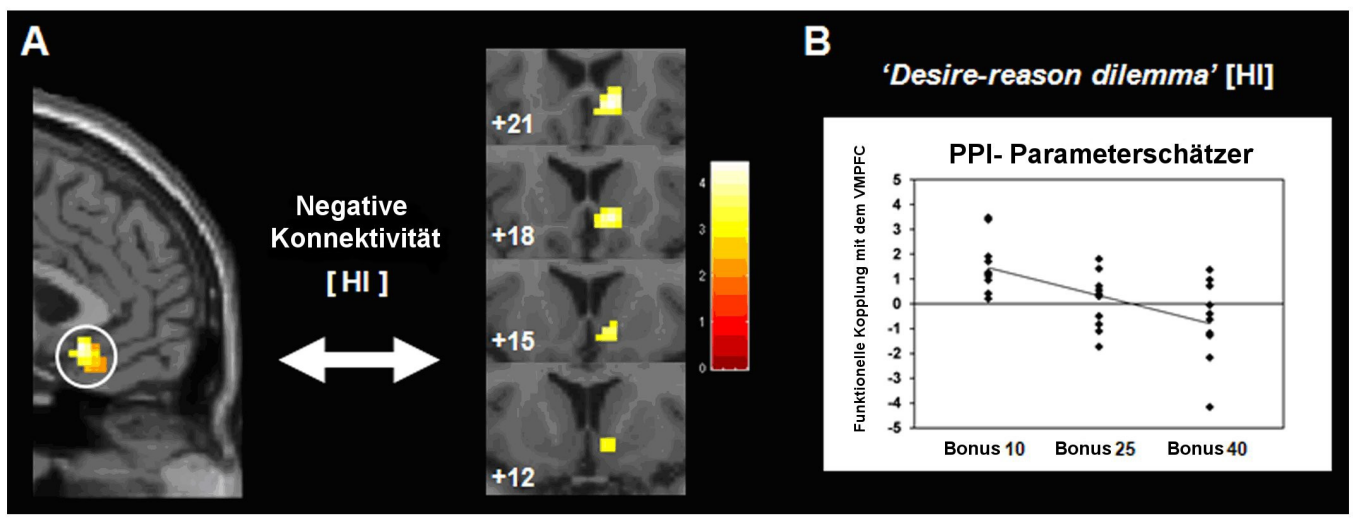

Abbildung 6: Wertigkeitsabhängige Zunahme der inversen funktionellen Interaktion zwischen dem VMPFC und dem rechten ventralen Striatum mit zunehmender Wertigkeit der vorangegangenen Belohnungsoption während des Desire- Reason-

\section{Dilemmas in der HI- Gruppe}

(A) Parametrische Zunahme der inversen Konnektivität zwischen dem VMPFC und dem ventralen Striatum mit zunehmender Wertigkeit der Belohnungspoption während der Zielverfolgung (siehe auch Tabelle 7). (B) Kontrastwerte der PPI- Parameter des ventralen Striatums in der HI- Gruppe (Vergleich der einzelnen Wertigkeiten der Belohnungsoption in der Bonusrunde versus während der Zielverfolgung). Die Parameterschätzer für die Stärke der funktionellen Interaktion zwischen dem VMPFC und dem ventralen Striatum zeigten während der Zielverfolgung eine signifikante Abnahme mit zunehmender Wertigkeit der Belohnungsoption.

Um des Weiteren zu überprüfen, ob diese wertigkeitssensitive Downregulation der ventromedialen frontalen Aktivierung während des Dilemmas mit Veränderungen der funktionellen Konnektivität in anderen Hirnregionen des Belohnungssystems oder in höheren präfrontalen Regionen, wie es Hare et al. (2009) suggerieren, einherging, wurde die funktionelle Konnektivität des VMPFC untersucht. Es wurde beobachtet, dass der VMPFC eine zunehmende inverse funktionelle Interaktion mit nur einer Hirnregion aufwies, die den Nacc und den benachbarten ventromedialen Nucleus caudatus umfasste (Tabelle 7 und Abb. 6A). Diese Ergebnisse konnten allerdings erneut nur für die HI- Gruppe gezeigt werden. Im weiteren Verlauf dieser Arbeit wird diese Hirnregion als ventrales Striatum bezeichnet. Durch eine Auswertung der Parameterschätzer einzelner Regressorwerte aus der PPI- Analyse konnte gezeigt werden, dass sich in der Gruppe der HI- Probanden, jedoch nicht bei den LOStudienteilnehmern, die Stärke der funktionellen Kopplung mit der Wertigkeit der unmittelbar zur Verfügung stehenden, aber abzulehnenden Belohnung staffelte (Abb. 6B). Dies deutet darauf hin, dass die funktionellen Interaktionen zwischen dem VMPFC und dem ventralen 
Striatum eine zentrale Rolle spielen dürften, wenn hoch- impulsive Probanden ihren Wunsch nach Boni zunehmender Wertigkeit erfolgreich kontrollierten.

Tabelle 7: Parametrischer Anstieg der inversen Konnektivität zwischen dem VMPFC und dem rechten ventralen Striatum in der Gruppe der HI- Probanden während des Desire- Reason- Dilemmas

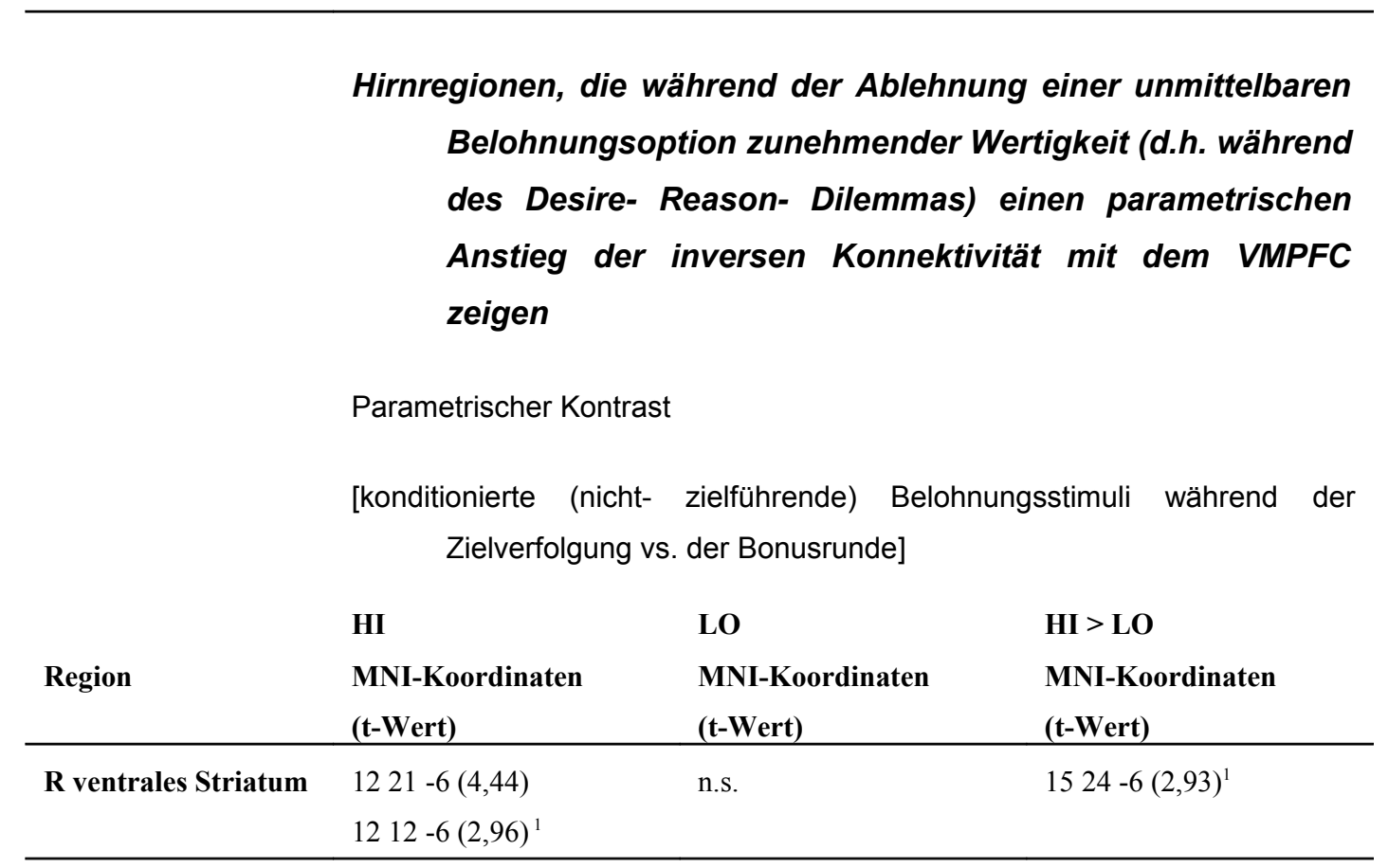

Aktivierungen sind mit $\mathrm{p}<0,001$, unkorrigiert dargestellt, mit einer minimalen Clustergröße von 10 Voxels, wenn nicht anderweitig beschrieben. ${ }^{1}$ Aktivierungen sind mit $\mathrm{p}<0,005$, unkorrigiert dargestellt.

Der Vollständigkeit halber sind in der Tabelle 8 die Hirnregionen dargestellt, in denen positive Aktivierungen mit zunehmender Wertigkeit der unmittelbaren Belohnung entweder in der Bonusrunde oder während der Zielverfolgung gemessen wurden. Die Auswertung der Daten ergab, dass beide Gruppen, also sowohl die HI- als auch die LO-Probanden, in der Bonusrunde einen ähnlichen Anstieg der Hirnaktivierung mit zunehmender Wertigkeit der Belohnungsoption im rechten parietalen Kortex und im rechten mittleren frontalen Gyrus zeigten (Tabelle 8A). Alle übrigen Hirnregionen wurden ausschließlich in der HI- Gruppe entweder in der Bonusrunde (Tabelle 8A) oder während der Zielverfolgung (Tabelle 8B) aktiviert. Ausgenommen davon ist ein kleines Areal im rechten inferioren frontalen Sulkus 
(IFS), welches in der HI- Gruppe in beiden Kontexten mit zunehmender Wertigkeit der Belohnungsoption aktiviert wurde (Tabelle 8C).

Tabelle 8: Hirnregionen, die in der Bonusrunde und/ oder während der Zielverfolgung einen parametrischen Anstieg der Hirnaktivierung mit zunehmender Wertigkeit der Belohnungsoption zeigten

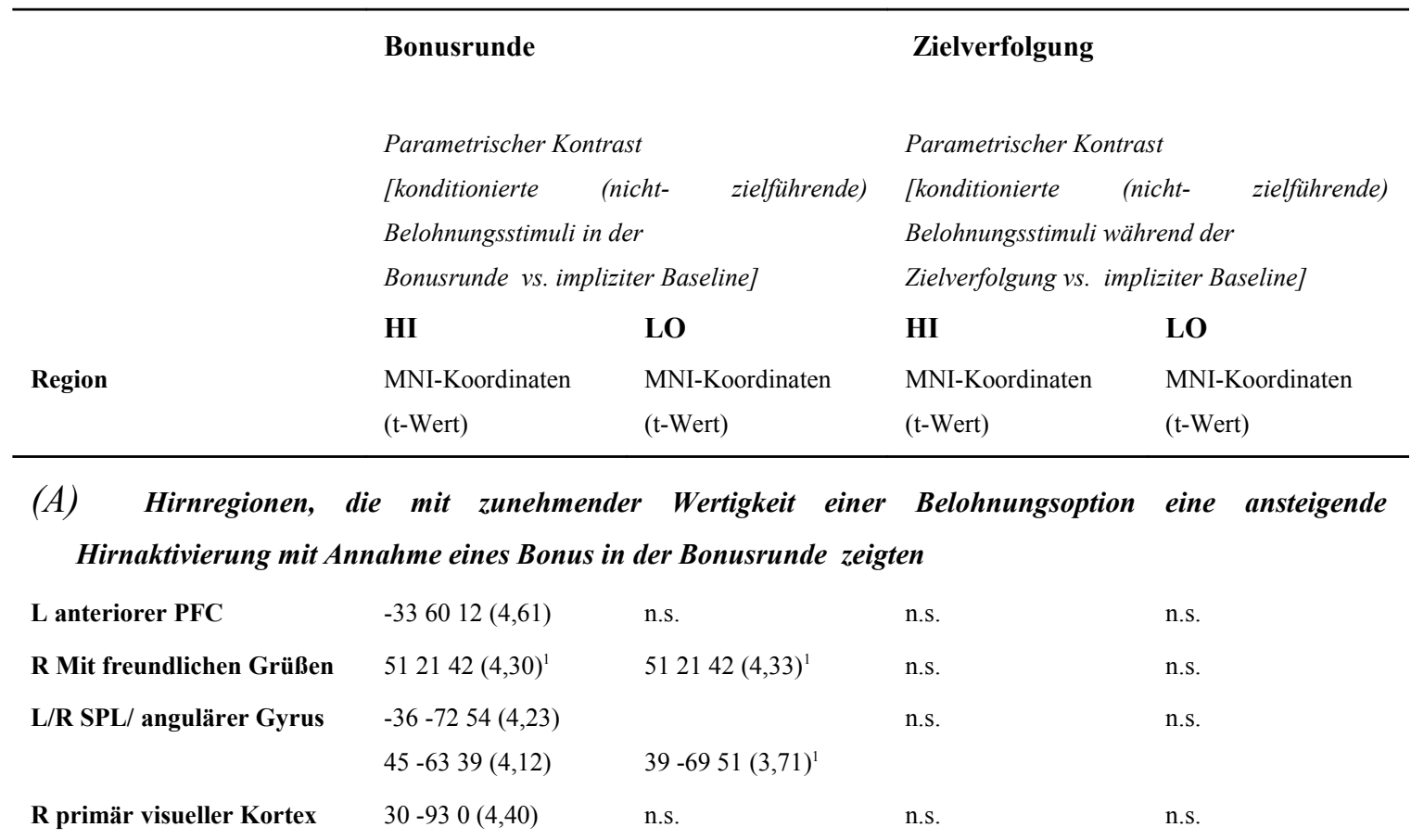

(B) Hirnregionen, die die mit zunehmender Wertigkeit einer Belohnungsoption eine ansteigende Hirnaktivierung mit Ablehnung eines Bonus während der Zielverfolgung zeigten

$\begin{array}{llllr}\text { L IFS } & \text { n.s. } & \text { n.s. } & -513615(4,76)^{1} & \text { n.s. } \\ \text { L Insel } & \text { n.s. } & \text { n.s. } & -391215(5,36)^{1} & \\ \text { L/R postcentraler Kortex } & \text { n.s. } & \text { n.s. } & -45-3348(6,63) & \text { n.s. }\end{array}$

(C) Hirnregionen, die in beiden Kontexten mit zunehmender Wertigkeit einer Belohnungsoption eine ansteigende Hirnaktivierung zeigten
R IFS
$363918(4,21)$
n.s.
$423621(4,47)$
n.s.

Aktivierungen sind mit $\mathrm{p}<0,001$, unkorrigiert, dargestellt mit einer minimalen Clustergröße von 10 Voxel, wenn nicht anderweitig. 


\section{$4 \quad$ Diskussion}

In dieser Studie wurde mittels des funktionellen MRTs der Zusammenhang zwischen der Impulsivität und den neuronalen Mechanismen der Fähigkeit untersucht, den Wunsch nach einer unmittelbaren Belohnung zu kontrollieren.

\subsection{Hauptbefunde}

Die vorliegende Studie hat gezeigt, dass gesunde, nicht- klinische Individuen, die sich selbst mittels der Barratt- Impulsivitätsskala als hoch- impulsiv charakterisiert haben, ihr Verlangen nach einer direkten Belohnung erfolgreich durch Aktivierung zweier komplementärer Hirnmechanismen kontrollieren können. Als erstes zeigte sich, dass Entscheidungen, die sich gegen eine unmittelbare Belohnung richteten, zu einer generellen Abschwächung der belohnungsabhängigen neuronalen Aktivierung in mesolimbischen Strukturen des Belohnungssystems führten (Tabelle 3). In Replikation $\mathrm{zu}$ den Ergebnissen der Vorgängerstudie von Diekhof \& Gruber (2010) ging die Abschwächung dieser Aktivierung mit einer inversen funktionellen Interaktion (d.h. mit einer Abnahme der positiven funktionellen Konnektivität im Vergleich zur impliziten Baseline) zwischen dem anteroventralen präfrontalen Kortex (avPFC) und dem rechten Nucleus accumbens (Nacc) einher (Abb. 4C, D). Zweitens wurde beobachtet, dass die hoch- impulsiven Probanden eine lineare Abschwächung der Aktivierung im ventromedialen präfrontalen Kortex (VMPFC) in Abhängigkeit von der Wertigkeit der unmittelbaren Belohnung aufwiesen, wenn sie während der Zielverfolgung eine unmittelbare Belohnung zunehmender Wertigkeit ablehnen mussten, um das übergeordnete Ziel $\mathrm{zu}$ erreichen (Abb. 5, Tabelle 6). Diese Devaluation der vorausgegangenen Belohnungsoption führte zu Änderungen der funktionellen Konnektivität zwischen dem VMPFC und dem rechten ventralen Striatum (i.e.S. dem Nacc und dem benachbarten ventromedialen Nucleus caudatus) (Abb. 6). Es ist denkbar, dass durch diesen neuronalen Kreislauf das Verlangen nach einer bedeutenden, aber suboptimalen unmittelbar zur Verfügung stehenden Belohnung reguliert wird.

Von noch größerer Bedeutung ist jedoch die Beobachtung, dass sich die neuronalen Mechanismen der Gruppe der hoch- impulsiven Probanden qualitativ von den Probanden unterschieden, die sich selbst anhand der BIS- 11 als extrem- kontrollierte Menschen klassifiziert haben. Insbesondere die extrem- kontrollierten Probanden haben keine inverse 
funktionelle Konnektivität zwischen dem Nacc und dem avPFC während des Desire- ReasonDilemmas gezeigt. In der LO- Gruppe konnte des Weiteren keine parametrische Downregulation der ventromedialen frontalen Aktivierung als Antwort auf die vorangegangene Belohnung unterschiedlicher Wertigkeit beobachtet werden (Tabelle 6). Auch konnte keine kontext- oder wertigkeitssensitive Veränderung der funktionellen Interaktion mit dem ventralen Striatum nachgewiesen werden (Tabelle 7). Diese Ergebnisse stützen die Annahme, dass nicht- klinische Probanden, die in ihren Persönlichkeitseigenschaften die beiden Extreme der Impulsivität widerspiegeln, qualitativ unterschiedliche neuronale Mechanismen rekrutieren können. In Situationen, die Selbstkontrolle erfordern, könnten die Ergebnisse dieser Studie unterschiedliche kognitive Strategien reflektieren.

\subsection{Ein neuartiges Studiendesign zur Messung der Impulsivität}

Das Ziel der vorliegenden Studie war es, den Zusammenhang zwischen der Impulsivität als Persönlichkeitseigenschaft und den neuronalen Mechanismen der Fähigkeit der Selbstkontrolle weiter zu erklären. Dafür habe ich gezielt untersucht, welche neuronalen Prozesse es nicht- klinischen, hoch- impulsiven Personen (HI- Probanden) ermöglichen, ihr Verhalten erfolgreich von wunschorientierten Belohnungsoptionen zu entkoppeln, um ein höherwertiges und langfristiges Ziel zu erreichen. Im MRT hatten die Studienteilnehmer eine modifizierte Version der sequentiellen Forced-Choice- Aufgabe aus der Vorgängerstudie von Diekhof \& Gruber (2010) zu bearbeiten.

Durch die multidimensionale Natur der Impulsivität wird nicht nur die Etablierung einer allgemeinen Definition der Impulsivität erschwert, sondern auch ihre Messung. Es existiert eine Vielzahl von Messmethoden, um Aspekte der Impulsivität messen zu können. Es wird vorrangig zwischen psychometrischen und neuropsychologischen Methoden unterschieden. Mithilfe neuropsychologischer Messverfahren kann sowohl der Einfluss der Impulsivität auf das Verhalten (motorische Impulsivität) als auch auf die Entscheidungsfindung (kognitive Impulsivität) gemessen werden. Zwei gängige Verfahren sind das Go-/ No- Go- Paradigma und das Delay- Discounting- Paradigma. In der vorliegenden Studie wurde ein neuartiges Studiendesign zur Erfassung der Impulsivität verwendet, das nicht strikt dem Go-/ No- Gooder Delay-Discounting- Paradigma zuzuordnen ist. Es wurde vielmehr eine Zwischenform dieser beiden Messverfahren gewählt, um in der vorliegenden Studie eine Art 
Belohnungsimpulsivität mit motorischer Komponente zu objektivieren. Zur Messung der motorischen Komponente der Impulsivität hatten die Probanden gemäß einer typischen Go-/ No- Go- Aufgabe immer dann eine Antwort zu geben, wenn sie durch Anzeigen eines GoSignals dazu aufgefordert wurden. Im vorliegenden Experiment sollten die Probanden immer dann eine bestimmte Taste drücken, wenn ihnen ein farbiges Quadrat auf dem Bildschirm präsentiert wurde und sich so für oder gegen die Annahme eines unmittelbaren Bonus im Kontext des jeweiligen Aufgabentyps entscheiden. Ein entsprechendes No- Go- Signal, das die Unterdrückung einer präpotenten Antwort erforderte, wurde den Probanden in der vorliegenden Studie nicht präsentiert. Die Unterdrückung einer präpotenten motorischen Antwort auf die visuell präsentierten Belohnungsstimuli war vielmehr durch die Verhaltensregeln, insbesondere während der Zielverfolgung vorgegeben. Die Studienteilnehmer sollten während der Zielverfolgung alle zielrelevanten Farben annehmen und alle nicht- zielrelevanten Farben ablehnen. Dies galt auch für nicht-zielrelevante Farben mit einer direkten Belohnungsassoziation. Dies führte zu einem Desire-Reason-Dilemma, in dem das Verlangen, die potentielle direkte Belohnung anzunehmen, mit dem Erreichen der übergeordneten Zielsetzung konkurrierte.

Zur Erfassung der Belohnungsimpulsivität wurden in das Studiendesign der vorliegenden Arbeit wesentliche Aspekte des Delay-Discounting- Paradigmas integriert. Im Rahmen der intertemporalen Entscheidungsfindung sollte im vorliegenden Experiment eine Wahl zwischen Belohnungsoptionen getroffen werden, die zu unterschiedlichen Zeitpunkten auftraten. Die Entscheidung der Probanden über die Annahme oder Ablehnung einer direkt belohnten Farbe in der Bonusrunde war frei. Während der Zielverfolgung hingegen waren die Probanden angehalten, ihre Tendenz zu überwinden, eine direkt belohnte Farbe anzunehmen, da dies der übergeordneten Zielsetzung widersprach (diese Bedingung erzeugte ein DesireReason-Dilemma, siehe Diekhof \& Gruber, 2010). Die kurzen Blöcke bestanden aus jeweils 4 aufeinander folgenden Quadraten bis zum Erreichen des Ziels, lange Blöcke enthielten 7 aufeinander folgende Quadrate. Nach Ainslie (1975) wird impulsives Verhalten dadurch erklärt, dass eine unmittelbare Belohnung ihre Attraktivität im Laufe der Zeit verliert. In der vorliegenden Studie spielte der Zeitfaktor gegenüber der zunehmenden Wertigkeit der unmittelbaren Belohnung eine eher untergeordnete Rolle. Die Probanden entschieden sich vielmehr in Abhängigkeit von der Höhe der unmittelbar zur Verfügung stehenden Belohnung für oder gegen die Annahme eines Bonus, weniger in Abhängigkeit von der Zeit bis zum Erreichen des Endes eines Blocks. 


\subsection{Gesunde, hoch- impulsive Probanden können ihren generellen Wunsch nach einer unmittelbaren Belohnung durch einen persönlichkeitsspezifischen neuronalen}

Mechanismus kontrollieren

Der wesentliche Unterschied zwischen Personen mit einer hohen oder niedrigen Impulsivität ist die Fähigkeit zur Selbstkontrolle. Unter Selbstkontrolle versteht man im Kontext dieser Arbeit die Fähigkeit, höherwertige Ziele zu erreichen trotz wiederholter Beeinflussung durch direkt verfügbare Belohnungen (Patton et al., 1995; Evenden, 1999). In zahlreichen Studien konnte gezeigt werden, dass ein Mangel an Selbstkontrolle mit Auffälligkeiten in der frontostriatalen Konnektivität (Sonuga- Barke, 2002; Jentsch and Taylor, 1999; Hare et al., 2009; Diekhof \& Gruber, 2010), mit Veränderungen in der dopaminergen Autoregulation und der belohnungsabhängigen Aktivierung in mesolimbischen Strukturen (Abler et al., 2006; Hariri et al., 2006; Zald et al., 2008; Buckholtz et al., 2010; siehe auch Marinelli \& White, 2000), sowie mit strukturellen Änderungen im VMPFC (Matsuo et al., 2008) assoziiert ist.

In der vorliegenden Studie haben die beiden extremen Gruppen unterschiedlicher Impulsivität keine Verhaltensunterschiede gezeigt, ihr Verlangen nach einer unmittelbaren Belohnung zu kontrollieren (siehe Ergebnisse der Verhaltensdaten). Dies deutet darauf hin, dass nichtklinische, hoch- impulsive Probanden in der Lage sind, ihren Mangel an Selbstkontrolle zu kompensieren und so das in dieser Studie erzeugte Desire-Reason-Dilemma erfolgreich zu lösen. In Anbetracht der Verhaltensdaten lässt sich daraus schließen, dass signifikante Gruppendifferenzen in der funktionellen Hirnaktivierung und der neuronalen Konnektivität während der erfolgreichen Bewältigung des Dilemmas persönlichkeitsspezifische und kompensatorische Hirnmechanismen widerspiegeln könnten. In klinischen Populationen wurde beobachtet, dass eine Kompensation krankheitsspezifischer Defizite oft mit einer zunehmenden Rekrutierung funktionsrelevanter Hirnregionen verbunden ist (Manoach, 2003). In Übereinstimmung mit dieser Hypothese konnte in der vorliegenden Studie in der nichtklinischen Gruppe der hoch- impulsiven Probanden eine stärkere funktionelle inverse Kopplung zwischen dem avPFC und dem Nacc beobachtet werden als in der extremkontrollierten Stichprobe (Tabelle 5 und Abb. 4B). Bei den HI- Studienteilnehmern ging diese inverse Konnektivität mit einer erfolgreichen Downregulation der belohnungsabhängigen Aktivierung im Nacc einher (Tabelle 3 und Abb. 4A). Im Einklang mit vorherigen Evidenzen, einschließlich der Studie von Diekhof \& Gruber (2010) unterstreichen diese Ergebnisse die Auffassung, dass der avPFC in Zusammenhang mit der erfolgreichen Umsetzung von Flexibilität im menschlichen Verhalten gesehen werden kann, welche es den Menschen 
ermöglicht, Entscheidungen ohne Beeinflussung einer direkt zur Verfügung stehenden Belohnung zu treffen (Daw et al., 2006; Boorman et al., 2009; Diekhof \& Gruber, 2010).

Die vorliegende Studie weist jedoch auch einige ersichtliche Unterschiede zu den Ergebnissen der vorherigen Studie (Diekhof \& Gruber, 2010) auf, die im Weiteren näher beschrieben werden sollen: Im vorliegenden Experiment wurde zum einen der rechte Nacc im Gegensatz zu den Beobachtungen aus der Vorgängerstudie von Diekhof \& Gruber (2010) in beiden Gruppen und Kontexten deaktiviert. Nur in der Gruppe der hoch- impulsiven Probanden führte das Dilemma zu einer weiteren signifikanten Downregulation einer ohnehin schon negativen Signaländerung (Abb. 4B). Zum anderen zeigte die vorliegende Studie die inverse präfrontostriatale Kopplung während des Dilemmas nur in der Gruppe der HIStudienteilnehmer (Tabelle 4), die vor allem in der Entscheidungsaufgabe eine normale Verhaltensleistung erbrachten. Letztendlich ist die beobachtete inverse funktionelle Konnektivität eher als das Ergebnis einer verringerten positiven Kopplung als eines Anstiegs der negativen funktionellen Konnektivität zwischen den beiden Hirnregionen aus der vorherigen Studie (Diekhof \& Gruber, 2010) zu interpretieren. In der vorliegenden Studie könnten die Modifikationen, die im Vergleich zur Vorgängerstudie in der sequentiellen Zielverfolgungsaufgabe vorgenommen wurden, für die oben genannten Diskrepanzen verantwortlich sein. Denn die modifizierte Version der sequentiellen Zielverfolgungsaufgabe erforderte eine geringere Leistung der Studienteilnehmer als die ursprüngliche Version, die in der Studie von Diekhof \& Gruber (2010) verwendet wurde. In der modifizierten Aufgabe sollten die Probanden in einem Durchgang von jeweils 10 aufeinander folgenden Blöcken die gleichen Entscheidungsregeln anwenden. Während der Zielverfolgung sollten die Studienteilnehmer alle konditionierten, nicht- zielrelevanten Belohnungsstimuli ablehnen, in der Bonusrunde hingegen konnten alle Bonusstimuli zusätzlich eingesammelt werden, um am Ende eines Blocks einen Bonus von 50 Punkten zu erhalten. Diese klar definierten Verhaltensregeln waren vermutlich der Grund dafür, dass in der vorliegenden Studie gerade hoch- impulsive Probanden eine normale Verhaltensleistung zeigten, wenn sie dem Dilemma ausgesetzt waren. In der ursprünglichen Version der Zielverfolgungsaufgabe aus der Vorgängerstudie von Diekhof \& Gruber (2010) hingegen konnten die Desire- und DilemmaTrials in ein und demselben Block auftreten. Im Falle einer wiederholten Präsentation der konditionierten Belohnungstargets während eines Blocks mussten diese von den Probanden abgelehnt werden (für nähere Details zum Studiendesign siehe Diekhof \& Gruber, 2010). Diese Vorgabe machte es den Probanden erheblich schwerer, die korrekte Handlung auf die 
konditionierten Belohnungsstimuli auszuführen. Die veränderte Aufgabenstellung wäre auch eine Erklärung für die Tatsache, warum die Aktivierung des avPFC in der Vorgängerstudie fehlte und die impulsiven Probanden eine schlechtere Verhaltensleistung erbrachten (Diekhof \& Gruber, 2010).

In diesem Sinne stimmen die Ergebnisse der vorliegenden Studie mit der Auffassung überein, dass eine Kompensation nur dann möglich ist, wenn die Anforderungen der Aufgabe und die Leistung der Probanden aufeinander abgestimmt sind. Übersteigen die Anforderungen der Aufgabe die Leistung der Probanden, wie es möglicherweise in der Vorgängerstudie in der Gruppe der HI- Probanden der Fall war, ist es denkbar, dass relevante Hirnregionen nicht aktiviert werden und daraus ein Abfall der Verhaltensleistung resultiert (Manoach, 2003; Jansma et al., 2004). Insgesamt lässt sich sagen, dass die diskrepanten Ergebnisse der vorliegenden Studie im Vergleich zur Vorgängerstudie von Diekhof \& Gruber (2010) am ehesten als Konsequenz auf die Anwendung einer unterschiedlichen Aufgabenstellung interpretiert werden sollten und weniger als die Repräsentation echter Inkonsistenzen.

Es wäre jedoch auch denkbar, dass in der vorliegenden Studie während der Präsentation der aufeinander folgenden Blöcke mit gleichen Verhaltensregeln gleichzeitig weitere funktionelle neuronale Strukturen beeinflusst worden sind, die dafür benötigt werden, das immer wieder auftretende Dilemma zu bewältigen. Es gibt bereits eine erste Evidenz dafür, dass menschliche Verhaltensänderungen, die auch tatsächlich in die Praxis umgesetzt werden, mit einer funktionellen Reorganisation der Hirnaktivität in aufgabenrelevanten Regionen einhergehen (Kelly \& Garavan, 2005). Diese Reorganisation könnte Änderungen kompensatorischer kognitiver Hirnmechanismen widerspiegeln. Solch eine funktionelle Reorganisation könnte insbesondere die Höhe der interregionalen Konnektivität verändern, beispielsweise durch Verstärkung inhibitorischer Verbindungen (Fletcher et al., 1999). Aber auch eine Verstärkung der neuronalen Antwort aufgabenrelevanter Hirnregionen im Netzwerk wäre denkbar (Poldrack, 2000). Bezogen auf die Ergebnisse der vorliegenden Studie lässt sich vermuten, dass insbesondere die hoch- impulsiven Probanden durchgehend eine negative Konnektivität (i.e.S. eine Abnahme der positiven funktionellen Konnektivität im Vergleich zur impliziten Baseline) zwischen dem avPFC und dem Nacc während des Experiments aufrecht erhalten haben könnten, um die Anforderungen des Experiments durch selbstkontrolliertes Verhalten zu bewältigen. Diese aufrechterhaltene Verbindung könnte die belohnungsabhängige Aktivität mesolimbischer Strukturen im gesamten Experiment kontrolliert haben. Eine Aufhebung dieser zunehmenden Kontrolle der mesolimbischen Aktivität wäre demnach nur für die Annahme einzelner Bonustrials in der Bonusrunde 
notwendig. Dieser Ansatz wäre eine mögliche Erklärung für die relative Abnahme der negativen funktionellen Konnektivität, die sich als eine relative Zunahme der positiven Konnektivität im Vergleich zur impliziten Baseline gezeigt hat (Tabelle 4). Auf diese Weise könnte auch erklärt werden, warum zum einen der Nacc im Verlauf des gesamten Experiments deaktiviert wurde (Abb. 4B) und zum anderen warum die beobachtete inverse funktionelle Konnektivität während des Dilemmas in der Gruppe der hoch- impulsiven Probanden sogar eine verringerte positive Verbindung zwischen dem avPFC und dem Nacc widerspiegelte (Tabelle 4, Abb. 4B). Da es im vorliegenden Experiment keine Low- LevelKontrollbedingung gab (wie sie sonst in gemischten Studiendesigns verwendet wird, siehe zum Beispiel Visscher et al., 2003), war es in diesem Experiment nicht möglich, die Hypothese einer anhaltenden negativen präfrontostriatalen Verbindung in der Bonusrunde und während der Zielverfolgung in der Gruppe der HI- Probanden unmittelbar zu testen. Aufgrund der oben beschriebenen Beobachtungen in dieser Gruppe scheint es dennoch plausibel, diese Möglichkeit in einer nachfolgenden Studie umzusetzen.

\subsection{Hoch- impulsive Probanden können ihr Verlangen nach einer Belohnung} zunehmender Wertigkeit durch einen persönlichkeitsspezifischen Mechanismus kontrollieren

Die Auswertung der Daten der vorliegenden Studie führte zu dem Ergebnis, dass sich die neuronale Antwort im VMPFC in der Gruppe der Probanden, die in der BIS- 11 eine hohe Punktzahl erreicht haben, parametrisch mit der Wertigkeit der angenommenen unmittelbaren Belohnung veränderte (Tabelle 6, Abb. 5). Dieses Ergebnis bestätigt vorige Evidenzen, die belegen, dass der VMPFC eine generelle Rolle in der Bewertung der relativen Wertigkeit einer Belohnung spielt, insbesondere dann, wenn eine Entscheidung zwischen verschiedenen Belohnungsoptionen getroffen werden muss (McClure et al., 2004, 2007; Grabenhorst et al., 2008; Hare et al., 2008; Plassmann et al., 2008; Kable \& Glimcher, 2007; Boorman et al., 2009; DeMartino et al., 2009; Smith et al., 2010). In Studien mit nicht- klinischen Populationen wurde eine ähnliche Downregulation der ventromedialen frontalen Aktivität unter erfolgreicher Selbstkontrolle beobachtet (Campbell- Meiklejohn et al., 2008; Hare et al., 2009). Daten neurophysiologischer Studien belegen, dass der ventromediale präfrontale Kortex als Belohnungsprädiktor eine zunehmende neuronale Aktivierung aufweist (Hariri et al., 2006; Hahn et al., 2009). Eine aktuelle Studie von Hare et al. (2009) belegt, dass auf 
ähnliche Weise die Ablehnung eines beliebten, aber ungesunden Nahrungsmittels zu einer Downregulation der Aktivierung im VMPFC führt. Hare et al. (2009) haben dabei in einer fMRT- Studie untersucht, welche neuronalen Mechanismen selbstkontrolliertes Verhalten ermöglichen und wie diese Prozesse mit Hirnregionen des Belohnungssystems und der Entscheidungsfindung interagieren. Es wurden streng diäthaltende Menschen untersucht, die fünfzig Nahrungsmittel nach Geschmack und Nährwert bewerten sollten. Für jeden Probanden wurde ein Referenznahrungsmittel ausgewählt, welches neutral in Bezug auf den Geschmack und Nährwert war. Aufgabe der Probanden war es, eine Auswahl zwischen dem Referenznahrungsmittel und einem anderen Nahrungsmittel zu treffen und die Stärke ihrer Entscheidung durch eine der folgenden Angaben zu machen: Starkes Ja, Ja, Neutral, Nein, Starkes Nein. Es wurde angenommen, dass streng diäthaltende Menschen den Wert eines Nahrungsmittels anhand des Geschmacks und Nährwerts berechnen und integrieren. Anhand ihrer Entscheidungen wurden die Versuchspersonen in eine „selbstkontrollierende“ Gruppe (> $50 \%$ Ablehnung von leckeren ungesunden Nahrungsmitteln) und eine „nichtselbstkontrollierende“ Gruppe (> 50 \% Auswahl von leckeren ungesunden Nahrungsmitteln) klassifiziert. Für die Berechnung der Entscheidung waren von Bedeutung: Goal Values (GVs), Decision Values (DVs) und Prediction Errors (PEs). GVs waren die Zielwerte, die den prädizierten Wert einer Belohnung angaben. Unter den $D V S$ waren Entscheidungswerte zu verstehen, die für die Kosten- Nutzen- Abwägung notwendig sind. Die PEs beschrieben die Abweichung im erwarteten Wert. Hare et al. (2009) haben festgestellt, dass GVS zu einer Aktivierung im VMPFC führten. Eine Aktivierung des linken dorsolateralen präfrontalen Kortex (DLPFC) erfolgte bei erfolgreicher Selbstkontrolle in beiden Gruppen. In der „selbstkontrollierenden“ Gruppe korrelierte die neuronale Aktivität im VMPFC bei leckerem, aber ungesundem Essen mit der Aktivierung im DLPFC. Diese Ergebnisse stützen die Annahme, dass der VMPFC Teil des Bewertungssystems ist, das mithilfe spezifischer Teilkomponenten die Höhe und Verzögerung einer Belohnung integriert. Der VMPFC nimmt eine entscheidende Rolle beim Berechnen von Zielwerten ein. Kontrollareale wie der DLPFC werden erst bei schwierigen Entscheidungen, beispielsweise bei der Verzögerung einer Belohnung aktiviert und scheinen direkten Einfluss auf die neuronalen Strukturen zu nehmen, die für die Bewertung einer Belohnung notwendig sind.

Small et al. (2001) konnten zeigen, dass die Kontrolle des Verlangens nach bestimmten Speisen zu einer sinnesspezifischen Sättigung im Gehirn führte. Auf ähnliche Weise führte die Abwertung von Speisen mit wenigen Kalorien hinsichtlich Speisen hoher Kalorien im hungrigen Zustand zu einer signifikanten Abnahme der Aktivität im VMPFC (Goldstone et 
al., 2009). In Tierversuchen wurde eine fehlangepasste Bewertung der Wertigkeit konditionierter Stimuli, die nicht nur auf eine unmittelbare Belohnung ausgerichtet war, als ein definiertes Merkmal der Impulsivität beschrieben (Flagel et al., 2009). Deshalb scheint es plausibel anzunehmen, dass die Downregulation im VMPFC entscheidend für die Kompensation dieser fehlangepassten Eigenschaft bei hoch- impulsiven Probanden ist. Die Gruppe der HI- Probanden war vermutlich durch die wertigkeitssensitive Downregulation der ventromedialen frontalen Aktivität dazu in der Lage, notwendige Verhaltensänderungen in die Praxis umzusetzen, da so ihre neuronale Fähigkeit unterstützt wurde, ihr Verhalten von einer möglichen Belohnung zu entkoppeln.

In der Bonusrunde konnte in der Gruppe der hoch- impulsiven Probanden ein relativer, wenn auch nicht signifikanter Anstieg des ventromedialen frontalen Signals verzeichnet werden. Dieser Anstieg konnte mit zunehmender Wertigkeit der unmittelbaren Belohnung beobachtet werden und könnte die erfolgreiche Annahme der Belohnungsoptionen unterstützt haben (Abb. 4B). Diese Ergebnisse erhärten somit die Annahme, dass der VMPFC eher die relative als die absolute Wertigkeit einer gewählten Belohnungsoption kodiert (Daw et al., 2006; Boorman et al., 2009) und so die relative Abwertung einer unmittelbaren Belohnungsoption während der Zielverfolgung sowie die relative Zunahme der Wertigkeit der Belohnungsoptionen in der Bonusrunde repräsentiert.

Weiter lässt sich spekulieren, dass die beobachtete Abnahme der ventromedialen präfrontalen neuronalen Antwort während der Zielverfolgung eine relative Reduktion des erwarteten positiven Affekts reflektieren könnte (d.h. einen Misserfolg). Insbesondere für HI- Probanden sollte es sehr frustrierend sein, während der Zielverfolgung eine bedeutende unmittelbar zur Verfügung stehende Belohnung für das Erreichen eines höherwertigen, langfristigen Ziels ablehnen zu müssen. Diese Annahme ist kongruent mit Studiendaten, die die Regulation von Emotionen untersucht haben. Diese konnten nämlich zeigen, dass sich das Ausmaß der Deaktivierung des Signals im VMPFC mit der Höhe des gemessenen negativen Affekts staffelte (Delgado et al., 2008; Diekhof et al., 2011).

Die Daten der vorliegenden Studie demonstrieren darüber hinaus, dass die Fähigkeit, eine suboptimale Belohnungsoption abzuwerten, mit einer inversen funktionellen Kopplung zwischen dem VMPFC und dem ventralen Striatum (i.e.S dem ventralen Nucleus caudatus) einhergeht (Abb. 6, Tabelle 7). Solch eine funktionelle Beziehung steht in Übereinstimmung mit Daten aus vorigen fMRT- und Diffusionstensor- Magnetresonanz- Studien (Lehéricy et al., 2004; DiMartino et al., 2008; Draganski et al., 2008), aber auch mit Daten aus Tracer- 
Studien an nicht- menschlichen Primaten (Alexander \& Crutcher, 1990; Haber et al., 1995, 2000, 2006; Schilman et al., 2008; Haber \& Knutson, 2009). Die Daten dieser Studien haben feste anatomische Verbindungen zwischen den oben genannten Hirnregionen aufzeigen können. Die identifizierte Region im ventralen Striatum deckt sich mit dem Teil des ventralen Striatums, der Input vom VMPFC und dem anliegenden orbitofrontalen Kortex erhält (Haber \& Knutson, 2009). Die vorliegenden Daten zeigen erstmals, dass das Ausmaß der inversen präfrontostriatalen Kopplung in Abhängigkeit von der Wertigkeit der vorausgegangenen Belohnung zunimmt. Diese Tatsache ermöglicht es wahrscheinlich den hoch- impulsiven Probanden, ihr Verlangen nach einer suboptimalen zur Verfügung stehenden Belohnung während des Dilemmas zu kontrollieren. Diese Ergebnisse stehen im Einklang mit der Annahme, dass das ventrale Striatum eine essentielle Rolle in der Handlungskontrolle spielt, die auf eine Gewinnmaximierung ausgerichtet ist. In bisherigen Studien wurde eine zunehmende Aktivierung ähnlicher Teile des ventralen Striatums beobachtet, um StimulusHandlungs- Belohnungskontingenzen (Lauwereyns et al., 2002; Tricomi et al., 2004; Schlund \& Cataldo, 2005) und die Höhe einer Belohnung zu repräsentieren (Knutson et al., 2001b; Cromwell \& Schultz, 2003; Delgado et al., 2003; Knutson \& Cooper, 2005; Ballard \& Knudson, 2008). Insbesondere beim Menschen wurde eine regionale Aktivierung des ventromedialen Nucleus caudatus gefunden, die mit der Ablehnung einer möglichen Belohnung (Rogers et al., 2000; Cools et al., 2004; Watanabe K \& Hikosaka, 2005) und dem Erlernen neuer Stimulus- Antwort- Belohnungsassoziationen (O'Doherty et al., 2004; Delgado et al., 2005; Haruno \& Kawato, 2006) anstieg. In Tierstudien mit Ratten und nichtmenschlichen Primaten konnte gezeigt werden, dass Läsionen im ventralen und medialen Striatum, die mit der Region korrespondieren, die in der vorliegenden Studie identifiziert wurde, sowie Läsionen im VMPFC dazu führen, dass die Fähigkeit verloren geht, eine Antwort- Belohnungskontingenz zu unterbrechen (Li \& Shao, 1998; Ferry et al., 2000; Clarke et al., 2008). In Anbetracht dieser Untersuchungsergebnisse und der besonderen Rolle des Nucleus caudatus in der fokussierten Inhibition konkurrierender Handlungen (Mink, 1996; Redgrave et al., 1999; Jiang et al., 2003) lässt sich folgern, dass die in dieser Studie reziproke Interaktion mit dem VMPFC vermutlich für die Kontrolle eines fehlangepassten Verhaltensimpulses von entscheidender Bedeutung ist, eine Belohnung zunehmender Wertigkeit während der Zielverfolgung anzunehmen. Auf diese Weise könnten die vorliegenden Daten auch die Auffassung stützen, dass diese miteinander verbundenen Regionen suboptimale Belohnungskontingenzen modifizieren könnten, um es zu ermöglichen, 
wiederholt Handlungen zugunsten einer höheren, aber langfristigen Belohnung durchzuführen (O’Doherty et al., 2004).

\subsection{Extrem- kontrollierte Probanden können durch bestimmte neuronale}

\section{Mechanismen selbstkontrolliert handeln}

In der vorliegenden Studie zeichnete sich die Stichprobe der extrem- kontrollierten Probanden in den beiden Entscheidungsaufgaben vergleichsweise durch niedrige Veränderungen in der regionalen Hirnaktivität aus, insbesondere im Vergleich zur Gruppe der hoch- impulsiven Probanden (Tabelle 3, 6). Mögliche Erklärungen dafür könnten sein, dass es persönlichkeitsspezifische Differenzen in den individuellen neuronalen Verarbeitungsprozessen gibt oder aber voneinander abweichende Leistungsgrenzen, die für die Unterschiede zwischen dem impulsiven und kontrollierten Phänotyp verantwortlich sind. In Studien konnte bereits gezeigt werden, dass unterschiedliche Populationen (z.B. psychiatrische Patienten und gesunde Kontrollprobanden) trotz ähnlicher Ergebnisse in den Verhaltensdaten im Ausmaß ihrer neuronalen Aktivität in aufgabenrelevanten Regionen variieren können. Dabei geht eine höhere Verarbeitungskapazität häufig mit einer Abnahme der neuronalen Aktivität einher (Manoach et al., 2003; Jansma et al., 2004). Kontrollierte Probanden könnten sich demnach in ihrer neuronalen Leistungsfähigkeit von der Gruppe der hoch- impulsiven Probanden unterscheiden, mit deren Hilfe fundamentale kognitive Abläufe durchgeführt werden (Rypma \& Prabhakaran, 2009). Die Beobachtung, dass extremkontrollierte Probanden eine Downregulation der belohnungsabhängigen Aktivierung während des Desire-Reason-Dilemmas nur unter einer Absenkung der statistischen Schwelle auf $\mathrm{p}<0,05$, unkorrigiert (Tabelle 3) gezeigt haben und auch eine erwartete Änderung in der präfrontostriatalen Konnektivität (Tabelle 4) fehlte, spricht stark für diese Annahme. Alternativ könnten persönlichkeitsspezifische Differenzen auf diskrepante kognitive Strategien zurückzuführen sein oder auf Unterschiede in der Fähigkeit, eine einmal gewählte kognitive Strategie aufrecht zu erhalten (Miller MB et al., 2002). Denkbar wäre aber auch, dass nur eine unterschiedliche Sensitivität mesolimbischer Hirnregionen auf eine unmittelbare Belohnungsoption unterschiedlicher Wertigkeit reflektiert wird (Bodi et al., 2009). Die letztere Hypothese würde dabei mit Beobachtungen übereinstimmen, die Hare et al. (2009) gemacht haben. Sie haben festgestellt, dass Probanden mit einem starken Willen, ihr Essverhalten $\mathrm{zu}$ kontrollieren, keine wertigkeitssensitive ventromediale frontale Antwort 
zeigten, wenn ihnen verschiedene Lebensmittel unterschiedlichen Kaloriengehalts präsentiert wurden.

Zukünftige Studien sollten sich noch ausführlicher mit dem Phänotyp extrem- kontrollierter Probanden beschäftigen, welcher in bildgebenden Untersuchungen des zentralen Nervensystems bis jetzt weitestgehend vernachlässigt wurde. Dabei wird es sicherlich interessant sein, $\mathrm{zu}$ untersuchen, welche der oben genannten Gründe für die persönlichkeitsspezifischen Differenzen in Wirklichkeit verantwortlich sind. Aus den Daten der vorliegenden Studie kann man nur rückschließen, dass sich hoch- impulsive und extremkontrollierte Probanden qualitativ in ihren neuronalen Mechanismen unterscheiden, die sie zur Lösung des Desire- Reason-Dilemmas nutzen.

\subsection{Hoch- und niedrig- impulsive Probanden nutzen gemeinsame neuronale}

\section{Mechanismen zur Annahme oder Ablehnung einer Bonusoption}

Im Gegensatz zu den oben erwähnten Unterschieden zwischen den hoch- impulsiven und extrem- kontrollierten Probanden habe ich festgestellt, dass die Aktivität im rechten mittleren frontalen Gyrus (MFG) und im parietalen Kortex in beiden Gruppen während der Annahme eines Bonus parametrisch mit der Wertigkeit der unmittelbaren Belohnung anstieg (Tabelle 8A). In Anbetracht der vermuteten Rolle dieser Hirnregionen in höheren kognitiven Prozessen (d.h. in der Integration einer Wertigkeit) und in der mentalen Kalkulation (Gruber et al., 2001; Hoshi, 2006; van Eimeren et al., 2010; Kahnt et al., 2011) könnte man vermuten, dass der wertigkeitssensitive Anstieg der Aktivität in diesen Regionen höchst wahrscheinlich kognitive Abläufe während der Entscheidung für einen verfügbaren Bonus reflektiert. Dies lässt sich gut mit bisherigen Ergebnissen aus Studien an nicht- menschlichen Primaten vereinbaren, in denen der parietale Kortex dafür verantwortlich ist, spontane wertigkeitsorientierte Entscheidungen $\mathrm{zu}$ treffen (Platt \& Glimcher, 1999; Sugrue et al., 2004) und eine belohnungsabhängige Aufmerksamkeit aufrechtzuerhalten (Peck et al., 2009). Auf ähnliche Weise führen Ergebnisse aus Studien an menschlichen Probanden zu der Annahme, dass diese Hirnregionen generell bei langfristigen (McClure et al., 2004, 2005), multifaktoriellen (Zysset et al., 2006; Kahnt et al., 2011) und spontanen wertigkeitsorientierten Entscheidungen (Dorris \& Glimcher, 2004; Kable \& Glimcher, 2007) aktiviert werden.

Abschließend ist zu sagen, dass in dieser Studie im rechten inferioren frontalen Sulkus (IFS) eine Hirnregion identifiziert wurde, die die zunehmende Wertigkeit einer Belohnung in 
Abhängigkeit von der Aufgabenstellung regulierte. Dies gilt jedoch nur für die Gruppe der HI- Probanden (Tabelle 8B,C). Diese Tatsache lässt vermuten, dass diese Hirnregion eine komplementäre Rolle in der Präsentation der Wertigkeit einer Belohnung spielt. Eine Möglichkeit wäre, dass der IFS an der unwillkürlichen Suche nach oder der aktiven Aufrechterhaltung der Wertigkeit einzelner konditionierter Belohnungsstimuli mitwirkt. In Übereinstimmung mit Ergebnissen aus vorigen Studien wurde diese Hirnregion in einen Zusammenhang mit dem Arbeitsgedächtnis und der mentalen Kalkulation gebracht (Ungerleider, 1995; Goldman- Rakic, 1996; Gruber et al., 2001). Die Suche und Verfolgung der Wertigkeit einer Belohnungsoption war in der vorliegenden Studie jedoch nur während der Annahme eines Bonus in der Bonusrunde wichtig, während der Zielverfolgung hingegen war dieses Vorgehen eher unangepasst. Die Beobachtung, dass nur die hoch- impulsiven Probanden einen parametrischen Anstieg der neuronalen Aktivität dieser Hirnregion zeigten, könnte ein weiterer Indikator für ihre erhöhte Sensitivität für die Wertigkeit einer unmittelbaren Belohnung sein, die die hoch- impulsiven Probanden bevorzugt auf die konditionierten Stimuli richteten, als dies in der LO- Gruppe der Fall war.

Zusammengefasst lässt sich sagen, dass die Ergebnisse der vorliegenden Studie die Annahme unterstützen, dass nicht- klinische, hoch- impulsive Studenten persönlichkeitsspezifische und zum Teil kompensatorische Hirnmechanismen rekrutieren können, um erfolgreich selbstkontrolliert $\mathrm{zu}$ handeln. Die beobachtete Reduktion der belohnungsabhängigen Aktivierung in subkortikalen mesolimbischen Strukturen und im ventromedialen präfrontalen Kortex ermöglicht es wahrscheinlich den hoch- impulsiven Probanden, nicht ihrem Verlangen nach einer direkten Belohnung zugunsten eines langfristigen Ziels nachzugeben. Interessanterweise unterscheiden sich die neuronalen Mechanismen (d.h. die neuronalen Aktivierungen und Konnektivitätsmuster), die dieser Fähigkeit der hoch- impulsiven Probanden unterliegen, von denen, die extrem- kontrollierte Personen anwenden trotz ähnlicher Verhaltensleistungen. Diese Tatsache stützt somit die Annahme, dass zwei extreme Gruppen der Impulsivität unterschiedliche kognitive Strategien genutzt haben, ein langfristiges Ziel trotz einer ständig verfügbaren sofortigen Belohnung zu erreichen. 


\subsection{Ausblick}

Die vorliegende fMRT- Studie an nicht- klinischen Probanden hat gezeigt, dass es persönlichkeitsspezifische neuronale Mechanismen gibt, die es hoch- impulsiven Probanden ermöglichen, ihren Wunsch nach einer unmittelbaren Belohnung zu kontrollieren. Durch zwei komplementäre neuronale Mechanismen ist es hoch- impulsiven Probanden (HI) möglich, einen Mangel an Selbstkontrolle erfolgreich zu kompensieren. Nachfolgende Studien sollten an Probanden durchgeführt werden, die Störungen der Impulskontrolle aufweisen, beispielsweise an Personen mit Suchterkrankungen. Es wäre demnach interessant zu sehen, welche Veränderungen der neuronalen Aktivität in den in dieser Arbeit untersuchten Hirnstrukturen beobachtet werden können, wenn das in dieser Studie aufgestellte neuartige Studiendesign an einer klinischen Stichprobe getestet werden würde, oder aber ob sogar weitere Hirnregionen impulsives Verhalten vermitteln.

Weiterhin zeigen die Ergebnisse dieser Studie, dass extrem- kontrollierte Menschen verhältnismäßig niedrigere Veränderungen der neuronalen Aktivität aufweisen. Zukünftige Studien könnten sich noch ausführlicher mit dem Phänotyp extrem- kontrollierter Probanden beschäftigen, welcher in bildgebenden Untersuchungen des zentralen Nervensystems bis jetzt weitestgehend vernachlässigt wurde, um die neuronalen Mechanismen extremer Selbstkontrolle ohne Krankheitswert genauer zu erforschen. 


\section{Zusammenfassung}

Der Mensch muss täglich eine Vielzahl von Entscheidungen treffen. Der Prozess der menschlichen Entscheidungsfindung ist ein diffiziler Vorgang: Alternativen müssen gründlich gegeneinander abgewogen werden, Vor- und Nachteile in Betracht gezogen und persönliche Vorlieben berücksichtigt werden. Es liegt daher auf der Hand, dass bei Unsicherheit und einer Vielzahl von Optionen der Aufwand für unser Gehirn, eine Entscheidung zu treffen, enorm steigt. Wir Menschen haben deshalb über Generationen hinweg Verhaltensmuster entwickelt, um diese Komplexität zu reduzieren. Diese erlernten Schemata laufen quasi unbewusst und automatisch ab. Doch gerade reaktives und spontanes Verhalten bietet wiederum viele Möglichkeiten der Manipulation. Impulsivität kann $\mathrm{zu}$ schnellen, unüberlegten „Bauchentscheidungen“ führen, die nicht immer vorteilhaft sind. In bestimmten Situationen ist impulsives Handeln aber auch von großem Nutzen. In einer Gefahrensituation zum Beispiel kann langes Überlegen und langsames Handeln schwere negative Konsequenzen nach sich ziehen. Impulsives Handeln kann in diesen Situationen unter Umständen lebensrettend sein.

In dieser Studie wurde mittels der Bildgebung des funktionellen MRT der Zusammenhang zwischen der Impulsivität als Persönlichkeitseigenschaft und den neuronalen Prozessen der Fähigkeit untersucht, den Wunsch nach einer unmittelbaren Belohnung zu kontrollieren. Es sollte ein möglicher Zusammenhang zwischen der Impulsivität und dem funktionellen Zusammenspiel frontostriataler Regelkreise während des aktiven Prozesses der Entscheidungsfindung dargestellt werden. Dabei wurde durch den Vergleich zweier Extremgruppen gesunder Probanden (hoch- versus niedrig- impulsive Probanden) gezeigt, welchen Einfluss die Impulsivität auf die neuronalen Entscheidungsnetzwerke hat, die entweder auf eine kurzfristige oder langfristige Belohnungsoptimierung ausgerichtet sind. Niedrig- und hoch- impulsive Gruppen gesunder Probanden wurden hinsichtlich ihres Verhaltens und ihrer Aktivierungen im Gehirn in Situationen miteinander verglichen, in denen sie auf eine unmittelbare Belohnung unterschiedlicher Wertigkeit verzichten mussten, um eine übergeordnete Zielsetzung zu erreichen. Es konnte gezeigt werden, dass hochimpulsive Probanden (HI), die einen Mangel an Selbstkontrolle erfolgreich kompensieren können, zwei komplementäre Mechanismen aufweisen, wenn sie sich für das Vorgehen entscheiden, ein übergeordnetes Ziel auf Kosten einer unmittelbaren Belohnung zu erreichen. Als erster Mechanismus ist festzuhalten, dass selbstkontrollierte Entscheidungen zu einer 
Abschwächung der belohnungsabhängigen Aktivierung im Nucleus accumbens führten, welche von einer ansteigenden inversen Verbindung mit dem anteroventralen präfrontalen Kortex begleitet wurde. Der zweite Mechanismus ist, dass HI- Probanden ihren Wunsch nach einer höherwertigen, aber suboptimalen Belohnung durch Downregulation im ventromedialen präfrontalen Kortex kontrollierten. Diesem Mechanismus folgte eine ansteigende inverse Kopplung mit dem ventralen Striatum. Bedeutend dabei ist, dass sich diese neuronalen Mechanismen qualitativ von denen der extrem- kontrollierten Probanden unterschieden, trotz Ähnlichkeiten in ihrem Verhalten. Insgesamt lässt sich sagen, dass die Ergebnisse der vorliegenden Studie darauf hindeuten, dass es persönlichkeitsspezifische neuronale Mechanismen gibt, die es den HI- Probanden ermöglichen, ihren Wunsch nach einer unmittelbaren Belohnung zu kontrollieren. 


\section{$6 \quad$ Anhang}

\subsection{Barratt- Impulsivitäts-Skala, 11. Revision (BIS-11)}

Instruktion: In diesem Fragebogen geht es darum, wie man sein eigenes Verhalten steuert. Darin unterscheiden sich Menschen sehr voneinander. Manche Menschen mögen es gar nicht, langfristig zu planen, und handeln lieber ganz spontan. Andere Menschen ziehen es vor, nichts dem Zufall zu überlassen, sondern möchten auf alles vorbereitet sein. Niemand kann beurteilen, welches der bessere Weg ist. Bitte geben Sie an, wie oft die einzelnen Aussagen auf Sie zutreffen. Überlegen Sie dabei nicht, wie Sie sich gerne verhalten würden oder wie Sie meinen, dass man sich verhalten sollte, sondern versuchen Sie zu beurteilen, wie Sie sich tatsächlich verhalten.

Items: Die Antworten werden auf einer vierstufigen Skala gegeben: 1234 .

Dabei wird 1 angekreuzt, wenn die Aussage für Sie nie oder nur selten zutrifft.

Eine 2 ist anzukreuzen, falls die Aussage auf Sie manchmal oder gelegentlich zutrifft. Eine 3 entspricht einer Aussage, die für Sie oft zutrifft und 4 ist anzukreuzen, wenn die Aussage immer für Sie passend ist.

Es gibt drei Unterskalen: Aufmerksamkeit (Items 5, 6, 9, 11, 20, 24, 26 und 28), motorische Impulsivität (Items 2, 3, 4, 16, 17, 19, 21, 22, 23, 25 und 30) und Voraussicht (Items 1, 7, 8, 10, 12, 13, 14, 15, 18, 27 und 29).

Folgende Items sind negativ formuliert und müssen umgepolt bewertet werden: 1, 7, 8, 9, 10, $12,13,15,20$ und 29.

1. Ich bereite mich auf meine Aufgaben und Pflichten sorgfältig vor.

2. Ich tue Dinge, ohne darüber nachzudenken.

3. Ich bin entschlussfreudig.

4. Ich bin sorglos.

5. Ich passe nicht auf.

6. Gedanken rasen durch meinen Kopf.

7. Ich plane einen Ausflug rechtzeitig im Voraus.

8. Ich bin beherrscht. 
9. Ich kann mich leicht konzentrieren.

10. Ich spare mein Geld.

11. Ich drücke mich vor Theaterbesuchen oder Vorträgen.

12. Ich bin ein gründlicher Denker/ eine gründliche Denkerin.

13. Ich kümmere mich um Sicherheit am Arbeitsplatz.

14. Ich sage Dinge, ohne darüber nachzudenken.

15. Ich mag es, über schwierige Probleme nachzudenken.

16. Ich wechsle meine Jobs.

17. Ich handle impulsiv.

18. Mir wird schnell langweilig, wenn ich über ein Problem nachdenke.

19. Ich folge meinen augenblicklichen Eingebungen.

20. Ich bin ein ausdauernder Denker / eine ausdauernde Denkerin.

21. Ich wechsle meine Wohnung.

22. Ich kaufe Sachen spontan.

23. Ich kann nicht über zwei Dinge gleichzeitig nachdenken.

24. Ich wechsle meine Hobbies.

25. Ich gebe mehr Geld aus, als ich verdiene.

26. Wenn ich nachdenke, kommen mir oft nebensächliche Gedanken in den Sinn.

27. Ich kümmere mich mehr um die Gegenwart als um die Zukunft.

28. Im Theater oder bei Vorträgen werde ich unruhig.

29. Ich mag Puzzles und Geduldspiele.

30. Ich bin zukunftsorientiert.

\subsection{Instruktion Konditionierung}

Liebe Versuchsteilnehmerin, lieber Versuchsteilnehmer, zunächst vielen Dank, dass Sie sich bereit erklärt haben, an diesem Experiment teilzunehmen. Um den Ablauf des Versuchs zu erklären, haben wir Ihnen eine kurze Anleitung zusammengefasst. Falls Sie danach noch Fragen haben, zögern Sie bitte nicht, diese zu stellen.

Im ersten Teil unseres Experimentes werden wir Ihnen verschiedene farbige Quadrate auf dem Monitor präsentieren. Sobald ein neues Quadrat erscheint, sind Sie aufgefordert, nach eigenem Belieben, eine von zwei möglichen Antworttasten auf der Tastatur zu drücken und zu sehen, was die Folge ihrer freien Entscheidung ist. 
Die beiden Antworttasten auf der Tastatur haben dabei unterschiedliche Bedeutungen:

Die linke Taste (Alt-Taste) bedeutet, dass Sie dieses Quadrat annehmen (d.h. dass sie sich für dieses Quadrat entscheiden).

Die rechte Taste (Alt Gr- Taste) bedeutet dagegen, dass Sie dieses Quadrat ablehnen (d.h. dass Sie dieses Quadrat nicht haben möchten und sich dagegen entscheiden).

Die Bedeutung der Antworttasten ist insofern wichtig, da sie nach dem Tastendruck ein Feedback erhalten, ob die Entscheidung für oder gegen ein bestimmtes Quadrat zum Gewinn von Punkten (Belohnung) führt oder ob Ihre Entscheidung von einem neutralen Ergebnis, also keinem Gewinn, gefolgt wird.

Das Feedback wird dabei immer durch eines der folgenden Symbole dargestellt:

$0=$ neutrales Ergebnis, kein Zugewinn oder Verlust von Punkten

$10=$ kleine Belohnung, Sie gewinnen 10 Punkte

$25=$ mittlere Belohnung, Sie gewinnen 25 Punkte

$40=$ große Belohnung, Sie gewinnen 40 Punkte.

Wir bitten Sie auch darum, nicht mitzuzählen, wie oft sie ein Feedback einer bestimmten Sorte bekommen haben oder aufzuaddieren, was Sie bereits gewonnen haben.

Punkte, die Sie in diesem Experiment erhalten, werden Ihnen gutgeschrieben und später in einen Geldwert umgewandelt.

Wir wünschen Ihnen viel Spaß und Erfolg!

Sollten Sie etwas nicht genau verstanden haben, fragen Sie uns bitte jetzt!

Wir danken Ihnen für Ihre Mitarbeit und stehen Ihnen für weitere Informationen natürlich jederzeit zur Verfügung! 


\subsection{Instruktion MRT}

Liebe Versuchsteilnehmerin, lieber Versuchsteilnehmer, zunächst vielen Dank, dass Sie sich auch bereit erklärt haben, auch am zweiten Teil unseres Experimentes teilzunehmen. Um den Ablauf des Versuchs zu erklären, haben wir Ihnen eine kurze Anleitung zusammengefasst. Falls Sie danach noch Fragen haben, zögern Sie bitte nicht, diese zu stellen.

In diesem zweiten Teil des Experimentes werden Ihnen wieder verschiedenfarbige Quadrate in einer Sequenz von entweder 4 oder 7 Quadraten präsentiert. Sie sind aufgefordert, nur diejenigen Farben anzunehmen, die Ihnen durch den Hinweisstimulus als zielrelevant ausgewiesen werden, und dafür andere Farben gegebenenfalls auch abzulehnen, wenn diese nicht Teil der Zielvorgabe sind. Das erfolgreiche Erreichen des Ziels wird dabei am Ende eines Blockes mit 50 Punkten belohnt. Je nach konkreter Aufgabenstellung haben Sie jedoch in einigen Durchgängen die Möglichkeit, zumindest einen zusätzlichen Bonus über die direkt belohnten Farben zu bekommen (s.u.).

Dementsprechend gibt es 2 verschiedene Aufgabentypen, deren Regeln jeweils für 10 aufeinanderfolgende (5 kurze und 5 lange) Blöcke gelten. Der gegenwärtig geltende Aufgabentyp wird Ihnen dabei zu Anfang eines solche „Zehnerblockes“ mitgeteilt.

Erscheint der Hinweis „Bonusrunde“

- zielrelevante Farben immer annehmen

- nicht-relevante Farben (fast) immer ablehnen (s.u.)

- nicht-relevante Farben mit einer Belohnungsassoziation (10, 25 oder 40) dürfen auch als zusätzlicher Bonus angenommen werden, der dann zur Gesamtbelohnung des Blockes hinzuaddiert wird, während neutrale Farben, die nicht Teil der Zielvorgabe sind, immer abgelehnt werden müssen, da ansonsten das Ziel als verfehlt gilt. 
Bei der sogenannten ,, Zielverfolgung“ müssen Sie sich stattdessen wie folgt verhalten:

- zielrelevante Farben immer annehmen

- nicht-relevante Farben immer ablehnen (dies gilt auch für nicht-relevante Farben mit einer Belohnungsassoziation, da ansonsten das Ziel als verfehlt gilt und der Block vorzeitig ohne Belohnung abgebrochen wird).

Sie müssen sich relativ schnell entscheiden, da ansonsten das Ziel als verfehlt gilt (wenn Sie zu spät, falsch oder gar nicht drücken) und Sie gar keine Belohnung für den Block erhalten. „Bonusrunde“ und „Zielverfolgung“ wechseln sich jeweils nach 10 Blöcken eines Aufgabentyps ab. Ein „Zehnerblock“ beginnt immer mit 5 kurzen Blöcken (4 Durchgänge bis zum Ziel), gefolgt von 5 langen (7 Durchgänge). Punkte, die in „Bonusrunden“ und „Zielverfolgungen“ erworben werden, werden anschließend mit denen aus den anderen Experimenten zusammengerechnet und in einen Geldwert umgewandelt.

Wir wünschen Ihnen viel Spaß und natürlich viel Erfolg!

Sollten Sie etwas nicht genau verstanden haben, fragen Sie uns bitte jetzt!

Wir danken Ihnen für Ihre Mitarbeit und stehen Ihnen für weitere Informationen jederzeit gerne zur Verfügung! 


\section{$7 \quad$ Literaturverzeichnis}

Abler B, Walter H, Erk S, Kammerer H, Spitzer M (2006): Prediction error as a linear function of reward probability is coded in human nucleus accumbens. Neuroimage $\underline{31}$, $790-795$

Ainslie G (1975): Specious reward: a behavioral theory of impulsiveness and impulse control. Psychol Bull $\underline{\text { 82, }}$ 463- 498

Aktories K, Förstermann U, Hofmann F, Starke K: Allgemeine und spezielle Pharmakologie und Toxikologie. 10. Auflage; Urban \& Fischer Elsevier, München 2009

Alexander GE, Crutcher MD (1990): Functional architecture of basal ganglia circuits: neural substrates of parallel processing. Trends Neurosci $\underline{13}, 266-71$

American Psychiatric Association: Diagnostic and Statistical Manual IV: American Psychiatric Association. Washington, DC 1994

Aouizerate B, Rotgé JY, Bioulac B, Tignol, J (2007): Present contribution of neurosciences to a new clinical reading of obsessive-compulsive disorder. Encephale $\underline{33}, 203-210$

Arce E, Santisteban C (2006): Impulsivity: a Review. Psicothema 18, 213-220

Arnsten AF (1997): Catecholamine regulation of the prefrontal cortex. J Psychopharmacol $\underline{11}$, $151-162$

Ballard K, Knutson B (2009): Dissociable neural representations of future reward magnitude and delay during temporal discounting. Neuroimage $\underline{45}, 143-150$

Band GPH, Van Boxtel GJM (1999): Inhibitory motor control in stop paradigms: Review and reinterpretation of neural mechanisms. Acta Physiol (Amst.) 101, 179-211

Bannon MJ, Michelhaugh SK, Wang J, Sacchetti P (2001): The human dopamine transporter gene gene organization, transcriptional regulation and potential involvement in neuropsychiatric disorders. Eur Neuropsychopharmacol 11, 449- 455 
Barratt ES: Impulsiveness subtraits: arousal and information processing. In: Spence JT, Izard CE: Motivation, emotion, and personality. Elsevier/ North-Holland, Amsterdam New York 1985, 137-146

Barratt ES: Impulsiveness and aggression. In: Monahan J, Steadman HJ: Violence and mental disorder: Developments in risk assessment. University of Chicago Press, Chicago/ IL $1994,61-79$

Bechara A (2002): The neurology of social cognition. Brain 125, 1673- 1675

Bilder RM, Volavka J, Lachman HM, Grace AA (2004): The Catechol-O-Methyltransferase polymorphism: Relations to the tonic-phasic dopamine hypothesis and neuropsychiatric phenotypes. Neuropsychopharmacology 29, 1943-1961

Bódi N, Kéri S, Nagy H, Moustafa A, Myers CE, Daw N, Dibó G, Takáts A, Bereczki D, Gluck MA (2009): Reward-learning and the novelty-seeking personality: a between- and within-subjects study of the effects of dopamine agonists on young Parkinson's patients. Brain 132, 2385-2395

Boorman ED, Behrens TE, Woolrich MW, Rushworth MF (2009): How green is the grass on the other side? Frontopolar cortex and the evidence in favor of alternative courses of action. Neuron $\underline{11}, 733-743$

Brass M, Von Cramon DY (2002) : The role of the frontal cortex in task preparation. Cereb Cortex 12, 908-914

Buckholtz JW, Treadway MT, Cowan RL, Woodward ND, Benning SD, Li R, Ansari MS, Baldwin RM, Schwartzman AN, Shelby ES, Smith CE, Cole D, Kessler RM, Zald DH (2010): Mesolimbic dopamine reward system hypersensitivity in individuals with psychopathic traits. Nat Neurosci $\underline{13}, 419-421$

Campbell-Meiklejohn DK, Woolrich MW, Passingham RE, Rogers RD (2008): Knowing when to stop: the brain mechanisms of chasing losses. Biol Psychiatry $\underline{63}, 293-300$ 
Cardinal RN, Pennicott DR, Sugathapala CL, Robbins TW, Everitt BJ (2001): Impulsive choice induced in rats by lesions of the nucleus accumbens core. Science $292,2499-2501$

Carlsson A, Lindqvist M, Magnusson T (1957): 3,4-Dihydroxyphenylalanine and 5hydroxytryptophan as reserpine antagonists. Nature $\underline{180}, 1200$

Carlsson A, Lindqvist M, Magnusson T, Waldeck B (1958): On the presence of 3hydroxytyramine in brain. Science $\underline{127}, 471$

Carr DB, Sesack SR (2000): Projections from the rat prefrontal cortex to the ventral tegmental area: target specificity in the synaptic associations with mesoaccumbens and mesocortical neurons. J Neurosci 20, $3864-3873$

Clark L, Bechara A, Damasio H, Aitken MR, Sahakian BJ, Robbins TW (2008): Differential effects of insular and ventromedial prefrontal cortex lesions on risky decision-making. Brain 131, 1311-1322

Clarke HF, Robbins TW, Roberts AC (2008): Lesions of the medial striatum in monkeys produce perseverative impairments during reversal learning similar to those produced by lesions of the orbitofrontal cortex. J Neurosci $\underline{28}, 10972-10982$

Congdon E, Canli T (2005): The endophenotype of impulsivity: reaching consilience through behavioral, genetic, and neuroimaging approaches. Behav Cogn Neurosci Rev $\underline{4}, 262-281$

Cools R (2006): Dopaminergic modulation of cognitive functionimplications for L-DOPA treatment in Parkinson's disease. Neurosci Biobehav Rev $\underline{30}, 1-23$

Cools R, Clark L, Robbins TW (2004): Differential responses in human striatum and prefrontal cortex to changes in object and rule relevance. J Neurosci $\underline{24}, 1129-1135$

Cools R, Blackwell A, Clark L, Menzies L, Cox S, Robbins TW (2005): Tryptophan depletion disrupts the motivational guidance of goal-directed behavior as a function of trait impulsivity. Neuropsychopharmacology $\underline{30}, 1362-1373$

Cromwell HC, Schultz W (2003): Effects of expectations for different reward magnitudes on neuronal activity in primate striatum. J Neurophysiol $\underline{89}, 2823-2838$ 
Dalley JW, Mar AC, Economidou D, Robbins TW (2008): Neurobehavioral mechanisms of impulsivity: fronto-striatal systems and functional neurochemistry. Pharmacol Biochem Behav $\underline{90}, 250-260$

Daw ND, O'Doherty JP, Dayan P, Seymour B, Dolan RJ (2006): Cortical substrates for exploratory decisions in humans. Nature $\underline{441}, 876-879$

Del Arco A, Mora F (2008): Prefrontal cortex-nucleus accumbens interaction: in vivo modulation by dopamine and glutamate in the prefrontal cortex. Pharmacol Biochem Behav $\underline{90}, 226-235$

Delgado MR, Locke HM, Stenger VA, Fiez JA (2003): Dorsal striatum responses to reward and punishment: effects of valence and magnitude manipulations. Cogn Affect Behav Neurosci $\underline{3}, 27-38$

Delgado MR, Miller MM, Inati S, Phelps EA (2005): An fMRI study of reward-related probability learning. Neuroimage $\underline{24}, 862-873$

Delgado MR, Nearing KI, Ledoux JE, Phelps EA (2008): Neural circuitry underlying the regulation of conditioned fear and its relation to extinction. Neuron $\underline{59}, 829-838$

De Martino B, Kumaran D, Holt B, Dolan RJ (2009): The neurobiology of referencedependent value computation. J Neurosci $\underline{29}$, 3833-3842

Dickman, SJ (1990): Functional and dysfunctional impulsivity: personality and cognitive correlates. J Pers Soc Psychol 모, 95- 102

Diekhof EK, Gruber O (2010): When desire collides with reason: functional interactions between anteroventral prefrontal cortex and nucleus accumbens underlie the human ability to resist impulsive desires. J Neurosci $\underline{30}, 1488-1493$

Diekhof EK, Kipshagen HE, Falkai P, Dechent P, Baudewig J, Gruber O (2011): The power of imagination - How anticipatory mental imagery alters perceptual processing of fearful facial expressions. Neuroimage 54, 1703-1714 
Di Martino A, Scheres A, Margulies DS, Kelly AM, Uddin LQ, Shehzad Z, Biswal B, Walters JR, Castellanos FX, Milham MP (2008): Functional connectivity of human striatum: a resting state FMRI study. Cereb Cortex $\underline{18}, 2735-2747$

Dorris MC, Glimcher PW (2004): Activity in posterior parietal cortex is correlated with the relative subjective desirability of action. Neuron $\underline{44}, 365-378$

Dove A, Pollman S, Schubert T, Wiggins CJ, Von Cramon DY (2000): Prefrontal cortex activation in task switching: An event related fMRI study. Brain Res Cogn Brain Res $\underline{9}$, $103-109$

Draganski B, Kherif F, Klöppel S, Cook PA, Alexander DC, Parker GJ, Deichmann R, Ashburner J, Frackowiak RS (2008): Evidence for segregated and integrative connectivity patterns in the human Basal Ganglia. J Neurosci $\underline{28}, 7143-7152$

Drewe EA (1975): Go- no go learning after frontal lobe lesions in humans. Cortex $\underline{11}, 8-16$

Duncan J, Owen AM (2000): Common regions of the human frontal lobe recruited by diverse cognitive demands. Trends Neurosci $\underline{23}, 475-483$

Duvauchelle CL, Levitin M, MacConell LA, Lee LK, Ettenberg A (1992): Opposite effects of prefrontal cortex and nucleus accumbens infusions of flupenthixol on stimulant-induced locomotion and brain stimulation reward. Brain Res $\underline{576}, 104-110$

Evenden JL (1999): Varieties of impulsivity. Psychopharmacology (Berl) 146, 348-361

Eysenck SBG, Eysenck HJ (1977): The place of impulsivity in a dimensional system of personality description. Br J Soc Clin Psychol 16, 57-68

Ferry AT, Ongür D, An X, Price JL (2000): Prefrontal cortical projections to the striatum in macaque monkeys: evidence for an organization related to prefrontal networks. J Comp Neurol $\underline{425}, 447-470$

Flagel SB, Akil H, Robinson TE (2009): Individual differences in the attribution of incentive salience to reward-related cues: Implications for addiction. Neuropharmacology $\underline{56}, 139-$ 148 
Fletcher P, Buchel C, Josephs O, Friston K, Dolan R (1999): Learning-related neuronal responses in prefrontal cortex studied with functional neuroimaging. Cereb Cortex $\underline{9}, 168-$ 178

Franken IH, van Strien JW, Nijs I, Muris P (2008): Impulsivity is associated with behavioral decision-making deficits. Psychiatry Res $\underline{158}, 155-163$

Frankle WG, Laruelle M, Haber SN (2006): Prefrontal cortical projections to the midbrain in primates: evidence for a sparse connection. Neuropsychopharmacology $\underline{31}, 1627-1636$

Friston KJ, Frith CD, Frackowiak RS, Turner R (1995a): Characterizing dynamic brain responses with fMRI: a multivariate approach. Neuroimage $\underline{2}, 166-172$

Friston KJ, Frith CD, Turner R, Frackowiak RS (1995b): Characterizing evoked hemodynamics with fMRI. Neuroimage $\underline{2}, 157-165$

Friston KJ, Holmes A, Poline JB, Price CJ, Frith CD (1996): Detecting activations in PET and fMRI: levels of inference and power. Neuroimage $\underline{4}, 223-235$

Friston KJ, Buechel C, Fink GR, Morris J, Rolls E, Dolan RJ (1997): Psychophysiological and modulatory interactions in neuroimaging. Neuroimage $\underline{6}, 218-229$

Friston KJ, Harrison L, Penny W (2003): Dynamic causal modelling. Neuroimage 19, 1273 1302

Gitelman DR, Penny WD, Ashburner J, Friston KJ (2003): Modeling regional and psychophysiologic interactions in fMRI: the importance of hemodynamic deconvolution. Neuroimage $\underline{19}, 200-207$

Gjedde A, Kumakura Y, Cumming P, Linnet J, Møller A (2010): Inverted-U-shaped correlation between dopamine receptor availability in striatum and sensation seeking. Proc Natl Acad Sci USA $\underline{107}, 3870-3875$

Goebel R, Kriegeskorte N: Funktionelle Magnet Resonanz Tomographie. In: Funktionelle Bildgebung in Psychiatrie und Psychotherapie: Methodische Grundlagen und klinische Anwendungen; hrsg. v. Walter H; Schattauer Verlag, Stuttgart 2005, 27 
Goldman-Rakic PS (1996): The prefrontal landscape: implications of functional architecture for understanding human mentation and the central executive. Philos Trans R Soc Lond B Biol Sci $\underline{351}, 1445-1453$

Goldstone AP, de Hernandez CG, Beaver JD, Muhammed K, Croese C, Bell G, Durighel G, Hughes E, Waldman AD, Frost G, Bell JD (2009): Fasting biases brain reward systems towards high-calorie foods. Eur J Neurosci $\underline{30}$, 1625-1635

Goto Y, Grace AA (2008): Limbic and cortical information processing in the nucleus accumbens. Trends Neurosci $\underline{31}, 552-558$

Grabenhorst F, Rolls ET, Bilderbeck A (2008): How cognition modulates affective responses to taste and flavor: top-down influences on the orbitofrontal and pregenual cingulate cortices. Cereb Cortex $\underline{18}, 1549-1559$

Grace AA (1991): Phasic versus tonic dopamine release and the modulation of dopamine system responsivity: a hypothesis for the etiology of schizophrenia. Neuroscience $\underline{41}, 1$ 24

Grace AA, Floresco SB, Goto Y, Lodge DJ (2007): Regulation of firing of dopaminergic neurons and control of goal-directed behaviors. Trends Neurosci $\underline{30}, 220-227$

Gruber O, Indefrey P, Steinmetz H, Kleinschmidt A (2001): Dissociating neural correlates of cognitive components in mental calculation. Cereb Cortex $\underline{11}, 350-359$

Haber SN, Knutson B (2010): The reward circuit: linking primate anatomy and human imaging. Neuropsychopharmacology $\underline{35}, 4-26$

Haber SN, Kunishio K, Mizobuchi M, Lynd-Balta E (1995): The orbital and medial prefrontal circuit through the primate basal ganglia. J Neurosci $\underline{15}$, 4851-4867

Haber SN, Kim KS, Mailly P, Calzavara R (2006): Reward-related cortical inputs define a large striatal region in primates that interface with associative cortical connections, providing a substrate for incentive-based learning. J Neurosci 26, 8368-8376 
Hahn T, Dresler T, Ehlis AC, Plichta MM, Heinzel S, Polak T, Lesch KP, Breuer F, Jakob PM, Fallgatter AJ (2009): Neural response to reward anticipation is modulated by Gray's impulsivity. Neuroimage $\underline{46}, 1148-1153$

Hare TA, O'Doherty J, Camerer CF, Schultz W, Rangel A (2008): Dissociating the role of the orbitofrontal cortex and the striatum in the computation of goal values and prediction errors. J Neurosci $\underline{28}, 5623-5630$

Hare TA, Camerer CF, Rangel A (2009): Self-control in decision-making involves modulation of the vmPFC valuation system. Science $\underline{324}$, 646-648

Hariri AR, Brown SM, Williamson DE, Flory JD, de Wit H, Manuck SB (2006): Preference for immediate over delayed rewards is associated with magnitude of ventral striatal activity. J Neurosci 26, 13213-13217

Haruno M, Kawato M (2006): Different neural correlates of reward expectation and reward expectation error in the putamen and caudate nucleus during stimulus-action-reward association learning. J Neurophysiol 95, 948-959

Herpertz SC: Impulsivität und Persönlichkeit. Kohlhammer Verlag, Stuttgart 2001

Herpertz SC, Saß H (1997): Impulsivität und Impulskontrolle. Nervenarzt $\underline{68}, 171-183$

Herpertz SC, Saß H (2000): Die Sichtweise der Borderline- Persönlichkeitsstörung in der historischen und aktuellen psychiatrischen Klassifikation. In: Kernberg OF, Dulz B, Sachsse U: Handbuch der Borderline- Störungen. Schattauer, Stuttgart 2000, 115- 124

Ho MY, Al Zahrani SS, Al Ruwaitea AS, Bradshaw CM and Szabadi E (1998): 5hydroxytryptamine and impulse control: prospects for a behavioural analysis. J Psychopharmacol $\underline{12}, 68-78$

Hoshi E (2006): Functional specialization within the dorsolateral prefrontal cortex: a review of anatomical and physiological studies of non-human primates. Neurosci Res $\underline{54}, 73-84$ 
Jackson ME, Frost AS, Moghaddam B (2001): Stimulation of prefrontal cortex at physiologically relevant frequencies inhibits dopamine release in nucleus accumbens. $\mathrm{J}$ Neurochem $\underline{78}, 920-923$

Jansma JM, Ramsey NF, van der Wee NJ, Kahn RS (2004): Working memory capacity in schizophrenia: a parametric fMRI study. Schizophr Res $\underline{68}, 159-171$

Jentsch JD, Taylor JR (1999): Impulsivity resulting from frontostriatal dysfunction in drug abuse: implications for the control of behavior by reward-related stimuli. Psychopharmacology (Berl) 146, 373-390

Jiang H, Stein BE, McHaffie JG (2003): Opposing basal ganglia processes shape midbrain visuomotor activity bilaterally. Nature $\underline{423}, 982-986$

Kable JW, Glimcher PW (2007): The neural correlates of subjective value during intertemporal choice. Nat Neurosci $\underline{10}, 1625-1633$

Kahnt T, Heinzle J, Park SQ, Haynes JD (2011): Decoding different roles for vmPFC and dlPFC in multi-attribute decision making. Neuroimage $\underline{56}, 709-715$

Kalenscher T, Ohmann T, Güntürkün O (2006): The neuroscience of impulsive and selfcontrolled decisions. Int J Psychophysiol 62, 203-211

Kelly AM, Garavan H (2005): Human functional neuroimaging of brain changes associated with practice. Cereb Cortex $\underline{15}, 1089-1102$

Knutson B, Cooper JC (2005): Functional magnetic resonance imaging of reward prediction. Curr Opin Neurol 18, 411-417

Knutson B, Adams CM, Fong GW, Hommer D (2001a): Anticipation of increasing monetary reward selectively recruits nucleus accumbens. J Neurosci 21, RC159

Knutson B, Fong GW, Adams CM, Varner JL, Hommer D (2001b): Dissociation of reward anticipation versus outcome with event-related FMRI. NeuroReport $\underline{12}, 3683-3687$

Kwong KK, Belliveau JW, Chesler DA, Goldberg IE, Weisskoff RM, Poncelet BP, Kennedy DN, Hoppel BE, Cohen MS, Turner R, et al. (1992): Dynamic magnetic resonance 
imaging of human brain activity during primary sensory stimulation. Proc Natl Acad Sci USA $\underline{89}, 5675-5679$

Lauwereyns J, Watanabe K, Coe B, Hikosaka OA (2002): Neural correlate of response bias in monkey caudate nucleus. Nature $\underline{418}, 413-417$

Lee B, London ED, Poldrack RA, Farahi J, Nacca A, Monterosso JR, Mumford JA, Bokarius AV, Dahlbom M, Mukherjee J, Bilder RM, Brody AL, Mandelkern MA (2009): Striatal dopamine $\mathrm{d} 2 / \mathrm{d} 3$ receptor availability is reduced in methamphetamine dependence and is linked to impulsivity. J Neurosci $\underline{29}, 14734-14740$

Lehéricy S, Ducros M, Van de Moortele PF, Francois C, Thivard L, Poupon C, Swindale N, Ugurbil K, Kim DS (2004): Diffusion tensor fiber tracking shows distinct corticostriatal circuits in humans. Ann Neurol 52, $522-529$

Li L, Shao J (1998): Restricted lesions to ventral prefrontal subareas block reversal learning but not visual discrimination learning in rats. Physiol Behav $\underline{65}, 371-379$

Logue AW (1988): Research on self-control- An integrating framework. Behav Brain Sci 11 , $665-709$

Love TM, Stohler CS, Zubieta JK (2009): Positron emission tomography measures of endogenous opioid neurotransmission and impulsiveness traits in humans. Arch Gen Psychiatry $\underline{66}, 1124-1134$

Manoach DS (2003): Prefrontal cortex dysfunction during working memory performance in schizophrenia: reconciling discrepant findings. Schizophr Res $\underline{60}$, 285-298

Manuck SB, Flory JD, McCaffery JM, Matthews KA, Mann JJ, Muldoon MF (1998): Aggression, impulsivity, and central nervous system serotonergic responsivity in a nonpatient sample. Neuropsychopharmacology $\underline{19}, 287-299$

Marinelli M, White FJ (2000): Enhanced vulnerability to cocaine self-administration is associated with elevated impulse activity of midbrain dopamine neurons. J Neurosci $\underline{20}$, $8876-8885$ 
Marneros A: Affekttaten und Impulstaten: Forensische Beurteilung von Affektdelikten. 1. Auflage; Schattauer Verlag, Stuttgart 2007

Matsuo K, Nicoletti M, Nemoto K, Hatch JP, Peluso MA, Nery FG, Soares JC (2008): A voxel-based morphometry study of frontal gray matter correlates of impulsivity. Hum Brain Mapp 무, 1188-1195

McClure SM, Laibson DI, Loewenstein G, Cohen JD (2004): Separate neural systems value immediate and delayed monetary rewards. Science $\underline{306}, 503-507$

McClure SM, Ericson KM, Laibson DI, Loewenstein G, Cohen JD (2007): Time discounting for primary rewards. J Neurosci $\underline{27}, 5796-5804$

Miller EK, Cohen JD (2001): An integrative theory of prefrontal cortex function. Annu Rev Neurosci 24, 167-202

Miller MB, Van Horn JD, Wolford GL, Handy TC, Valsangkar-Smyth M, Inati S, Grafton S, Gazzaniga MS (2002): Extensive individual differences in brain activations associated with episodic retrieval are reliable over time. J Cogn Neurosci 14, 1200-1214

Mink JW (1996): The basal ganglia: focused selection and inhibition of competing motor programs. Prog Neurobiol 50, 381-425

Monterosso J, Ainslie G (1999): Beyond discounting: possible experimental models of impulse control. Psychpharmacology (Berl) $\underline{145}$, 339- 347

Nigg JT (2000): On inhibition/ disinhibition in developmental psychpathology: Views from cognitive and personality psychology and a working inhibition taxonomie. Psychol Bull $\underline{126}, 220-246$

O’Boyle MO, Barratt ES (1993): Impulsivity and DSM-III-R personality disorders. Person Indiv Diff $\underline{14}, 609-611$

O'Doherty J, Dayan P, Schultz J, Deichmann R, Friston K, Dolan RJ (2004): Dissociable roles of ventral and dorsal striatum in instrumental conditioning. Science $\underline{304}, 452-454$ 
O’Doherty J, Buchanan TW, Seymour B, Dolan RJ (2006): Predictive neural coding of reward preference involves dissociable responses in human ventral midbrain and ventral striatum. Neuron $\underline{49}, 157-166$

Ogawa S, Tank DW, Menon R, Ellermann JM, Kim SG, Merkle H, Ugurbil K (1992): Intrinsic signal changes accompanying sensory stimulation: functional brain mapping with magnetic resonance imaging. Proc Natl Acad Sci USA $\underline{89}, 5951-5955$

Ongür D, Price JL (2000): The organization of networks within the orbital and medial prefrontal cortex of rats, monkeys and humans. Cereb Cortex 10, $206-219$

Oswald LM, Wong DF, Zhou Y, Kumar A, Brasic J, Alexander M, Ye W, Kuwabara H, Hilton J, Wand GS (2007): Impulsivity and chronic stress are associated with amphetamine-induced striatal dopamine release. Neuroimage $\underline{36}, 153-166$

Owen AM (1997): The functional organization of working memory processes within human lateral frontal cortex: the contribution of functional neuroimaging. Eur J Neurosci $\underline{9}, 1329$ $-1339$

Patton JH, Stanford MS, Barratt ES (1995): Factor structure of the Barratt Impulsiveness Scale. J Clin Psychol 미, 768-774

Peck CJ, Jangraw DC, Suzuki M, Efem R, Gottlieb J (2009): Reward modulates attention independently of action value in posterior parietal cortex. J Neurosci $\underline{29}, 11182-11191$

Peters UH: Lexikon Psychiatrie, Psychotherapie, Medizinische Psychologie. 6. Auflage; Urban \& Fischer Verlag, München- Jena 2007

Plassmann H, O'Doherty J, Shiv B, Rangel A (2008): Marketing actions can modulate neural representations of experienced pleasantness. Proc Natl Acad Sci USA $\underline{105}$, 1050-1054

Platt ML, Glimcher PW (1999): Neural correlates of decision variables in parietal cortex. Nature $\underline{400}, 233-238$ 
Plutchik R, van Praag HM: The nature of impulsivity: definitions, ontology, genetics and relations to aggression. In: Hollander E, Stein DJ: Impulsivity and Aggression. vol. 1; John Wiley, Chichester 1995, 7-24

Poldrack RA (2000): Imaging brain plasticity: conceptual and methodological issues: a theoretical review. Neuroimage $\underline{12}, 1-13$

Redgrave P, Prescott TJ, Gurney K (1999): The basal ganglia: a vertebrate solution to the selection problem? Neuroscience $\underline{89}, 1009-1023$

Rogers RD, Andrews TC, Grasby PM, Brooks DJ, Robbins TW (2000): Contrasting cortical and subcortical activations produced by attentional-set shifting and reversal learning in humans. J Cogn Neurosci 12, 142-162

Rypma B, Prabhakaran V (2009): When less is more and when more is more: The mediating roles of capacity and speed in brain-behavior efficiency. Intelligence $\underline{37}, 207-222$

Schilman EA, Uylings HB, Galis-de Graaf Y, Joel D, Groenewegen HJ (2008): The orbital cortex in rats topographically projects to central parts of the caudate-putamen complex. Neurosci Lett $\underline{432}, 40-45$

Schlund MW, Cataldo MF (2005): Integrating functional neuroimaging and human operant research: brain activation correlated with presentation of discriminative stimuli. J Exp Anal Behav $\underline{84}, 505-519$

Schultz W (2000): Multiple reward signals in the brain. Nat Rev Neurosci 1, 199 -207

Sesack SR, Pickel VM (1992): Prefrontal cortical efferents in the rat synapse on unlabeled neuronal targets of catecholamine terminals in the nucleus accumbens septi and dopamine neurons in the ventral tegmental area. J Comp Neurol $\underline{320}, 145-160$

Silbersweig D, Clarkin JF, Goldstein M, Kernberg OF, Tuescher OE, Levy KN, Brendel G, Pan H, Beutel M, Pavony MT, Epstein J, Lenzenweger MF, Thomas KM, Posner MI, Stern E (2007): Failure of frontolimbic inhibitory function in the context of negative emotion in borderline personality disorder. Am J Psychiatry 164, 1832-1841 
Simmons A, Stein M, Matthews S, Feinstein J, Paulus M (2006): Affective ambiguity for a group recruits ventromedial prefrontal cortex. Neuroimage 29, 655-661

Small DM, Zatorre RJ, Dagher A, Evans AC, Jones-Gotman M (2001): Changes in brain activity related to eating chocolate: from pleasure to aversion. Brain $\underline{124}, 1720-1733$

Smith DV, Hayden BY, Truong TK, Song AW, Platt ML, Huettel SA (2010): Distinct value signals in anterior and posterior ventromedial prefrontal cortex. J Neurosci $\underline{30}$, 2490-2495

Sommer M, Döhnel K, Sodian B, Meinhardt J, Thoermer C, Hajak G (2007): Neural correlates of true and false belief reasoning. Neuroimage $\underline{35}, 1378-1384$

Sonuga-Barke EJ (2002): Psychological heterogeneity in AD/HD: a dual pathway model of behaviour and cognition. Behav Brain Res 130, 29-36

Stephan KE, Marshall JC, Friston KJ, Rowe JB, Ritzl A, Zilles K, Fink GR (2003): Lateralized cognitive processes and lateralized task control in the human brain. Science $\underline{301}, 384-386$

Stephan KE, Kasper L, Harrison LM, Daunizeau J, den Ouden HE, Breakspear M, Friston KJ (2008): Nonlinear dynamic causal models for fMRI. Neuroimage $\underline{42}, 649-662$

Sugrue LP, Corrado GS, Newsome WT (2004): Matching behavior and the representation of value in the parietal cortex. Science $\underline{304}, 1782-1787$

Thews G, Mutschler E, Vaupel P: Anatomie, Physiologie und Pathophysiologie des Menschen. 6. Auflage; Wissenschaftliche Verlagsgesellschaft, Stuttgart 2007

Thulborn KR, Waterton JC, Matthews PM, Radda GK (1982): Oxygenation dependence of the transverse relaxation time of water protons in whole blood at high field. Biochim Biophys Acta $\underline{714}, 265-270$

Trantham-Davidson H, Neely LC, Lavin A, Seamans JK (2004): Mechanisms underlying differential D1 versus D2 dopamine receptor regulation of inhibition in prefrontal cortex. J Neurosci 24, 10652-10659 
Trepel M: Neuroanatomie. Struktur und Funktion. 3. Auflage; Urban \& Fischer, München, Jena 2004

Tricomi EM, Delgado MR, Fiez JA (2004): Modulation of caudate activity by action contingency. Neuron $\underline{41}, 281-292$

Tzschentke TM, Schmidt WJ (2000): Functional relationship among medial prefrontal cortex, nucleus accumbens and ventral tegmental area in locomotion and reward. Crit Rev Neurobiol 14, 131-142

Ungerleider LG (1995): Functional brain imaging studies of cortical mechanisms for memory. Science $\underline{270}, 769-775$

van Eimeren L, Grabner RH, Koschutnig K, Reishofer G, Ebner F, Ansari D (2010): Structure-function relationships underlying calculation: a combined diffusion tensor imaging and fMRI study. Neuroimage $\underline{52}, 358-363$

Visscher KM, Miezin FM, Kelly JE, Buckner RL, Donaldson DI, McAvoy MP, Bhalodia VM, Petersen SE (2003): Mixed blocked/event-related designs separate transient and sustained activity in fMRI. Neuroimage $\underline{19}, 1694-1708$

Volkow ND, Wang GJ, Fowler JS, Ding YS (2005): Imaging the effects ofmethylphenidate on brain dopamine: Newmodel on its therapeutic actions for attentiondeficit/hyperactivity disorder. Biol Psychiatry $\underline{57}, 1410-1415$

Watanabe K, Hikosaka O (2005): Immediate changes in anticipatory activity of caudate neurons associated with reversal of position-reward contingency. J Neurophysiol $\underline{94}$, $1879-1887$

Watanabe M, Sakagarni M (2007): Integration of cognitive and motivational context information in the primate prefrontal cortex. Cereb Kortex 17, 101-109

Weishaupt D, Köchli VD, Marincek B: Wie funktioniert MRI? Springer- Verlag, Berlin 2006 
Winstanley CA, Theobald DE, Dalley JW, Robbins TW (2004): Fractionating impulsivity: Contrasting effects of central 5-HT depletion on different measures of impulsive behavior. Neuropsychopharmacology $\underline{29}, 1331-1343$

Winstanley CA, Eagle D, Robbins T (2006): Behavioral models of impulsivity in relation to ADHD: Translation between clinical and preclinical studies. Clin Psychol Rev 26, 379395

Worsley KJ, Marrett S, Neelin P, Vandal AC, Friston KJ, Evans AC (1996): A unified statistical approach for determining significant signals in images of cerebral activation. Hum Brain Mapp $\underline{4}, 58-73$

Wrase J, Kahnt T, Schlagenhauf F, Beck A, Cohen MX, Knutson B, Heinz A (2007): Different neural systems adjust motor behavior in response to reward and punishment. Neuroimage $\underline{36}, 1253-1262$

Yacubian J, Sommer T, Schroeder K, Gläscher J, Braus DF, Büchel C (2007): Subregions of the ventral striatum show preferential coding of reward magnitude and probability. Neuroimage $\underline{38}, 557-563$

Zald DH, Cowan RL, Riccardi P, Baldwin RM, Ansari MS, Li R, Shelby ES, Smith CE, McHugo M, Kessler RM (2008): Midbrain dopamine receptor availability is inversely associated with novelty-seeking traits in humans. J Neurosci $\underline{28}, 14372-14378$

Zysset S, Wendt CS, Volz KG, Neumann J, Huber O, von Cramon DY (2006): The neural implementation of multi-attribute decision making: a parametric fMRI study with human subjects. Neuroimage $\underline{31}, 1380-1388$

\section{Teilpublikation der Dissertation:}

Diekhof EK, Nerenberg L, Falkai P, Dechent P, Baudewig J, Gruber O (2011): Impulsive Personality and the Ability to Resist Immediate Reward: An fMRI Study Examining 
Interindividual Differences in the Neural Mechanisms Underlying Self-Control. Hum Brain Mapp. 2011 Sep 21. doi: 10.1002/hbm.21398. [Epub ahead of print] 


\section{Danksagung}

Mit der Fertigstellung meiner Dissertation möchte ich allen danken, die mich begleitet und unterstützt haben und am Zustandekommen dieser Arbeit beteiligt waren.

Ich bedanke mich bei meinem Doktorvater Prof. Dr. med. Oliver Gruber, der es mir durch die Bereitstellung des Themas und die interessante Aufgabenstellung ermöglicht hat, diese Promotion durchzuführen und somit einen Einblick in das wissenschaftliche Arbeiten zu gewinnen.

Ein ganz besonders herzlicher Dank gilt Frau Dr. rer. med. Esther Diekhof. Danke für die großartige Betreuung, deine Geduld in der Beantwortung all meiner Fragen und die Unterstützung im Umgang mit diversen Computerprogrammen.

Hiermit möchte ich mich auch bei dem MRT-Team des Universitätsklinikums Göttingen, insbesondere Ilona Pfahlert für die Unterstützung bei der Datenerhebung und der Durchführung der Messungen bedanken.

Selbstverständlich gebührt auch allen Probanden, die an der Studie teilgenommen haben, auf diesem Wege mein Dank. 